\title{
Preparation of phosphines through C-P bond formation
}

\author{
Iris Wauters, Wouter Debrouwer and Christian V. Stevens
}

\section{Review}

\section{Address:}

Research Group SynBioC, Department of Sustainable Organic Chemistry and Technology, Faculty of Bioscience Engineering, Ghent University, Coupure links 653, 9000 Ghent, Belgium

Email:

Christian V. Stevens* - Chris.Stevens@Ugent.be

* Corresponding author

Keywords:

cross-coupling; enantioselectivity; hydrophosphination; organophosphorus chemistry; phosphines; phosphine-boranes; substitution reactions; trivalent phosphorus
Beilstein J. Org. Chem. 2014, 10, 1064-1096. doi:10.3762/bjoc. 10.106

Received: 22 January 2014

Accepted: 09 April 2014

Published: 09 May 2014

This article is part of the Thematic Series "Organophosphorus chemistry".

Guest Editor: P. R. Hanson

(c) 2014 Wauters et al; licensee Beilstein-Institut. License and terms: see end of document.

\begin{abstract}
Phosphines are an important class of ligands in the field of metal-catalysis. This has spurred the development of new routes toward functionalized phosphines. Some of the most important $\mathrm{C}-\mathrm{P}$ bond formation strategies were reviewed and organized according to the hybridization of carbon in the newly formed $\mathrm{C}-\mathrm{P}$ bond.
\end{abstract}

\section{Introduction}

Phosphines are an important class of organophosphorus compounds. They are often used as ligands in metal complex catalysis and they have become a popular reagent for organocatalysis [1]. The methods most widely used for the synthesis of phosphines include the reaction of organometallic compounds with halophosphines, the reaction of metal phosphides with alkyl halides, the reduction of other phosphorus compounds and the hydrophosphination [2]. Research in the past years has focused on the catalytic synthesis of phosphines $[3,4]$. The asymmetric catalytic synthesis of chiral phosphines has only recently emerged and is under full development. Chiral phosphines are interesting ligands for the preparation of transition metal complex catalysts for asymmetric synthesis $[5,6]$. Only a minor part of the chiral phosphines are chiral at the phosphorus atom ( $P$-stereogenic) [7-9].

A major drawback of phosphines is their highly oxidizable nature. They are easily converted to the corresponding phosphine oxide which makes the isolation difficult. To prevent losses during purification, the phosphines are sometimes deliberately transformed into the corresponding oxides (or sulfides). However, this requires an additional reduction step afterwards to get the phosphine back [10-15]. Therefore phosphines are sometimes protected by generation of the corresponding phosphine-borane complex [16,17]. The phosphine-borane complex is a stable intermediate toward the free phosphine. If 
necessary the boranato group can be removed by treatment with an excess of amine [18]. However, not all phosphines are prone to oxidation and show good air-stability [19].

This review will provide a general overview on phosphine synthesis over the last 10 to 15 years. Only reactions establishing a $\mathrm{C}-\mathrm{P}$ bond will be discussed. The synthesis of phosphine-based polymers was not included [20]. Reactions involving pentavalent phosphorus derivatives (phosphine oxides, phosphonates, phosphinates and phosphate derivatives, etc.) are out of the scope of this review.

\section{Review}

\section{Preparation of alkylphosphines via formation of a $\mathrm{C}\left(\mathrm{sp}^{3}\right)-\mathrm{P}$ bond}

Reaction of organometallic reagents with halophosphines

One of the main approaches to synthesize a carbon-phosphorus bond involves the displacement of a halogen atom from phosphorus by an organometallic reagent. This method has proven its usefulness for many years. A variety of organometallic compounds have been described. Most frequently used are the Grignard [21,22] and lithium species. But also organozinc [23,24], organolead [25], organomercury [26] or aluminum-based [27] reagents have been used. However, nowadays it is recommended to avoid the use of certain reagents such as organomercury or organolead compounds as they pose a serious toxicological hazard [28,29].

Despite the fact that the methodology is historically useful it also has major drawbacks. The presence of an anionic carbon reagent in the reaction restricts the scope of the methodology. The aspired phosphines cannot contain certain functional groups that are able to react with the organometallic compound. Further, stoichiometric amounts of reagents are required. Also, attention should be paid to the handling of halophosphines as some of the simple alkyldichlorophosphines are extremely corrosive and flammable in air.

Asymmetric phosphines are difficult to access via a nucleophilic substitution at a halophosphine due to the limited availability of unsymmetrical halophosphines and their weak configurational stability. $P$-stereogenic chlorophosphines racemize easily even at room temperature [30].

Enantiopure $P$-stereogenic compounds can be synthesized via a diastereoselective nucleophilic substitution at phosphorus utilizing chiral auxiliaries. Diastereomeric intermediates are formed that are separable by chromatography or recrystallization. The protocol has proven to be effective and has become the preferred approach for the synthesis of chiral phosphines. Commonly used chiral auxiliaries are chiral secondary alcohols (for example (-)-menthol (3), endo-borneol, etc.) or thiols that are reacted with halophosphines [31-34].

The diastereoisomers of menthylphosphinite boranes are popular synthetic intermediates for this approach (Scheme 1) [35]. The diastereomeric phosphinites 2, that were prepared from an alkyldichlorophosphine 1, were separated by preparative HPLC or recrystallization. Nucleophilic substitution of pure diastereomer $\left(R_{\mathrm{P}}\right)$-2a with methyllithium afforded the phosphine-borane $(S)-4$ with $94 \%$ enantiomeric excess. The substi-

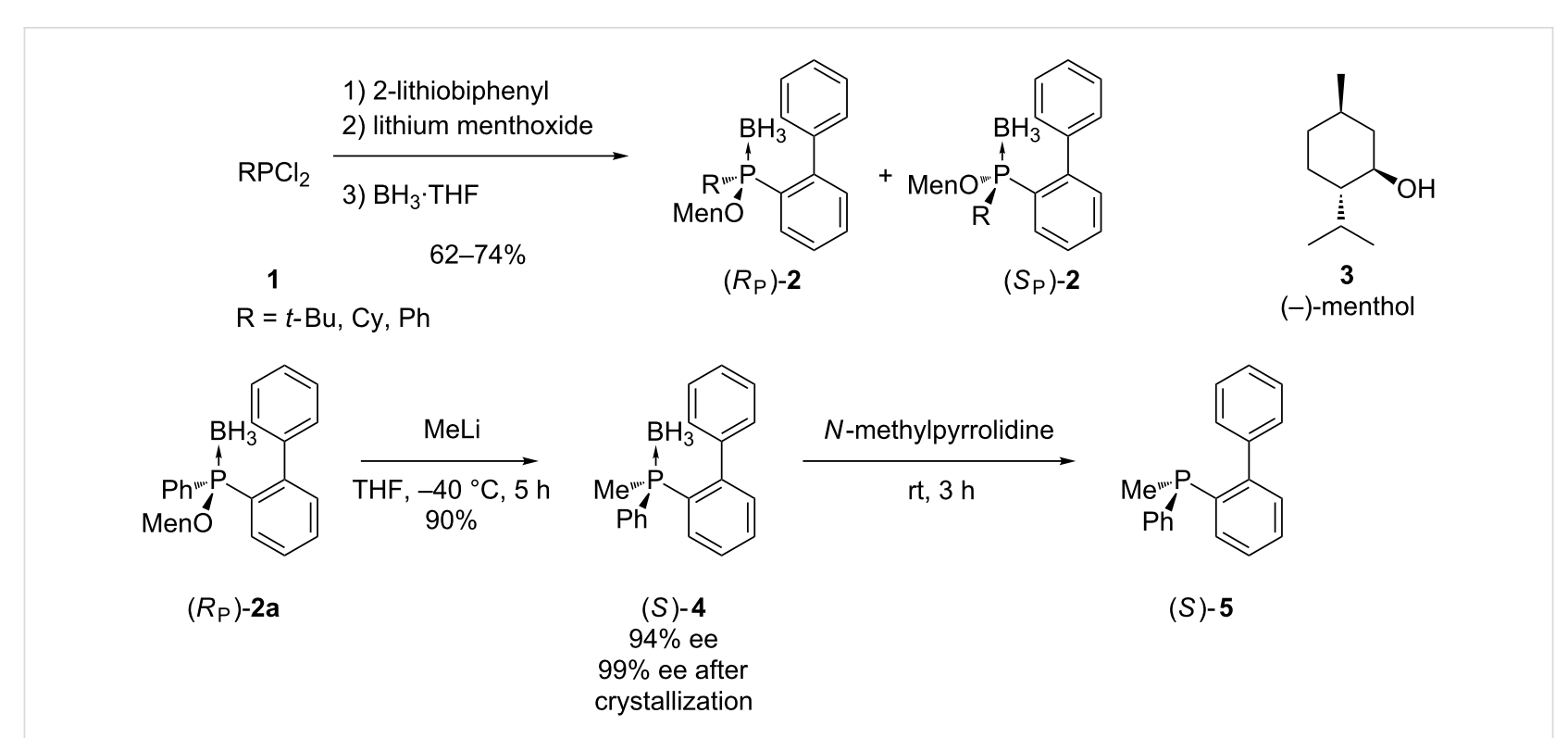


tution resulted in inversion of the configuration at the phosphorus center. Deboranation of the air stable borane adduct $(S)$ 4 to obtain $\mathbf{5}$, was achieved by treatment with $N$-methylpyrrolidine.

An alternative method is based on ephedrine as a chiral auxiliary and was developed by Genêt and Jugé [36,37]. The key synthetic intermediates in this approach are 1,3,2-oxazaphospholidine boranes 7 . These compounds are the result of the reaction between bis(diethylamino)alkylphosphine $\mathbf{6}$ and ephedrine, followed by protection with borane. The subsequent stereoselective ring opening of compound 7 with an organolithium reagent gives way to acyclic products $\mathbf{8}$ with retention of configuration at the phosphorus center. These phosphamide boranes $\mathbf{8}$ undergo methanolysis with inversion of configuration to produce intermediate phosphinite boranes $\mathbf{9}$ that are subsequently substituted with a second nucleophile. A following deprotection of the boranato group gives the chiral phosphines 10. Both enantiomers can be obtained by preparation of different starting oxazaphospholidine borane complexes 7 from (-)-ephedrine or (+)-ephedrine [38] or by starting from the same oxazaphospholidine borane adduct 7 and then changing the order of addition of the organolithium reagents (Scheme 2).

Acidolysis with $\mathrm{HCl}$ of compounds 8a results in the stereoselective synthesis of chiral chlorophosphine boranes 11a [39]. The borane complex has a good configurational stability with borane as a protecting group, in contrast to chlorophosphines that can undergo inversion at the phosphorus center [30]. They allow the synthesis of a variety of $P$-chiral tertiary phosphine boranes 12a via substitution of the chlorine atom with organometallic nucleophiles. This substitution causes an inversion of configuration at the phosphorus center (Scheme 3). Schuman et al. have prepared several dialkenylphosphines using this methodology [40].

\section{Nucleophilic substitution with metallated organophosphines}

Another classical method for the preparation of phosphines is the nucleophilic substitution of alkyl halides with phosphide anions derived from secondary phosphines or phosphine-borane

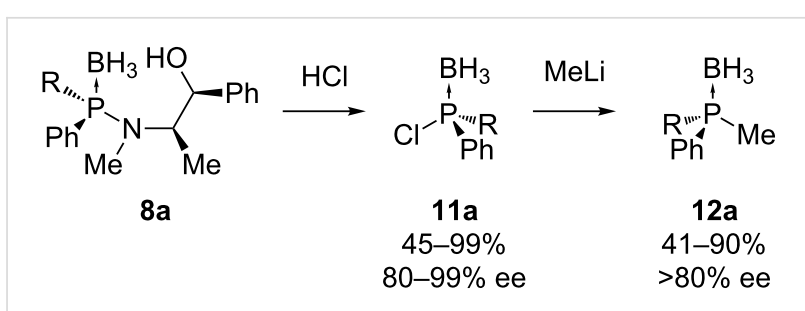

$\mathrm{R}=o-\mathrm{MeO}-\mathrm{C}_{6} \mathrm{H}_{4}, o-\mathrm{Tol}, 2-$ naphthyl, o-PhPh, $c-\mathrm{Hex}$

Scheme 3: Chlorophosphine boranes 11a as $P$-chirogenic electrophilic building blocks.

complexes [41]. This approach requires stoichiometric amounts of base. Numerous examples of this approach are available $[22,42-48]$.

In recent years methodologies were developed for the asymmetric alkylation. Livinghouse and Wolfe have reported an enantioselective method for the preparation of chiral tertiary phosphine-boranes starting from a racemic secondary phosphine borane precursor such as 13a (Table 1) [49]. A nucleophilic phosphide reagent was prepared by deprotonation of $\mathbf{1 3 a}$ Table 1: Alkylations of dynamically resolved tert-butylphenylphos-
phine borane 13a.

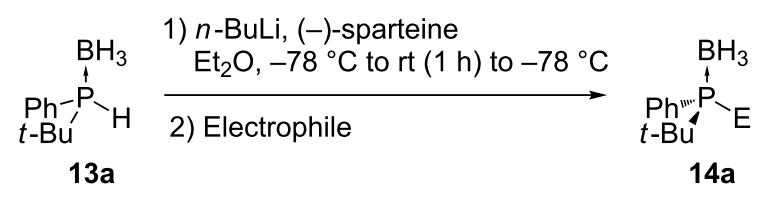

Entry Electrophile Yields of 14a (\%) ee of 14a (\%)

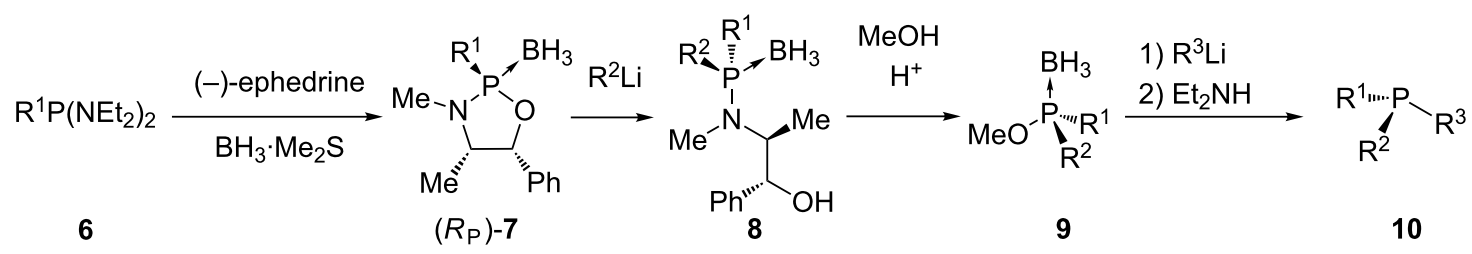

Scheme 2: Enantioselective synthesis of chiral phosphines 10 with ephedrine as a chiral auxiliary. 
in the presence of $(-)$-sparteine. The subsequent alkylation of the lithium phosphide with an electrophile proceeded with good enantiocontrol via dynamic resolution. One enantiomer is thermodynamically favored by the spartein auxiliary. The enantioselectivity was found to be time and temperature dependent. Simple stirring of the intermediate (-)-sparteine-lithium complex of 13a for $1 \mathrm{~h}$ at $25{ }^{\circ} \mathrm{C}$ prior to alkylation resulted in an increase in enantiomeric excess of $\mathbf{1 4 a}$.

The organocatalyst $\mathbf{1 6}$ has also been used to carry out an asymmetric alkylation reaction (Scheme 4). The monoalkylation of phosphine-borane complex 15 was performed in the presence of the Cinchona alkaloid ammonium salt 16 [50]. However, the enantioselectivity of the reaction was low.

Imamoto et al. prepared a new tetraphosphine ligand 19 by deprotonation of enantiopure secondary diphosphine borane $\mathbf{1 7}$ at low temperature (Scheme 5) [51]. The configuration was retained during the nucleophilic attack at 18. This approach provides a very straightforward access to $P$-stereogenic tertiary phosphines but requires the availability of $P$-chiral substrates.

Jugé and co-workers synthesized chiral tertiary phosphine-borane complexes $\mathbf{1 2 b}$ starting from $P$-stereogenic chlorophosphine-borane complexes 11b (Scheme 6) [52]. These complexes are accessible with the ephedrine methodology (vide supra). Treatment of $\mathbf{1 1 b}$ with $t$-butyllithium leads to metal-halogen exchange. After reaction of the phosphide anion 20 with an electrophile, the chiral tertiary phosphine boranes $\mathbf{1 2 b}$ are formed with retention of configuration at the phosphorus atom.

\section{Catalytic $\mathrm{C}\left(\mathrm{sp}^{3}\right)-\mathrm{P}$ bond formation}

Only a few examples of a metal catalyzed C $\left(\mathrm{sp}^{3}\right)-\mathrm{P}$ crosscoupling exist and they are mostly restricted to benzylic and allylic coupling partners.

Ager and Laneman have synthesized tertiary phosphine oxide 23 through the nickel-catalyzed coupling of benzyl bromide (21a) with diphenylphosphine chloride (22a) (Scheme 7) [53]. However oxidation occurred during work-up.

The group of Togni has investigated a palladium-catalyzed enantioselective coupling reaction between allylic substrates $\mathbf{2 4}$ and several secondary phosphines $\mathbf{2 5} \mathbf{a}$ as nucleophiles [54]. The scope of the reaction was limited to 1,3-diphenylallyl acetate 24. The reaction produced not only $\mathbf{2 6}$, but gave several side products 27-29 (Table 2).
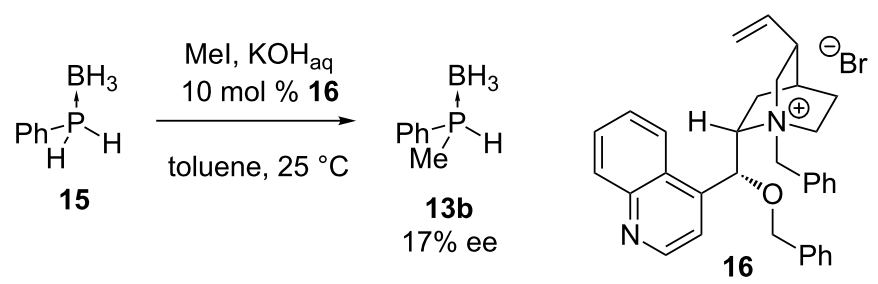

Scheme 4: Monoalkylation of phenylphosphine borane 15 with methyl iodide in the presence of Cinchona alkaloid-derived catalyst 16.

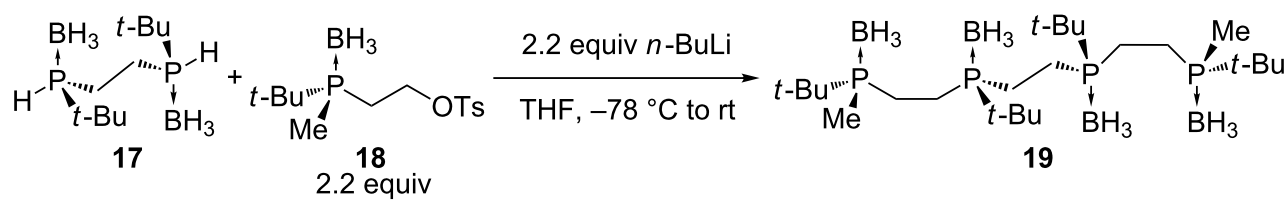

Scheme 5: Preparation of tetraphosphine borane 19.

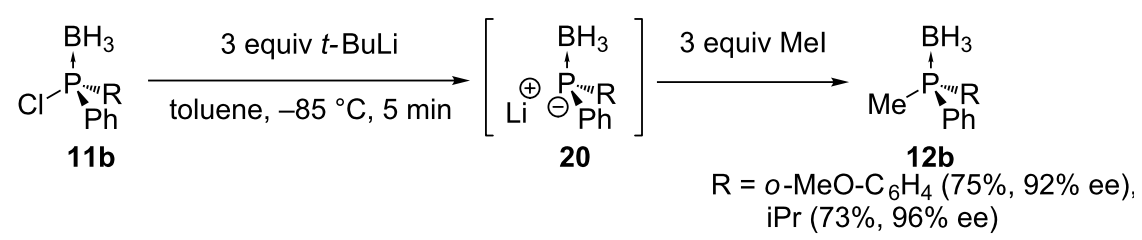




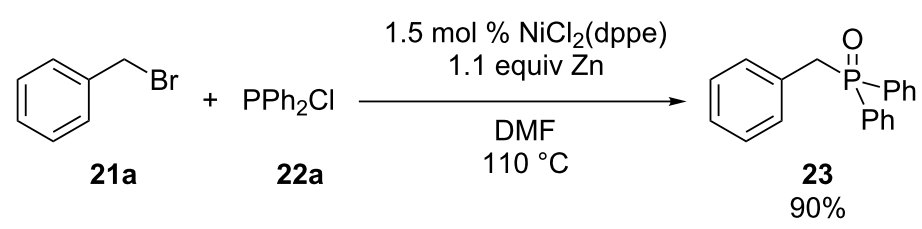

Scheme 7: Nickel-catalyzed cross-coupling (dppe = 1,2-bis(diphenylphosphino)ethane).

Table 2: Palladium-catalyzed asymmetric allylic phosphination ( $\mathrm{dba}=$ dibenzylideneacetone)<smiles>CC(=O)OC(C=Cc1ccccc1)c1ccccc1</smiles>

24
$5 \mathrm{~mol} \% \mathrm{Pd}(\mathrm{dba})_{2}$ $+\mathrm{HPR}_{2}$ $5.2 \mathrm{~mol} \%\left(R, S_{\mathrm{P}}\right)$-Josiphos $\mathrm{C}_{6} \mathrm{D}_{6}, 40^{\circ} \mathrm{C}$ $48-72 \mathrm{~h}$<smiles>[R20]C(/C=C/c1ccccc1)c1ccccc1</smiles>

26

$\mathrm{R}_{2} \mathrm{P}-\mathrm{PR} \mathrm{R}_{2}$<smiles>[R20]/C(=C\Cc1ccccc1)c1ccccc1</smiles>

28<smiles>[R20]C(CCc1ccccc1)c1ccccc1</smiles>

29

27 ee of $\mathbf{2 6}(\%)$

\begin{tabular}{ccccc}
\hline Entry & $\mathrm{R}$ & $\mathbf{2 6 : 2 7 : 2 8 : 2 9 ( \% )}$ & Yield of 26 (\%) & ee of 26(\%) \\
\hline 1 & $\mathrm{Ph}$ & $89: 11: 0: 0$ & 79 & 44 \\
2 & Cy & $65: 28: 6: 1$ & 85 & 45 \\
3 & 2-naphthyl & $91: 6: 1: 2$ & 83 & 42
\end{tabular}

Another example of a $\mathrm{C}\left(\mathrm{sp}^{3}\right)-\mathrm{P}$ cross-coupling was reported by Lanteri et al. [55]. A palladium catalyst effectuated the coupling of $n-\mathrm{Bu}_{3} \mathrm{SnPPh}_{2}(\mathbf{3 0})$ with several perfluoroalkyl iodides 31 (Scheme 8). The stannane $\mathbf{3 0}$ was in situ generated by the reaction of the diphenylphosphide anion with $n-\mathrm{Bu}_{3} \mathrm{SnCl}$. After oxidation, the perfluoroalkyl-substituted phosphine oxides $\mathbf{3 2}$ were obtained in low to moderate yields (15-51\%) although full conversion was observed. The byproduct formed was reduced perfluoroalkane $\mathrm{HC}_{n} \mathrm{~F}_{2 n+1}$.
Ethyl diazoacetate (33) was reacted with the secondary phosphine borane 13a in the presence of a copper catalyst [56]. The product 14b was obtained in good yield with retention of configuration at the phosphorus center (Scheme 9). Other chiral phosphine boranes $\mathbf{1 3}$ were reacted similarly. This protocol is limited to the availability of these chiral substrates.

Protocols for the enantioselective cross-coupling of benzyl or alkyl halides with racemic secondary phosphines have been

$$
\begin{gathered}
\mathrm{Ph}_{3} \mathrm{P} \\
\qquad \begin{array}{l}
\text { 1) } 2 \text { equiv } \mathrm{Na} \\
\text { 2) } 2 \text { equiv } t \text { - } \mathrm{BuOH} \\
\text { 3) } n-\mathrm{Bu}_{3} \mathrm{SnCl}
\end{array} \\
{\left[\begin{array}{c}
n-\mathrm{Bu}_{3} \mathrm{Sn}-\mathrm{PPh}_{2} \\
\mathbf{3 0}
\end{array}\right]+\mathrm{C}_{n} \mathrm{~F}_{2 n+1} \mid}
\end{gathered}
$$

0.7 equiv

1) $10 \mathrm{~mol} \%\left(\mathrm{Ph}_{3} \mathrm{P}\right)_{2} \mathrm{PdCl}_{2}$ $40 \mathrm{~mol}^{\%} \mathrm{PPh}_{3}, 3$ equiv $\mathrm{CsF}$ toluene, $80^{\circ} \mathrm{C}, 24 \mathrm{~h}$

2) $\mathrm{H}_{2} \mathrm{O}_{2}$

\section{$\mathrm{Ph}_{2} \mathrm{P}(\mathrm{O}) \mathrm{C}_{n} \mathrm{~F}_{2 n+1}$}

32

$$
\begin{aligned}
& n=4: 22 \% \\
& n=6: 15 \% \\
& n=8: 51 \%
\end{aligned}
$$




$$
\begin{aligned}
& \mathrm{N}_{2} \approx \stackrel{\mathrm{O}}{\mathrm{O}}_{\mathrm{OEt}} 33 \\
& t-{ }_{\mathrm{Ph}} \stackrel{\mathrm{CH}_{3} \mathrm{CN}, \mathrm{rt}}{\mathrm{P}_{\mathrm{P}}^{\mathrm{B}}-\mathrm{mol} \% \mathrm{Cul}} \\
& \text { 13a } \\
& 99 \% \text { ee } \\
& \text { 14b } \\
& 80 \%
\end{aligned}
$$

Scheme 9: Copper iodide catalyzed carbon-phosphorus bond formation.

developed. These reactions were catalyzed by chiral platinum or ruthenium complexes. The enantioselectivity is based on a dynamic kinetic resolution. Upon reaction with the catalyst precursor containing a chiral ligand $\left(\mathrm{L}^{*}\right)$, a diastereomeric metal-phosphido complex 34 is formed. Rapid pyramidal inversion of this key catalytic intermediate $\mathbf{3 4}$ occurs. This complex performs a nucleophilic attack on the electrophile resulting in tertiary phosphines $\mathbf{1 0}$, in which the substituent ' $E$ ' comes from the electrophile. If the inversion of the diastereomers $\mathbf{3 4}$ is much faster than their reactions with an electrophile, $P$-stereogenic phosphines $\mathbf{1 0}$ are formed enantioselectively. The ratio of phosphine end products $\mathbf{1 0}$ is determined by the equilibrium $\left(K_{\text {eq }}\right)$ between the complexes $\mathbf{3 4}$ and the rate of nucleophilic attack $\left(k_{\mathrm{S}}\right.$ and $\left.k_{\mathrm{R}}\right)$ on the electrophile. The enantioselectivity of the end products $\mathbf{1 0}$ is related to the ratio of the diastereomeric phosphido complexes 34. The major phosphine product is derived from the major diastereomeric phosphido complex. The dynamic kinetic resolution approach has been reviewed in more detail by Glueck [57,58]. Scheme 10 relates to reactions of secondary phosphines with several electrophiles, including alkyl halides (alkylation), alkenes (hydrophosphination) and aryl iodides (arylation).

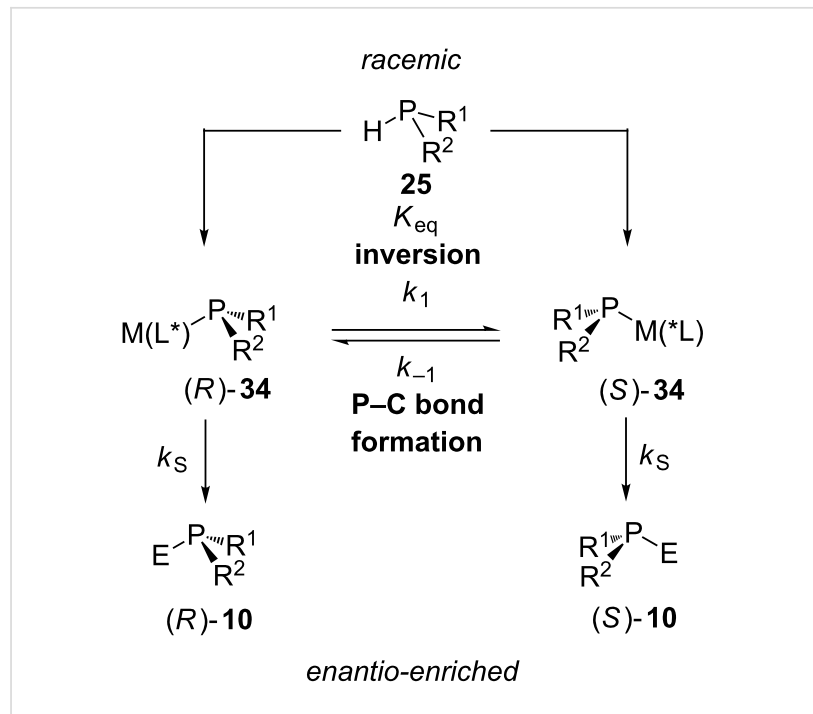

Scheme 10: Thermodynamic kinetic resolution as the origin of enantioselectivity in metal-catalyzed asymmetric synthesis of $P$-stereogenic phosphines.

Chan et al. synthesized $P$-stereogenic phosphine boranes using a ruthenium catalyst. The secondary phosphine 36a underwent an enantioselective alkylation to 12c (Scheme 11). The mechanism of the reaction is based on the formation of an electronrich ruthenium-phosphido complex that enhances the nucleophilicity at the phosphorus atom. This permitted the reaction to proceed with the less electrophilic benzylic chlorides $\mathbf{3 5}$ instead of bromides. The metal-catalyzed reaction was faster than the achiral base-mediated alkylation of 36a. Bisphosphines 37 were also reported with high enantiomeric excesses. The procedure is mainly restricted to benzylic halides but also allowed for the asymmetric alkylation with ethyl bromide. All the phosphines were isolated as their air-stable phosphine-borane complexes 12c, 37 [59,60].

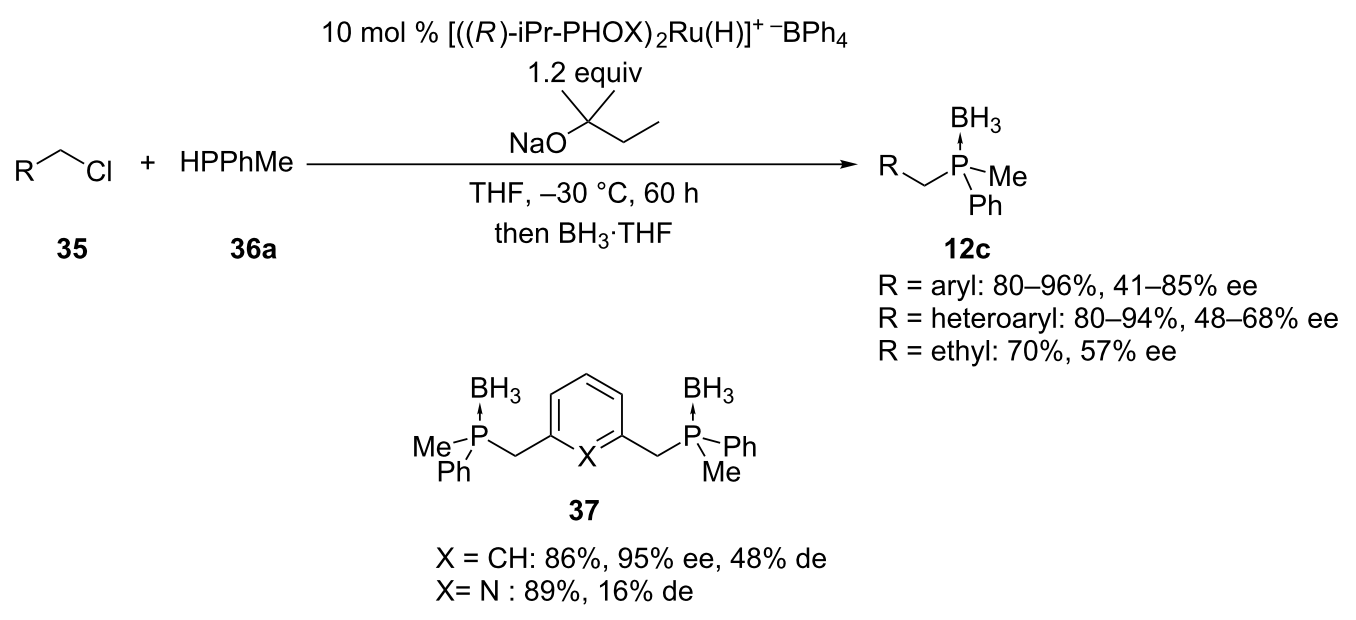

Scheme 11: Ru-catalyzed asymmetric phosphination of benzyl and alkyl chlorides 35 with HPPhMe (36a, PHOX = phosphinooxazoline). 
The group of Glueck has reported a method for the asymmetric alkylation of racemic secondary phosphines $\mathbf{3 6} \mathbf{b}$ by means of a chiral platinum-based catalyst 39 (Scheme 12) [61]. The enhanced nucleophilicity at phosphorus of the platinum-phosphido intermediate was beneficial for the alkylation. The scope of the reaction was investigated using diverse benzylic bromides 22b and secondary phosphines 36b. Bidentate ligands 40 and 41 were also synthesized [61,62]. This procedure was also restricted to benzylic halides. High enantiomeric excesses were reported. As expected, a mechanistic study suggested that the major enantiomer of product was formed from the major diastereomer of the platinum-phosphido intermediate [63]. Glueck and co-workers also developed an analogous method for the tandem alkylation/arylation of primary phosphines on the basis of a platinum catalyst resulting in several enantio-enriched phosphaacenaphtalenes [64].

\section{Hydrophosphination}

Hydrophosphination involves the addition of $\mathrm{P}-\mathrm{H}$ to an unsaturated $\mathrm{C}-\mathrm{C}$ bond. In this reaction phosphines, silylphosphines $[65,66]$ or phosphine-borane complexes are used as phosphinating agents to react with unactivated or activated alkenes, dienes and alkynes. Hydrophosphination has gained much interest as an alternative to the classical phosphine syntheses involving a substitution that is incompatible with certain functional groups. Moreover the addition of $\mathrm{P}-\mathrm{H}$ to an unsaturated $\mathrm{C}-\mathrm{C}$ bond is more efficient than substitution reactions when considering atom efficiency, what makes it not only greener but also more economical. Other phosphination reactions of unsaturated bonds, such as diphosphination, thiophosphination or selenophosphination, were not included [67].
Depending on the regioselectivity of the reaction, the addition of $\mathrm{P}-\mathrm{H}$ to the unsaturated bond results in the formation of different products 43 (Scheme 13). The product that results from the Markovnikov addition of $\mathrm{P}-\mathrm{H}$ corresponds to the $\alpha$-adduct and the anti-Markovnikov addition is referred to as the $\beta$-adduct. The stereoselectivity of the method determines the conformation at the newly formed chiral centers.

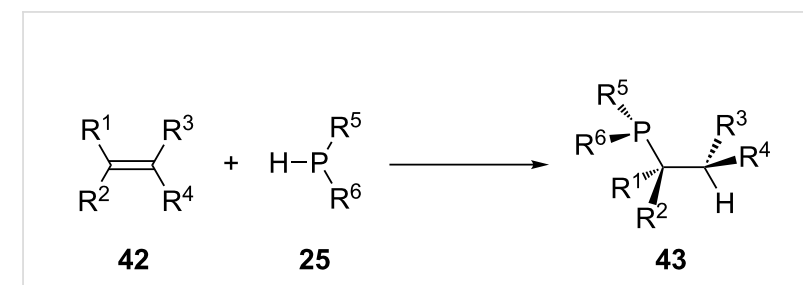

Scheme 13: Different adducts 43 can result from hydrophosphination.

The hydrophosphination typically proceeds via thermal $[68,69]$, radical, acidic [70-72] or basic [73,74] initiation. Radical addition of secondary phosphines to alkenes can be accomplished by thermal activation [75,76], through the use of radical initiators (AIBN) [77-82] or photochemically by irradiation with UV or visible light [22,83-85]. Most of these reactions give antiMarkovnikov products. The hydrophosphination of activated alkenes (e.g., Michael acceptors) has also been shown to take place at room temperature in the absence of a catalyst $[86,87]$ and even under solvent-free conditions [88]. More recently also metal complex-assisted or organocatalyzed hydrophosphinations have been reported. Several reviews focusing on hydrophosphination have been pusblished [89-91].

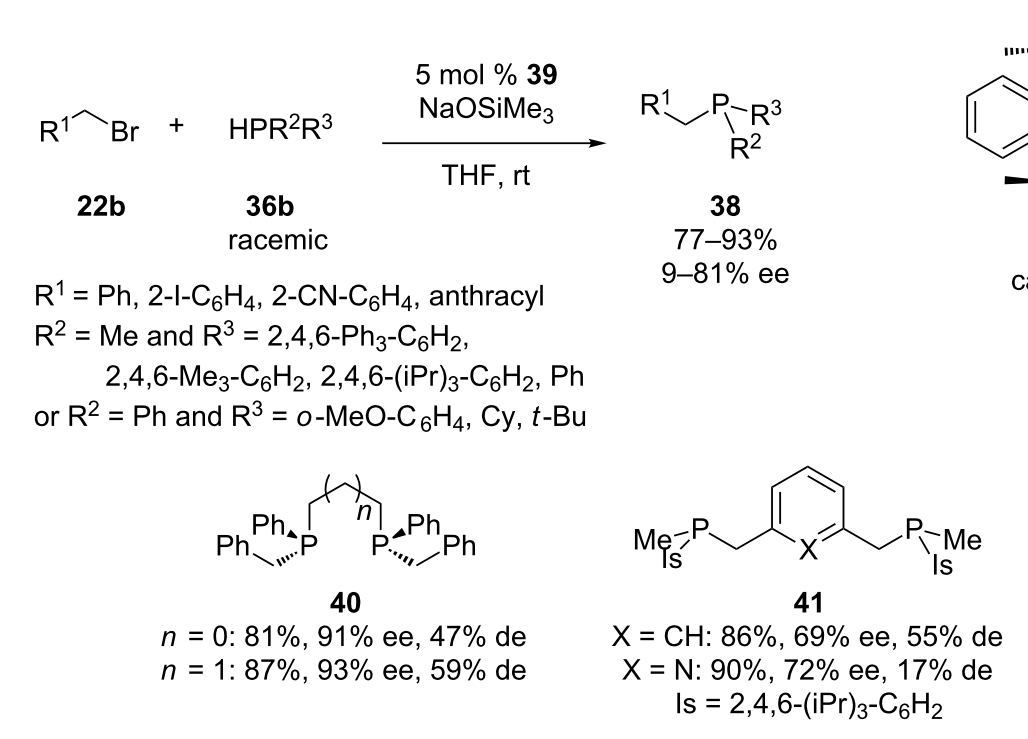

Scheme 12: Pt-catalyzed asymmetric alkylation of secondary phosphines $36 \mathrm{~b}$. 
In recent years a lot of progress has been made in the metal complex-catalyzed hydrophosphination. It was shown that several metals can function as catalysts for the inter- and intramolecular addition of $\mathrm{PH}_{3}$ and $\mathrm{R}_{2} \mathrm{PH}$ to alkenes. Most research has focused on the use of platinum [92-96], palladium [97-99] or nickel [100-104] complexes. Other catalysts that have been less investigated are iron [105-107], rhodium [108110], lanthanides [111-114], copper [115] and alkaline-earth metals $[114,116]$. The catalyst activates either the P-nucleophile or the C-electrophile.

Chiral phosphines have attracted more and more interest since they are employed as ligands in transition metal complexes to perform asymmetric catalysis [117]. Enantiopure phosphines have mostly been prepared by starting from enantiopure products or by resolution. The methodologies for catalytic asymmetric hydrophosphination of olefins are limited. Chiral metal complexes have been used to promote and control the asymmetric $\mathrm{P}-\mathrm{H}$ addition reaction. Recent reviews covering the asymmetric hydrophosphination reaction catalyzed by metal catalysts have been published by Glueck [118,119] and Pullarkat and Leung [120]. Some recent developments in the asymmetric catalytic hydrophosphination will be discussed.

The group of Glueck reported on an approach to chiral phosphines by the addition of secondary phosphines 36c to Michael acceptor alkenes (acrylonitrile or derivatives and acrylate esters 44) in the presence of $\operatorname{Pt}((R, R)$-Me-DuPhos $)$ complexes
(Scheme 14). However, the products $\mathbf{4 5}$ suffered from low enantioselectivities [121]. The mode of action is based on the activation of the P-nucleophile. The proposed mechanism includes the $\mathrm{P}-\mathrm{H}$ oxidative addition to platinum giving a platinum-phosphido complex. Subsequent nucleophilic attack on a Michael acceptor alkene was suggested to lead to a zwitterion intermediate. Addition of a protic additive was beneficial for the selectivity and reaction rate [95].

Several chiral cyclic phosphines were acquired via the lanthanide catalyzed intramolecular hydrophosphination of phosphinoalkenes. Scheme 15 shows the diastereoselective synthesis of 2,5-dimethylphospholanes 49 from 47 with a lanthanide catalyst 48 [122]. The common mechanism when using lanthanide [113] or alkaline earth metal [123] catalysts is based on the formation of a phosphido-metal complex that undergoes insertion of the olefin. Protonolysis of the metal-alkyl complex via $\sigma$-bond metathesis with the phosphine reagent completes the catalytic cycle giving the product and regenerating the phosphido intermediate.

The group of Togni has developed an enantioenriched hydrophosphination of vinyl nitriles catalyzed by a dicationic nickel complex (Table 3). The method is based on the activation of the electrophile. It was suggested that complexation of the nitrile $\mathbf{5 0}$ to the chiral nickel Lewis acid activates the double bond towards 1,4-addition of the phosphine $\mathbf{2 5} \mathbf{b}$. A final proton transfer yields the phosphine product 51 [124,125].

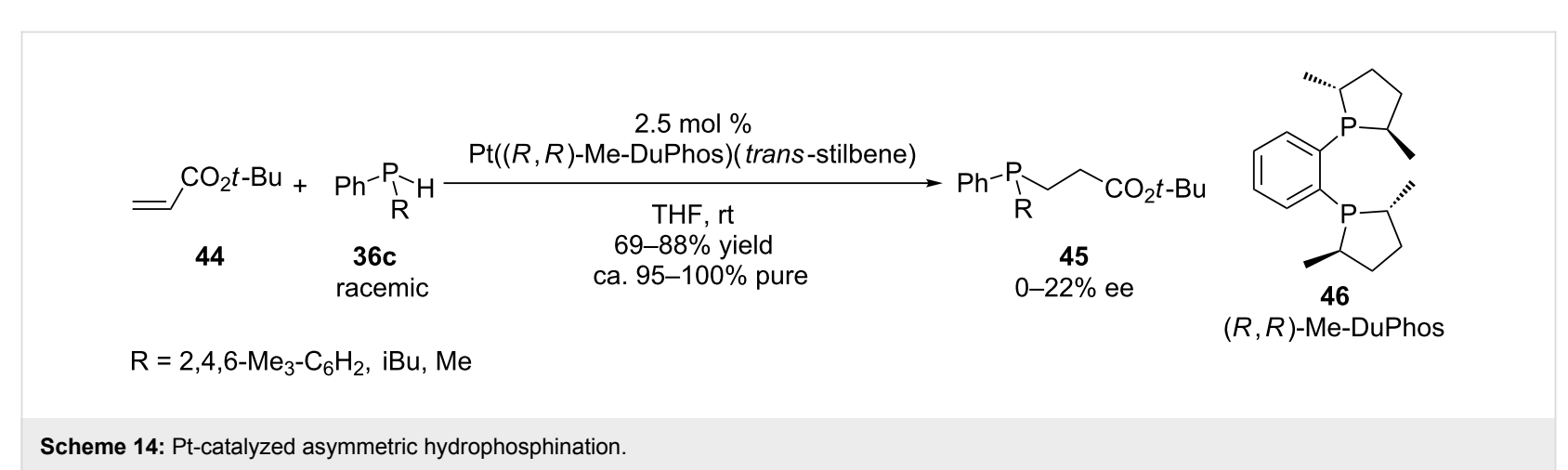

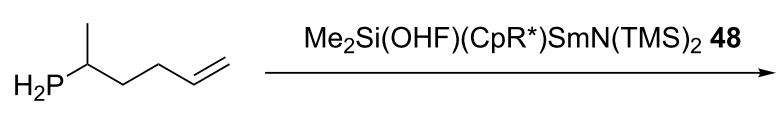

47

$\mathrm{OHF}=$ octahydrofluorenyl

$\mathrm{Cp}=\mathrm{C}_{5} \mathrm{H}_{3}$

$\mathrm{R}^{*}=(-)$-menthyl

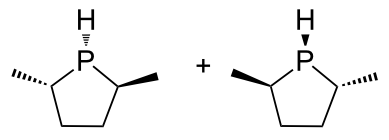

49

$96 \%$ de 
Table 3: Ni-catalyzed asymmetric hydrophosphination of methacrylonitrile $\mathbf{5 0}$

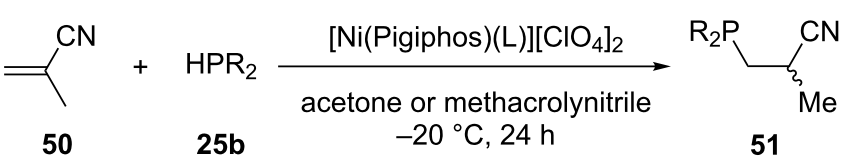

50 25b $-20^{\circ} \mathrm{C}, 24 \mathrm{~h}$

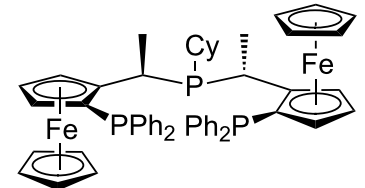

52

Pigiphos

\begin{tabular}{cccc}
\hline Entry & $\mathrm{R}$ & Yield of 51 (\%) & ee of 51 (\%) \\
\hline 1 & $\mathrm{Ph}$ & 10 & 32 \\
2 & $\mathrm{Cy}$ & not isolated & 70 \\
3 & $\mathrm{iPr}$ & 95 & 98 \\
4 & $\mathrm{Ad}$ & 97 & 89 \\
6 & $t$-Bu & 86 & 90
\end{tabular}

A chiral Pincer-palladium complex $\mathbf{5 5}$ has been used for the addition of diarylphosphines $\mathbf{2 5 c}$ to enones $\mathbf{5 3}$ (Table 4) [126]. Several enones $\mathbf{5 3}$, having electron-donating or -withdrawing groups on the aromatic ring, reacted with a variety of electronrich and -poor diarylphosphines 25c. The chiral phosphine oxides 54 were obtained in high yield with excellent stereoselectivities. In the proposed mechanism the catalyst $\mathbf{5 5}$ acts as a base toward the diarylphosphine 25c. Some other examples of palladium-catalyzed asymmetric hydrophosphination are the ad- dition of diphenylphosphine to $\alpha, \beta$-unsaturated ketones $[127,128]$, esters [129], sulfonic esters [130] or to dienones [131]. The proposed mechanism is ubiquitous in metalcatalyzed hydrophosphination involving a $\mathrm{P}-\mathrm{H}$ oxidative addition, insertion of the olefin into the $\mathrm{Pd}-\mathrm{H}$ bond and reductive elimination.

In 2007 several papers appeared reporting on organocatalyzed asymmetric hydrophosphinations. The organocatalytic process

Table 4: Palladium-catalyzed asymmetric addition of diarylphosphines $\mathbf{2 5 c}$ to enones $\mathbf{5 3 .}$<smiles></smiles>

53
$\mathrm{HPAr}_{2}$

25c 1.2 equiv
1) $2 \mathrm{~mol} \%(S, S)-55$ $\mathrm{CH}_{2} \mathrm{Cl}_{2}, \mathrm{rt}, 2 \mathrm{~h}$
2) aq $\mathrm{H}_{2} \mathrm{O}_{2}$, rt

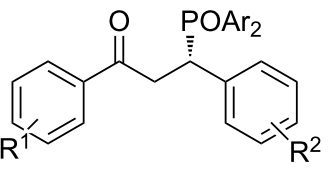

54

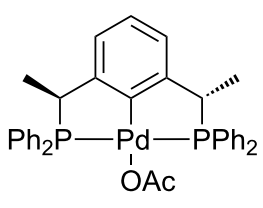

$(S, S)-55$

\begin{tabular}{|c|c|c|c|c|c|}
\hline Entry & $\mathrm{R}^{1}$ & $\mathrm{R}^{2}$ & $\mathrm{Ar}$ & Yield of 54 (\%) & ee of $54(\%)$ \\
\hline 1 & $\mathrm{H}$ & $\mathrm{H}$ & $\mathrm{Ph}$ & 93 & 99 \\
\hline 2 & $p-\mathrm{Br}-$ & $\mathrm{H}$ & $\mathrm{Ph}$ & 89 & 99 \\
\hline 3 & p-MeO- & $\mathrm{H}$ & $\mathrm{Ph}$ & 75 & 98 \\
\hline 4 & $m-\mathrm{Br}-$ & $\mathrm{H}$ & $\mathrm{Ph}$ & 93 & 97 \\
\hline 5 & $p-\mathrm{NO}_{2-}$ & $\mathrm{H}$ & $\mathrm{Ph}$ & 78 & 95 \\
\hline 6 & $\mathrm{H}$ & $p-\mathrm{Br}-$ & $\mathrm{Ph}$ & 90 & 98 \\
\hline 7 & $\mathrm{H}$ & $p-\mathrm{NO}_{2-}$ & $\mathrm{Ph}$ & 88 & 99 \\
\hline 8 & $\mathrm{H}$ & $m-\mathrm{Br}-$ & $\mathrm{Ph}$ & 90 & 99 \\
\hline 9 & $\mathrm{H}$ & o-MeO- & $\mathrm{Ph}$ & 69 & 90 \\
\hline 10 & $\mathrm{H}$ & p-Me- & $\mathrm{Ph}$ & 63 & 90 \\
\hline 11 & $\mathrm{H}$ & $\mathrm{H}$ & $p-\mathrm{MeO}-\mathrm{C}_{6} \mathrm{H}_{4}$ & 86 & 94 \\
\hline 12 & $\mathrm{H}$ & $\mathrm{H}$ & $p-\mathrm{Cl}-\mathrm{C}_{6} \mathrm{H}_{4}$ & 92 & 96 \\
\hline
\end{tabular}


has the advantage that in contrast to a metal-catalyzed method, it cannot undergo product inhibition as a result of the coordination ability of phosphorus to a metal catalyst.

The addition of diphenylphosphine to a range of nitroalkenes $\mathbf{5 6}$ has been described using a bifuntional Cinchona alkoid/thiourea catalyst $\mathbf{5 8}$ [132]. The catalyst $\mathbf{5 8}$ is able to simultaneously activate both the electrophilic and nucleophilic reagents. On one hand the thiourea presumably binds the nitro group while on the other hand the tertiary amine enables proton transfer from phosphorus to carbon (Table 5).

The organocatalyzed hydrophosphination of $\alpha, \beta$-unsaturated aldehydes has been described by Carlone et al. [133] and Ibrahem et al. [134]. The method is based on activation of the aldehyde 59 via iminium-ion formation by reaction with chiral pyrrolidine 62 derivatives and acid (Scheme 16). Subsequent treatment with sodium borohydride forms the air-stable phosphine-borane product and also reduces the aldehyde. The method gives compounds $\mathbf{6 1}$ in high yields and enantioselectivities (ee up to $99 \%$ ) for $\alpha, \beta$-unsaturated aldehydes containing either aliphatic or aromatic groups.

\section{Preparation of alkenylphosphines via forma- tion of a $\mathrm{C}\left(\mathrm{sp}^{2}\right)-\mathrm{P}$ bond}

The $\mathrm{C}\left(\mathrm{sp}^{2}\right)-\mathrm{P}$ bond formation is reviewed for arylic and vinylic phosphines. The group of Gaumont has provided a recent review (2010) on the main synthetic methods to obtain alkenylphosphines [135].

\section{Reaction of organometallic reagents with halophos- phines}

The reaction of an organometallic reagent with the P-atom of halophosphines is a classical method used for the synthesis of both alkenyl- and arylphosphines. The organometallic reagents are mostly Grignard reagents [136-138] or organolithium [139142] derivatives. Other organometallic reagents such as aluminum [143] or organomercury [26,144] reagents have been used less frequently.

Grignard or organolithium compounds are highly reactive nucleophiles and do not tolerate the presence of various functional groups. As a consequence, new approaches were developed including zinc, zirconium and copper reagents.

Table 5: Organocatalytic asymmetric hydrophosphination of nitroalkenes 56.

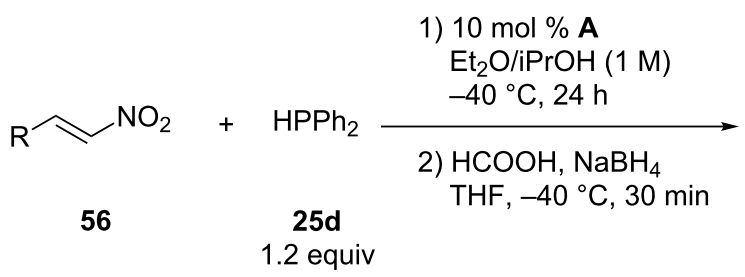

1.2 equiv

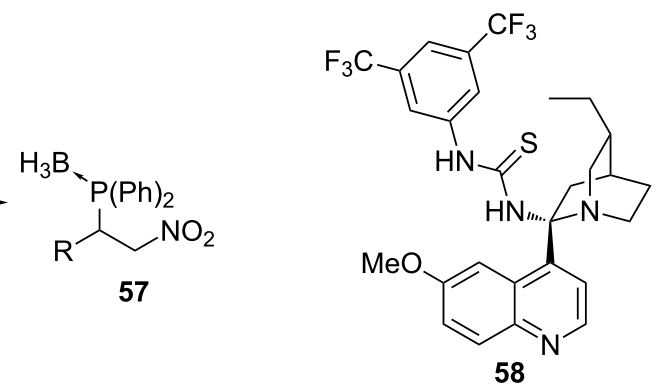

58

\begin{tabular}{|c|c|c|c|c|c|}
\hline \multirow[b]{2}{*}{ Entry } & \multirow[b]{2}{*}{$\mathrm{R}$} & \multirow[b]{2}{*}{ Yield of 57 (\%) } & \multirow[b]{2}{*}{ ee of $57(\%)$} & \multicolumn{2}{|c|}{ After crystallizaton } \\
\hline & & & & Yield of 57 (\%) & ee of $57(\%)$ \\
\hline 1 & $\mathrm{Ph}-$ & 86 & 67 & 36 & 99 \\
\hline 2 & $p-\mathrm{Me}-\mathrm{C}_{6} \mathrm{H}_{4-}$ & 67 & 52 & & \\
\hline 3 & o-F- $\mathrm{C}_{6} \mathrm{H}_{4-}^{-}$ & 83 & 45 & 24 & 99 \\
\hline 4 & $\mathrm{o}-\mathrm{BnO}-\mathrm{C}_{6} \mathrm{H}_{4}^{-}$ & 90 & 60 & 37 & 99 \\
\hline
\end{tabular}

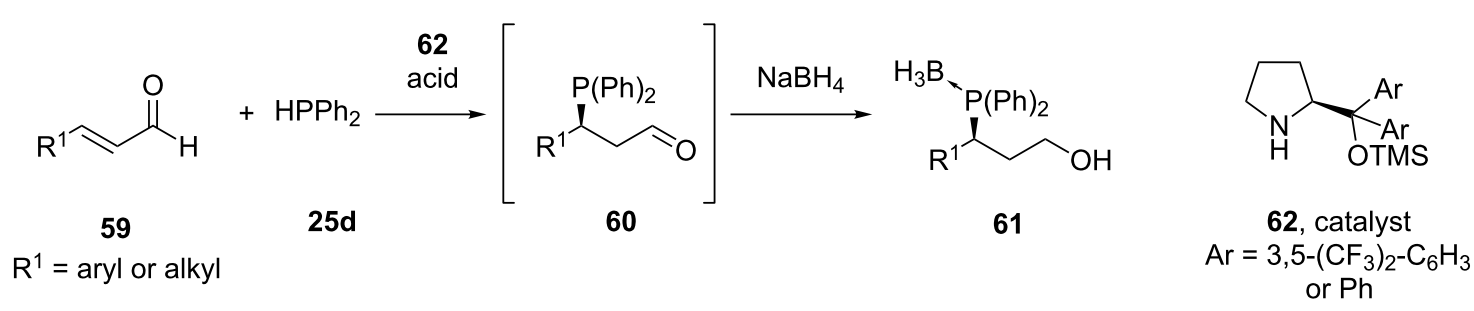


Polyfunctional alkenylphosphine $\mathbf{6 5}$ was accessible via the reaction of organozinc derivative $\mathbf{6 4}$ with chlorophosphine 22a. The organozinc bromide 64 was prepared from the corresponding alkenyl iodide 63. To prevent oxidation, the phosphines were protected as the corresponding borane adducts $\mathbf{6 5}$. The methodology is also applicable for aryl bromide $\mathbf{6 6}$ (Scheme 17) $[23,24]$.

Alkenylphosphines were also synthesized by reacting alkenylzirconocenes 69 with a chlorophosphine 22 b. Alkenylzirconocene compounds $\mathbf{6 9}$ displaying different substitution patterns were used, giving access to a variety of alkenylphosphines 71a via this method. If a more sterically hindered substrate (( $\alpha$-substituted alkenyl)zirconocene) or reagent $\left(\mathrm{iPr}_{2} \mathrm{PCl}\right)$ is used, a transmetallation of $\mathrm{Zr}(\mathrm{IV})$ to $\mathrm{Cu}(\mathrm{I})$ is necessary for the reaction in order to proceed (Scheme 18). An intermediate phosphorus-copper complex $\mathbf{7 0}$ is formed. The phosphines 71a were liberated by treatment with $\mathrm{Na}_{2}(\mathrm{dtc})$ or $\mathrm{Na}_{4}$ (edta) [145].

\section{Nucleophilic substitution with metallated organophosphines}

The method is based on the reaction of phosphorus nucleophiles, derived from secondary phosphines or phosphine-borane complexes, and carbon electrophiles. Nucleophilic substitution with metallated organophosphines is less frequently used for the synthesis of vinylphosphines $[42,146]$ due to possible isomerization to phospha-alkenes under basic conditions [147]. The method is mainly applied for the synthesis of arylphosphines. However, the nucleophilic reagents are incompatible with functional groups susceptible to nucleophilic attack. These sensitive groups have to be protected first to avoid undesired reactions. Despite these limitations this approach is still generally used for the synthesis of simple phosphines $[137,138,148,149]$.

The group of Imamoto reported the $\mathrm{S}_{\mathrm{N}} \mathrm{Ar}$ reaction of $P$-chiral secondary phosphine boranes $\mathbf{1 3 c}$ with halobenzenechromium complexes 72 in the presence of sec-butyllithium [150]. The

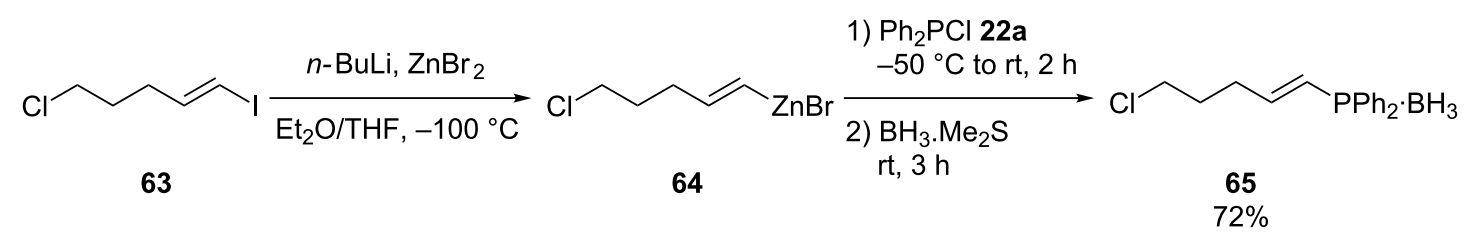

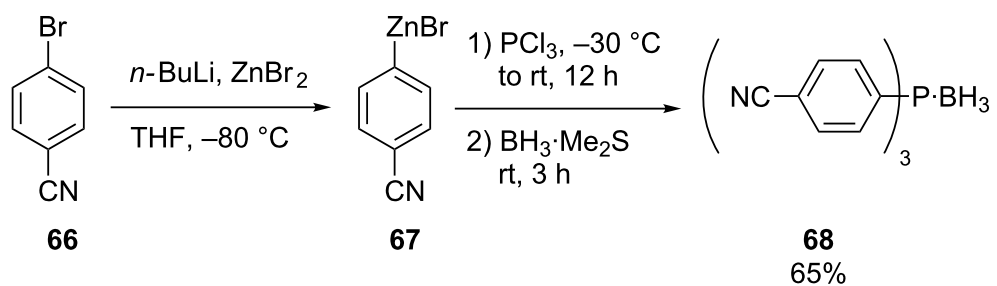

Scheme 17: Preparation of phosphines using zinc organometallics.

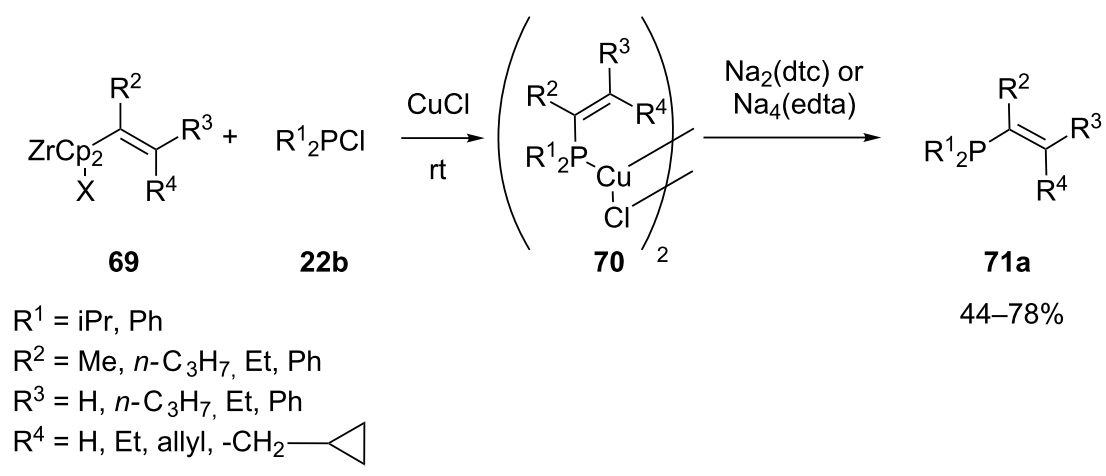


stereochemistry at the phosphorus atom was retained during the substitution when it was performed in THF at low temperature (Scheme 19). When fluorobenzenechromium complex $\mathbf{7 2}$ was used as a substrate, the yields of $\mathbf{7 3}$ were high (81-93\%), in contrast to the reaction with chloro- and bromobenzenechromium complexes. The former reacted in low yield (7\%), the latter did not react. The highly electronegative fluorine atom is needed for the $S_{N} A r$ reaction to take place, even though the arenechromium complexes are already very electron-deficient aromatic compounds.

The same group also developed a $P$-chiral ligand, QuinoxP 74, via deprotonation of chiral secondary phosphine borane 13d with $n$-butyllithium and subsequent nucleophilic substitution with 2,3-dichloroquinoxaline at low temperature (Scheme 20) [151]. After removal of the boranato group, the ligand was obtained in a good yield $(80 \%)$.

\section{Catalytic $\mathrm{C}\left(\mathrm{sp}^{2}\right)-\mathrm{P}$ bond formation}

The transition metal typically used for catalytic C-P bond formation is palladium [152] and, in some cases, nickel or copper. The phosphinating agents may comprise primary and secondary phosphines, silylphosphines [153] or phosphine-borane complexes.

The vinylic coupling partner mostly consists of alkenylhalides or alkenyltriflates. Vinyl triflates are used more since they can easily be derived from the corresponding ketone and they are more reactive then the vinyl chloride or bromide during the oxidative addition. More recently also vinyl tosylates and enol phosphates have proven to be suitable reagents.
The catalytic arylic C-P cross-coupling reaction can be a greener approach towards the widely used arylphosphines that are inaccessible by hydrophosphination. Recent advances in this area concern the synthesis of $P$-stereogenic phosphines through a dynamic kinetic resolution of racemic secondary phosphines in a metal-catalyzed $\mathrm{P}-\mathrm{H} /$ aryl halide coupling.

\section{$\mathrm{C}\left(\mathrm{sp}^{2}\right)-\mathrm{P}$ bond formation of vinylphosphines}

Palladium: Beletskaya and co-workers have described the synthesis of secondary and tertiary vinylphosphines by means of palladium catalyzed cross-coupling of vinylhalides and (silyl)phosphines [154-156]. Table 6 shows the protocols (A or B) generally used [157]. The vinylhalide substrates 75a were cross-coupled with diphenylphosphine or diphenyltrimethylsilylphosphine. When diphenylphosphine was used, triethylamine was added for the basic activation of the phosphinating agent. All the tested substrates 75a contained an alkoxy or amino group and depending on their position relative to the halogen, it was necessary to adjust the reaction temperature. The substrates bearing the halogen in the $\alpha$-position to the alkoxy or amino group proved to be more reactive. With the halogen in $\beta$-position the substrate was less activated and the temperature had to be raised. Method B gave lower yields and longer reaction times were required to compensate for the use of the less reactive diphenyltrimethylsilylphosphine.

Lipshutz et al. used a $\operatorname{Pd}(0)$ catalyst to synthesize triarylphosphine boranes by coupling secondary diphenylphosphine borane 13e with aryl nonaflates or triflates [158]. The article included one example with vinyl triflate $\mathbf{7 6}$ as a substrate (Scheme 21). The vinyl electrophile $\mathbf{7 6}$ was activated by the presence of the

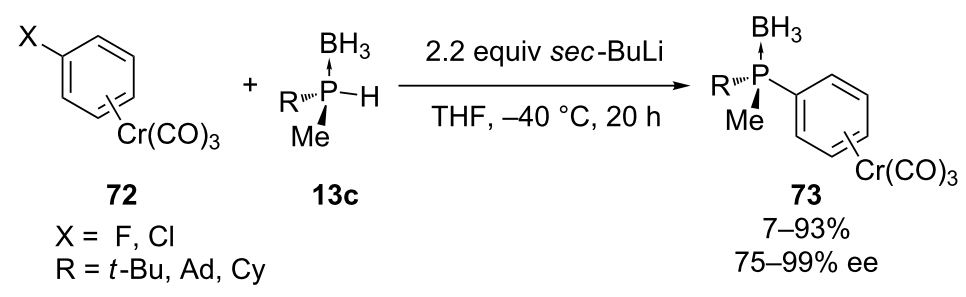

Scheme 19: $\mathrm{S}_{N} A r$ with $P$-chiral alkylmethylphosphine boranes $13 \mathrm{c}$.

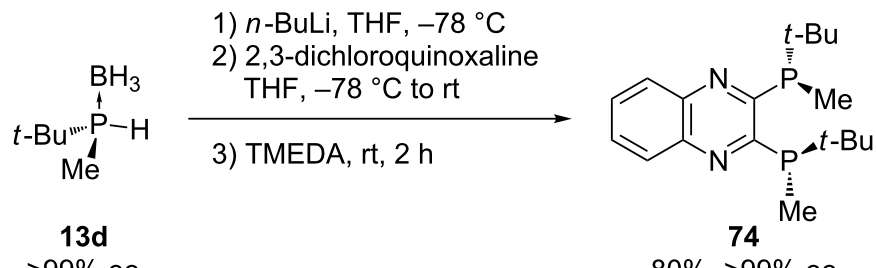

Scheme 20: Synthesis of QuinoxP 74 (TMEDA = tetramethylethylenediamine). 
Table 6: Pd-catalyzed cross-coupling reactions of diphenylphosphine with alkenylhalides $\mathbf{7 5 a}$.

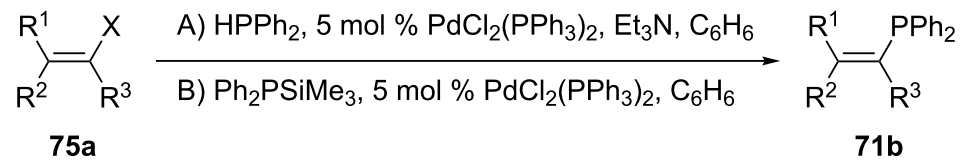

\begin{tabular}{|c|c|c|c|c|c|c|c|c|}
\hline Entry & $\mathrm{R}^{1}$ & $\mathrm{R}^{2}$ & $\mathrm{R}^{3}$ & $x$ & Method & Temp $\left({ }^{\circ} \mathrm{C}\right)$ & Time (h) & Yield of 71b (\%) \\
\hline 1 & $\mathrm{H}$ & $\mathrm{H}$ & OEt & $\mathrm{Br}$ & $\begin{array}{l}A \\
B\end{array}$ & $\begin{array}{l}20 \\
20\end{array}$ & $\begin{array}{c}1 \\
1.5\end{array}$ & $\begin{array}{l}97 \\
92\end{array}$ \\
\hline 2 & $\mathrm{Me}$ & $\mathrm{Me}$ & $\mathrm{NEt}_{2}$ & $\mathrm{Cl}$ & $\begin{array}{l}A \\
B\end{array}$ & $\begin{array}{l}20 \\
20\end{array}$ & $\begin{array}{c}6 \\
12\end{array}$ & $\begin{array}{l}84 \\
80\end{array}$ \\
\hline 3 & $\mathrm{H}$ & $\mathrm{OBu}$ & $\mathrm{Br}$ & $\mathrm{Br}$ & $\begin{array}{l}A \\
B\end{array}$ & $\begin{array}{l}120 \\
120\end{array}$ & $\begin{array}{l}36 \\
40\end{array}$ & $\begin{array}{l}94 \\
90\end{array}$ \\
\hline 4 & $\mathrm{Ph}$ & $N$-morpholine & $\mathrm{H}$ & $\mathrm{Br}$ & $\begin{array}{l}A \\
B\end{array}$ & $\begin{array}{l}70 \\
70\end{array}$ & $\begin{array}{l}24 \\
50\end{array}$ & $\begin{array}{l}92 \\
60\end{array}$ \\
\hline 5 & $\mathrm{Ph}$ & $N$-piperidine & $\mathrm{H}$ & $\mathrm{Br}$ & $\begin{array}{l}A \\
B\end{array}$ & $\begin{array}{l}70 \\
70\end{array}$ & $\begin{array}{l}24 \\
45\end{array}$ & $\begin{array}{l}90 \\
55\end{array}$ \\
\hline
\end{tabular}

carbonyl group so the reaction also took place without a palladium catalyst albeit in lower yield $(60 \%)$ and with formation of byproducts.

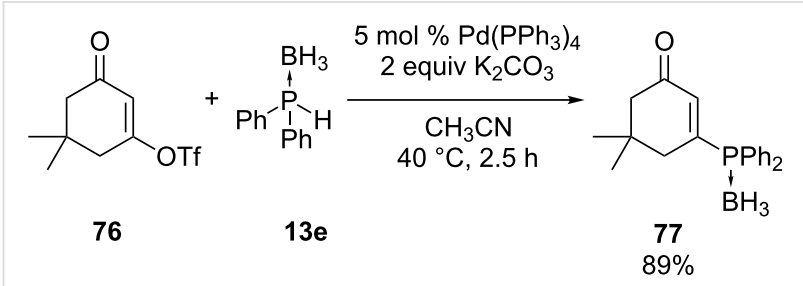

Scheme 21: Pd-Mediated couplings of a vinyl triflate $\mathbf{7 6}$ with diphenylphosphine borane $13 \mathrm{e}$.

Julienne et al. have reported the coupling of secondary phosphine boranes with unactivated vinyl triflates (Table 7 and Table 8) [159]. Cyclic and acyclic vinyl triflates (78 and 80a) were reacted with diaryl-, dialkyl- and alkylarylphosphine-borane complexes, $\mathbf{1 3 f}$ and $\mathbf{1 3 g}$ respectively. The reactions were performed with a palladium catalyst in the presence of a weak base. Sometimes microwave irradiation was used to shorten the reaction time.

Gilbertson et al. have converted a series of vinyl triflates $\mathbf{8 0 b}$ into the corresponding vinyl phosphine boranes $\mathbf{8 1 b}$ through palladium catalysis with $\mathrm{HPPh}_{2}$ (Table 9) [160]. The reaction proceeded under mild conditions $\left(40^{\circ} \mathrm{C}\right)$. These vinyltriflates 80b were obtained from the corresponding ketone 82 opening access to a range of other structures. The chiral phosphines $\mathbf{8 3}$ and $\mathbf{8 4}$ were prepared from the natural products menthone and camphor in the same manner (Figure 1). All products were converted to the corresponding borane complex to facilitate further handling. However, when the same conditions were applied with diphenylphosphine borane and cyclohexenyltriflate no reaction was observed. A similar methodology has been applied for the synthesis of several ligands [161-163].

Table 7: Palladium-catalyzed C-P coupling between acyclic vinyl triflates and phosphine boranes (dppp = 1,3-bis(diphenylphosphino)propane)

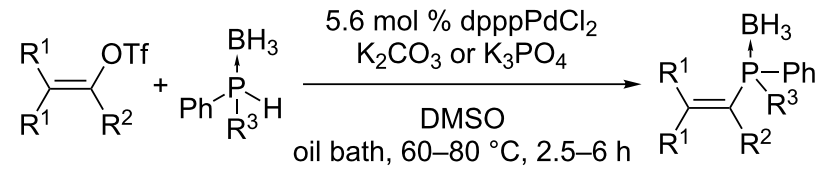

\begin{tabular}{|c|c|c|c|c|}
\hline Entry & $\mathrm{R}^{1}$ & $\mathrm{R}^{2}$ & $\mathrm{R}^{3}$ & Yield of $79 a(\%)$ \\
\hline 1 & $\mathrm{H}$ & $t-\mathrm{Bu}$ & $\mathrm{Ph}$ & 71 \\
\hline 2 & $\mathrm{H}$ & $t-\mathrm{Bu}$ & $\mathrm{Me}$ & 72 \\
\hline 3 & $\mathrm{Ph}$ & $\mathrm{Me}$ & $\mathrm{Ph}$ & 82 \\
\hline 4 & $\mathrm{Ph}$ & $\mathrm{Me}$ & $\mathrm{Me}$ & 87 \\
\hline
\end{tabular}


Table 8: Palladium-catalyzed C-P coupling between cyclic vinyl triflates and phosphine boranes (dppp = 1,3-bis(diphenylphosphino)propane).

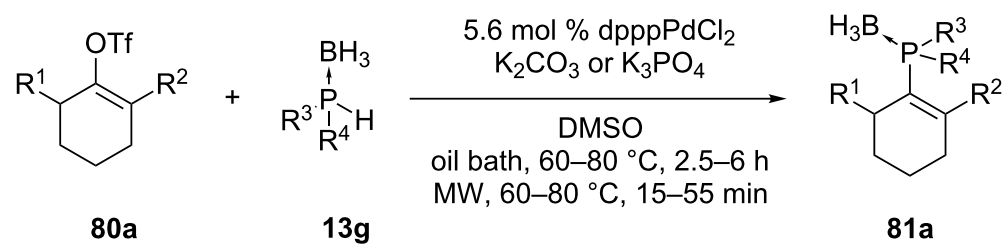

\begin{tabular}{|c|c|c|c|c|c|c|}
\hline Entry & $\mathrm{R}^{1}$ & $\mathrm{R}^{2}$ & $\mathrm{R}^{3}$ & $\mathrm{R}^{4}$ & Heating & Yield of $81 \mathrm{a}(\%)$ \\
\hline 1 & $\mathrm{H}$ & $\mathrm{H}$ & $\mathrm{Ph}$ & $\mathrm{Ph}$ & Oil bath & 68 \\
\hline 2 & $\mathrm{H}$ & $\mathrm{H}$ & $\mathrm{Ph}$ & $\mathrm{Ph}$ & MWI & 71 \\
\hline 3 & $\mathrm{H}$ & $\mathrm{H}$ & $\mathrm{Me}$ & $\mathrm{Ph}$ & Oil bath & 71 \\
\hline 4 & $\mathrm{H}$ & $\mathrm{H}$ & $t-\mathrm{Bu}$ & $\mathrm{Ph}$ & Oil bath & 70 \\
\hline 5 & $\mathrm{H}$ & $\mathrm{H}$ & $t-\mathrm{Bu}$ & $\mathrm{Ph}$ & MWI & 77 \\
\hline 6 & $\mathrm{H}$ & $\mathrm{H}$ & Et & $\mathrm{Et}$ & Oil bath & 50 \\
\hline 7 & $\mathrm{H}$ & $\mathrm{H}$ & Cy & Cy & MWI & 67 \\
\hline 8 & $\mathrm{Me}$ & $\mathrm{H}$ & $\mathrm{Ph}$ & $\mathrm{Ph}$ & Oil bath & 70 \\
\hline 9 & $\mathrm{H}$ & $\mathrm{Me}$ & $\mathrm{Ph}$ & $\mathrm{Ph}$ & Oil bath & 65 \\
\hline
\end{tabular}

Table 9: Palladium-catalyzed synthesis of vinylphosphines $\mathbf{8 1 b}$ from ketones $\mathbf{8 2}$ (dppb = 1,4-bis(diphenylphosphino)butane).

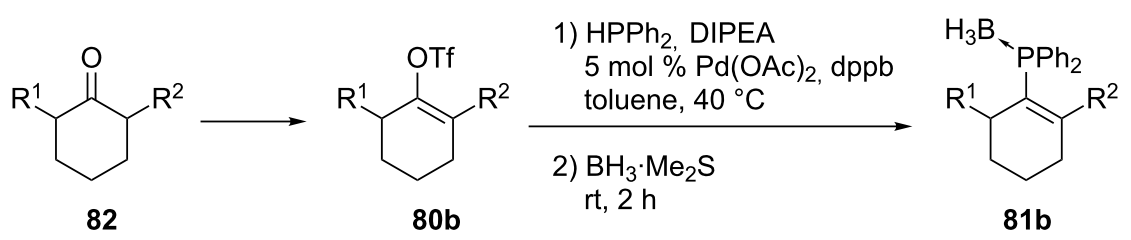

\begin{tabular}{ccccc}
\hline Entry & $\mathrm{R}^{1}$ & $\mathrm{R}^{2}$ & Yield of 81b (\%) \\
\hline 1 & $\mathrm{H}$ & $\mathrm{H}$ & 96 \\
2 & $\mathrm{Me}$ & $\mathrm{H}$ & $\mathrm{Me}$ & 89 \\
3 & $\mathrm{H}$ & $\mathrm{H}$ & 88 \\
4 & $t-\mathrm{Bu}$ & &
\end{tabular}

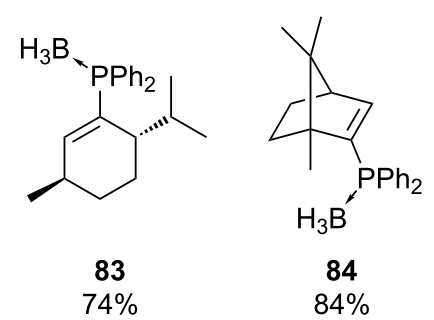

Figure 1: Menthone (83) and camphor (84) derived chiral phosphines.

Julienne et al. succeeded in coupling vinyl tosylates $\mathbf{8 5}$ and $\mathbf{8 7}$ with diphenylphosphine borane 13e despite the fact that alkenyl tosylates are poor reagents for cross-coupling [164]. The products 86 and 79b were formed in the presence of a palladium catalyst. The reaction proceeded at lower temperature when the vinyl tosylate was substituted with an electron-withdrawing group like in $\mathbf{8 5}$ (Scheme 22).

The group of Gaumont has also reported their preliminary results for the enantioselective palladium-catalyzed C-P crosscoupling reaction between an achiral vinyl triflate $80 \mathrm{c}$ and a racemic secondary phosphine-borane complex $\mathbf{1 3 b}$ (Scheme 23) [165]. Chiral phosphines with a $C$-stereogenic center have been studied but this was the first attempt for the asymmetric synthesis of a $P$-stereogenic compound. After evaluating several conditions the best catalyst was $(S, S)$-Me-DuPhos (46). An enantioenriched alkenylphosphine 81c was formed. The highest enantiomeric excess measured by chiral HPLC was $56 \%$. No reaction was observed without the palladium catalyst [165]. 
<smiles>CCOC(=O)C1=C([O-])CCCC1</smiles><smiles>P[Pb](c1ccccc1)c1ccccc1</smiles>

1) $5.6 \mathrm{~mol} \% \mathrm{dpppPdCl} 2, \mathrm{~K}_{2} \mathrm{CO}_{3}$ DMSO, $1 \mathrm{~h}, 80^{\circ} \mathrm{C}$

2) $\mathrm{BH}_{3} \cdot \mathrm{Me}_{2} \mathrm{~S}$<smiles>[B][PH]([B])(C1=C(C(=O)OCC)CCCC1)c1ccccc1</smiles>

86

$56 \%$<smiles>[B]P([B])(C(C)=C(c1ccccc1)c1ccccc1)(c1ccccc1)c1ccccc1</smiles>

$79 \mathrm{~b}$

Scheme 22: Palladium-catalyzed cross-coupling reaction of vinyl tosylates 85 and 87 with diphenylphosphine borane $13 e(d p p p=1,3-$ bis(diphenylphosphino)propane).

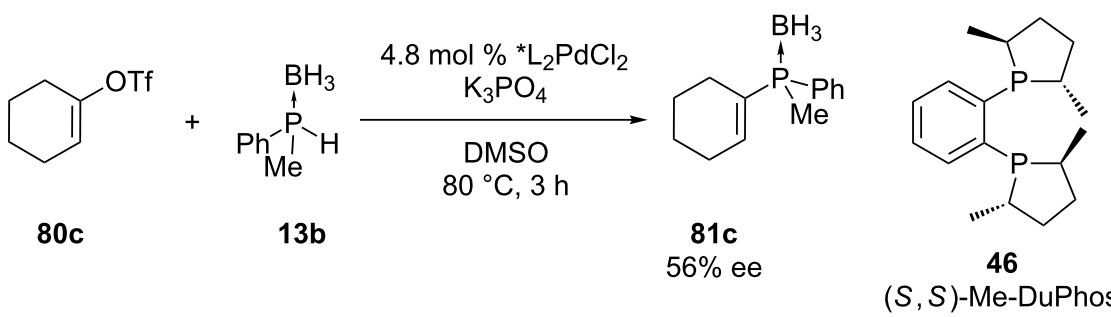

Scheme 23: Attempt for the enantioselective palladium-catalyzed C-P cross-coupling reaction between an alkenyltriflate $80 \mathrm{c}$ and a phosphine borane 13b.

Gillaizeau and co-workers have demonstrated the use of $\alpha$-amido enol phosphates $\mathbf{8 8}$ as vinylic coupling partners in the palladium-catalyzed C-P cross-coupling reaction (Scheme 24) [166]. The enol phosphates $\mathbf{8 8}$ were prepared from the corresponding amides. The phosphane function was introduced in the $\alpha$-position of the nitrogen. Several chiral and achiral secondary phosphine borane complexes 13 were used. The coupling was achieved under mild conditions. Most reactions gave $\mathbf{8 9}$ in low to good yields but in some cases the product could not be isolated, probably due to instability of the product. During the<smiles>[R20]C(=O)N1C[Te]CC=C1OP(=O)(O)Oc1ccccc1</smiles>

88
2 equiv 13e,h,i

5-10 mol \% (dppf) $\mathrm{PdCl}_{2}$ 2 equiv $\mathrm{Cs}_{2} \mathrm{CO}_{3}$

$\mathrm{CH}_{3} \mathrm{CN}, 40-60{ }^{\circ} \mathrm{C}, 2-3 \mathrm{~h}$$$
\mathrm{RO}
$$<smiles>[R]OC(=O)N1C[Te]CC=C1[PH]([R2])(C)C</smiles>

$28-95 \%$

99.4 to $>99.5 \%$ ee<smiles>[Pb]P(c1ccccc1)c1ccccc1</smiles><smiles>[18OH]P([PbH])c1ccccc1</smiles>

$13 e$

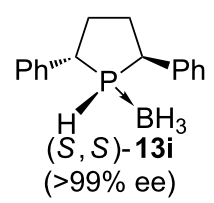

$n=1$ or 2

$\mathrm{R}=\mathrm{Me}$ or $t-\mathrm{Bu}$

phino)ferrocene) 
coupling reaction with $\mathbf{1 3 h}$ partial inversion of the phosphorus atom occurred, resulting in racemization.

Nickel: Most research has focused on the use of a palladium catalyst to perform the $\mathrm{C}-\mathrm{P}$ cross-coupling between secondary phosphines and vinylic electrophiles. A few reports are available concerning the nickel-catalyzed cross-coupling. Ager and Laneman have prepared phosphines 91 and 93 from vinyl triflate 90 and vinyl bromide 92, respectively, under similar conditions (Scheme 25) [53]. The reaction was catalyzed by $\mathrm{NiCl}_{2}$ (dppe) in the presence of zinc. The role of zinc was to reduce $\mathrm{Ni}(\mathrm{II})$ to $\mathrm{Ni}(0)$ and to form $\mathrm{Ph}_{2} \mathrm{PZnCl}$ for the transmetallation step.

Kazankova and co-workers have explored the catalysts $\left(\mathrm{Ph}_{3} \mathrm{P}\right)_{2} \mathrm{NiCl}_{2}$ and $\mathrm{Ni}(\mathrm{acac})_{2}$ for the coupling of several vinyl bromides $\mathbf{7 5 b}$ and chlorides with $\mathbf{2 5 d}$ (Table 10). These reactions proceeded without the addition of zinc [167].

Copper: The group of Buchwald has reported one example of a copper catalyst to accomplish the phosphination of the vinyl halide 94 (Scheme 26) [168]. The protocol uses $\mathrm{CuI}$ as catalyst in combination with $N, N^{\prime}$-dimethylethylenediamine (96) as ligand and a weak base $\mathrm{Cs}_{2} \mathrm{CO}_{3}$. The desired phosphine 95 is isolated in good yield.

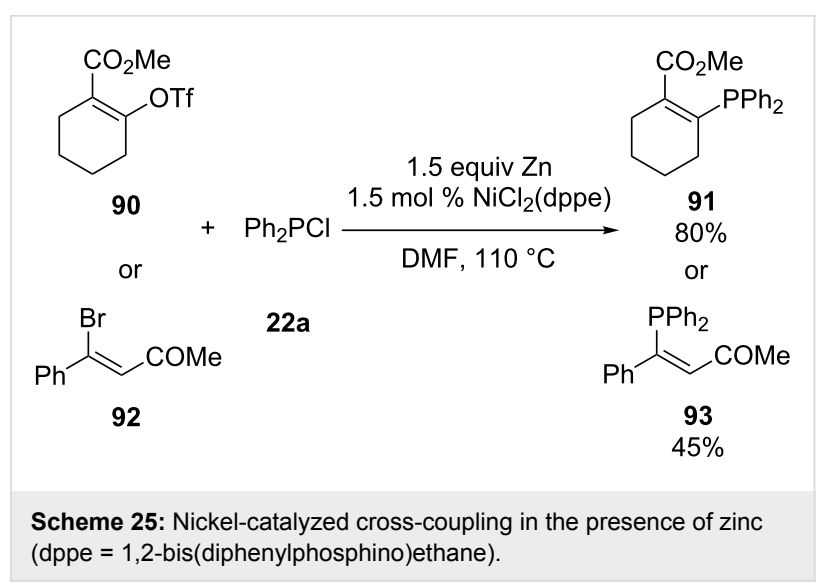

\section{$\mathrm{C}\left(\mathrm{sp}^{2}\right)-\mathrm{P}$ bond formation of arylphosphines}

The C-P bond formation of aryl phosphines is typically catalyzed by palladium, nickel and less frequently copper. The phosphorus coupling partners used are primary, secondary and tertiary phosphines, secondary phosphine-borane complexes, silyl- and stannylphosphines and phosphine chlorides. These phosphinating agents are coupled with aryl halides and triflates. Several general protocols are available.

Palladium: In 1987, Tunney and Stille reported on the palladium-catalyzed synthesis of several aryldiphenylphosphines by

Table 10: Alternative nickel-catalysed cross-coupling without zinc (acac = acetylacetone)

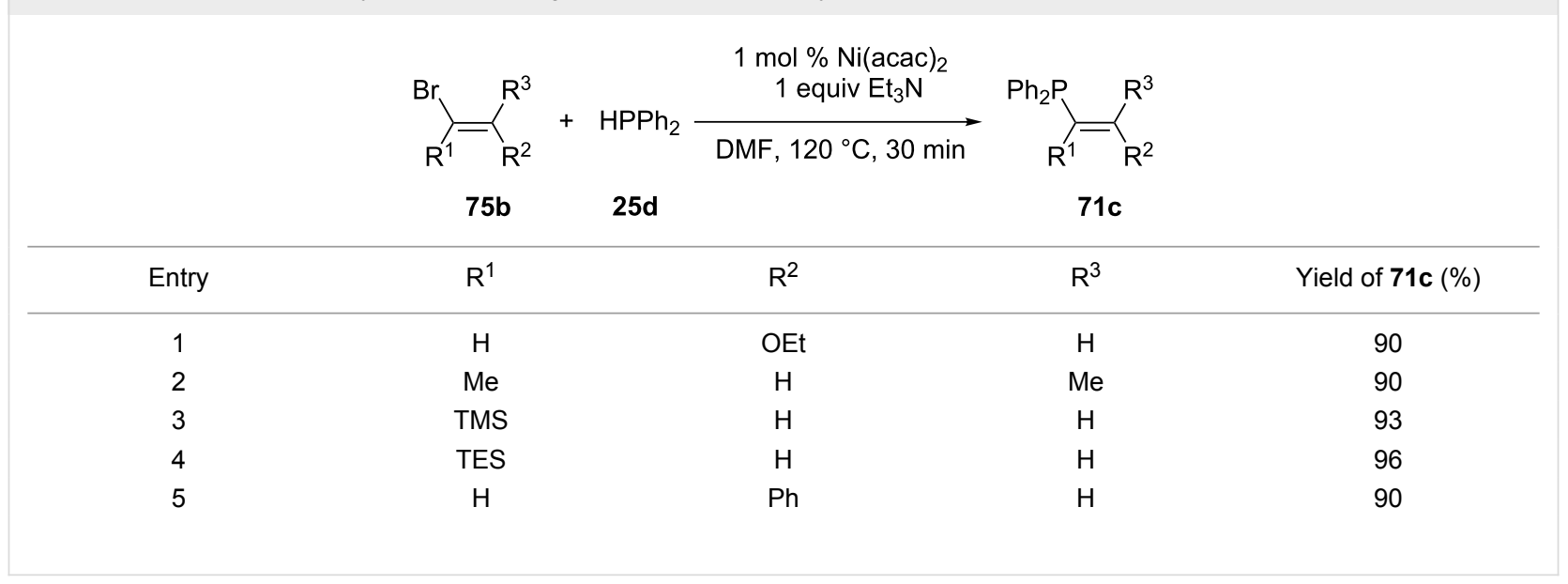

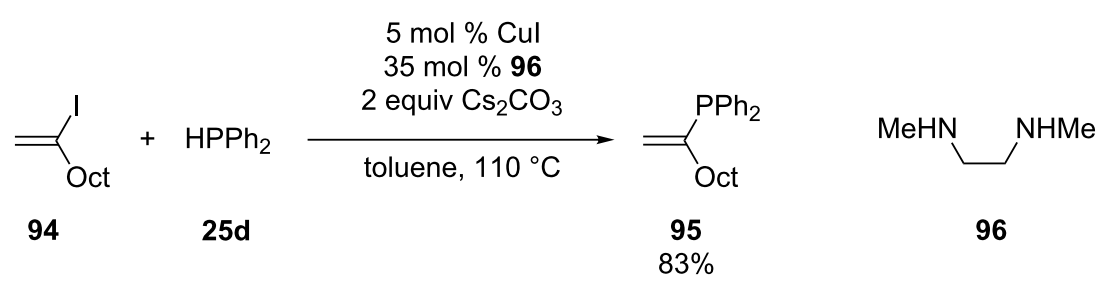


cross-coupling aryl halides with (trimethylsilyl)diphenylphosphine or (trimethylstannyl)diphenylphosphine [169]. No base is required for this method. Trimethylsilyl compounds are preferred over tristannyl derivatives since they are less toxic. However, in recent years the group of Rossi has reported a onepot procedure for the palladium-catalyzed coupling of aryl iodides 97 with in situ generated $\mathrm{Ph}_{2} \mathrm{SnBu}_{3}$ (30, Scheme 27) [170]. When naphthyl triflate was used as a substrate, $\mathrm{CuI}$ was added as a co-catalyst [171].

Imamoto et al. have developed a method for the palladiumcatalyzed $\mathrm{C}-\mathrm{P}$ bond formation using secondary phosphine boranes [41]. The authors also discovered how the choice of the solvent influences the stereochemistry of 100. When the coupling between aryl iodide $\mathbf{9 9}$ and asymmetric secondary phosphine borane 13b was performed in acetonitrile or DMF, the stereochemistry at the phosphorus atom was almost completely retained while the reaction performed in THF or toluene resulted mainly in inversion (Scheme 28) [172,173]. The stereochemistry also depended on the base used. The presence of $\mathrm{K}_{2} \mathrm{CO}_{3}$ or KOAc favored a good stereoselectivity in contrast to $\mathrm{K}_{3} \mathrm{PO}_{4}$ or DBU. Sodium hydride or $\mathrm{Ag}_{2} \mathrm{CO}_{3}$ promoted retention of configuration. The mechanism of the reaction was studied by Gaumont et al. through isolation of the reactive intermediate [174]. Lipshutz et al. reported the palladium-catalyzed phosphination of aryl triflates and nonaflates instead of aryl iodides with phosphine boranes [158]. The first examination towards an enantioselective C-P cross-coupling starting from racemic secondary phosphine boranes was performed by Gaumont and Pican [175]. The highest enantiomeric excess obtained was $45 \%$. The same group has shown that imidazolium based ionic liquids can be used as a medium to perform the $\mathrm{C}-\mathrm{P}$ cross-coupling reactions. This method allows an easy separation of the product from the catalyst and the recycling of the palladium catalyst [176].

Stelzer and co-workers have developed a general method for the coupling of primary or secondary phosphines instead of their silyl derivatives or borane complexes with functional aryliodides 101 [177-179]. It should be noted, however, that the reactions were again limited to (di)phenylphosphine (Scheme 29). The protocols use palladium as a catalyst in the presence of tertiary amines as base. A variety of hydrophilic phosphines $(\mathbf{1 0 2}, \mathbf{1 0 3})$ was synthesized. Since no protective groups were introduced, the method proves to be compatible with several functionalities. This methodology or in a slightly modified form has been used by several authors for the phosphination of a large variety of compounds [180-188]. Microwaveassisted procedures have also been developed [189-191].

Kwong et al. implemented a palladium-catalyzed phosphination of aryl bromides and triflates $\mathbf{1 0 4}$ with triarylphosphines

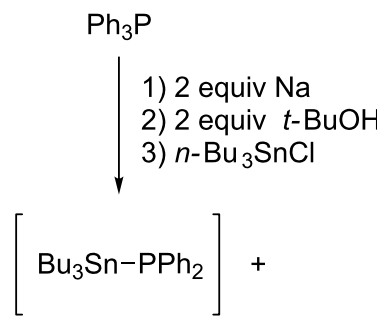

30<smiles>[R]c1ccc(I)cc1</smiles>

97

\section{1. $1.5 \mathrm{~mol} \%\left(\mathrm{Ph}_{3} \mathrm{P}\right)_{2} \mathrm{PdCl}_{2}$ toluene, $80^{\circ} \mathrm{C}, 24 \mathrm{~h}$}

\section{2. $\mathrm{H}_{2} \mathrm{O}_{2}$}

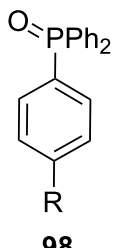

$88-97 \%$

GC yields

$$
\mathrm{R}=p-\mathrm{Cl}, p-\mathrm{Br}, p-\mathrm{CF}_{3}, p-\mathrm{NH}_{2}
$$

Scheme 27: Palladium-catalyzed cross-coupling of aryl iodides 97 with organoheteroatom stannanes 30.

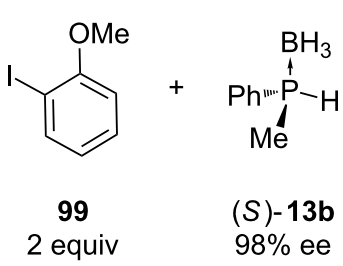

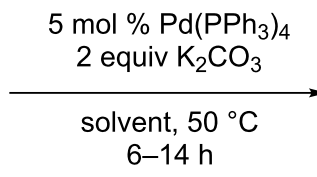

$6-14 \mathrm{~h}$<smiles>[B]P(c1ccccc1)[PH]([B])(C)c1ccccc1OC</smiles>

(R)-100<smiles>[BH3-][PH]([14CH3])([PbH2])c1ccccc1OC</smiles>

(S) -100

$\mathrm{CH}_{3} \mathrm{CN}: 77 \%, 98 \%$ ee $R$ THF: $79 \%, 62 \%$ ee $S$ 


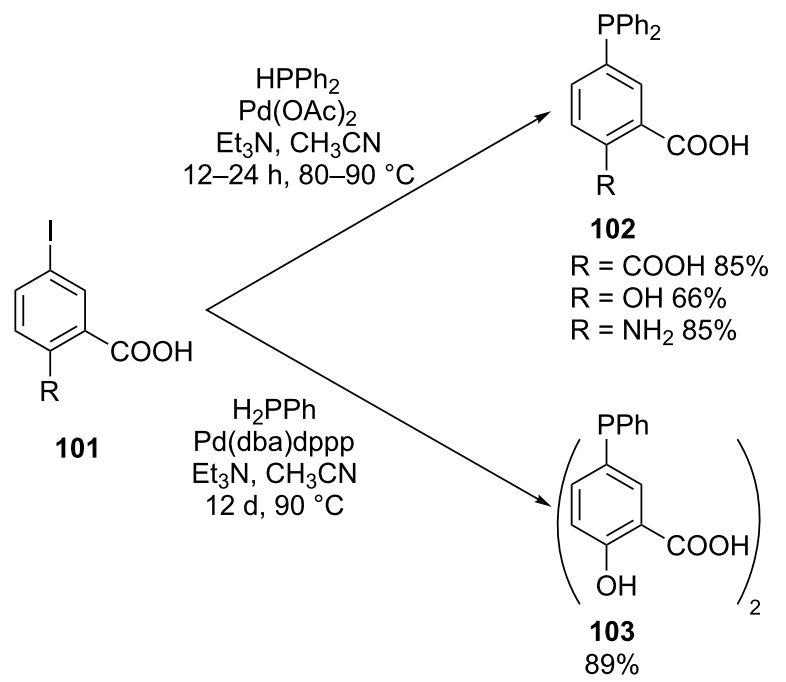

Scheme 29: Palladium-catalyzed $\mathrm{P}-\mathrm{C}$ cross-coupling reactions between primary or secondary phosphines and functional aryliodides $101(\mathrm{dba}=$ dibenzylideneacetone, $\mathrm{dppp}=1,3$ bis(diphenylphosphino)propane).

105a as phosphinating agents. This aryl-aryl exchange reaction was compatible with several functional groups such as ketones, aldehydes, esters, nitriles, ethers (Table 11) [192-195]. Products 106 a were isolated in only moderate yields. Several $P, N-$ biaryl ligands were prepared from the corresponding triflate under similar conditions [196,197]. The reaction also proceeded under solvent-free conditions with slightly higher yields [198]. A heterogeneous $\mathrm{Pd} / \mathrm{C}$ catalyst has been applied as well $[199,200]$.

Table 11: The phosphination of aryl bromides 104 with tertiary arylphosphines 105a.

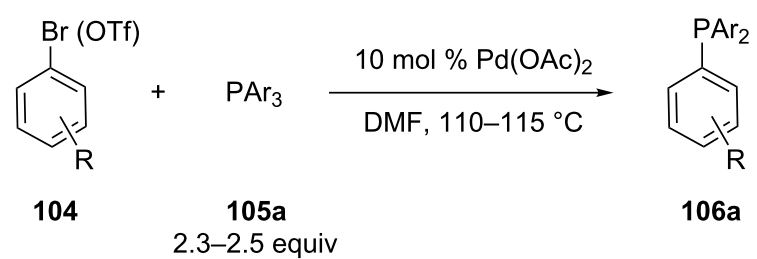

\begin{tabular}{cccc}
\hline Entry & $\mathrm{R}$ & $\mathrm{Ar}$ & Yield of 106a (\%) \\
\hline 1 & $-\mathrm{CHO}$ & $\mathrm{Ph}$ & 32 \\
2 & $-\mathrm{C}(\mathrm{O}) \mathrm{Me}$ & $\mathrm{Ph}$ & 40 \\
3 & $-\mathrm{CO}_{2} \mathrm{Me}$ & $\mathrm{Ph}$ & 30 \\
4 & $-\mathrm{CN}$ & $\mathrm{Ph}$ & 36 \\
5 & $-\mathrm{OMe}$ & $\mathrm{Ph}$ & 27 \\
6 & $-\mathrm{C}(\mathrm{O}) \mathrm{Me}$ & $p-\mathrm{Tol}_{2}$ & 39 \\
7 & $-\mathrm{C}(\mathrm{O}) \mathrm{Me}$ & $3,5-\mathrm{Me}_{2}-\mathrm{C}_{6} \mathrm{H}_{3}$ & 34 \\
8 & $-\mathrm{C}(\mathrm{O}) \mathrm{Me}$ & $p-\mathrm{MeO}_{-}-\mathrm{C}_{6} \mathrm{H}_{4}$ & 33
\end{tabular}

The group of Glueck has reported the first asymmetric palladium-catalyzed C-P bond formation for the synthesis of $P$-stereogenic phosphines by adding a catalytic amount of a chiral auxiliary. The enantioenriched phosphine 108 was obtained through coupling of racemic bulky secondary phosphine 107 with $\mathrm{PhI}$ in the presence of the base $\mathrm{NaOSiMe}_{3}$ and the Pd-catalyst (Scheme 30) [201]. In the following years, the scope and mechanism were elaborated [202-204]. In accordance with the mechanism given in Scheme 10, it was concluded that the major enantiomer of the product $\mathbf{1 0 8}$ was derived from the major diastereomer of the Pd-phosphido intermediate. Korff and Helmchen have prepared several triarylphosphines with this methodology. However, a modified catalyst system [Pd(Et-FerroTANE)] containing a ferrocenebased ligand was used [205]. This catalyst had the advantage that it was easily prepared in situ while the unstable catalyst used by Glueck et al., required storage at $-25{ }^{\circ} \mathrm{C}$ in the dark.

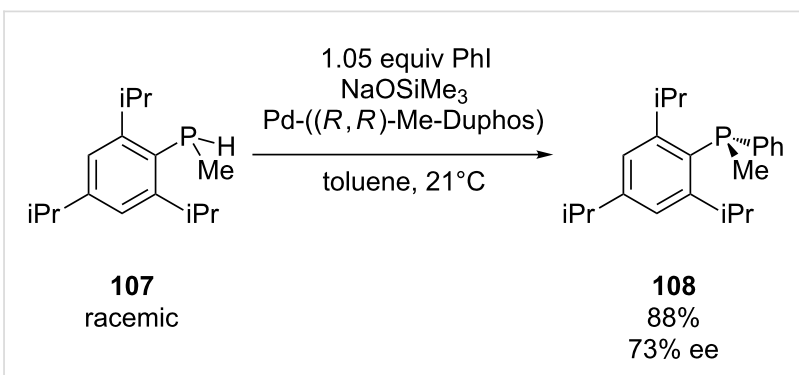

Scheme 30: Enantioselective synthesis of a $P$-chirogenic phosphine 108.

The protocol of Tunney and Stille starting from silylphosphines has been modified by Chan, Bergman and Toste to be enantioselective by using a $[\mathrm{Pd}($ Et-FerroTANE) $]$ catalyst. $P$-stereogenic phosphine boranes 111 and 112 were synthesized by arylation of racemic silylphosphines $\mathbf{1 1 0}$ under dynamic kinetic control (Scheme 31). The best enantiomeric excess was obtained when an ortho-amide substituent was present in the substrate 109 [206].

Nickel: Cristau et al. were the first which achieved the nickelcatalyzed arylation of diphenylphosphine [207]. Upon reaction of bromobenzene (113) with $\mathbf{2 5 d}$ in the presence of $\mathrm{NiBr}_{2}$ a mixture of triphenylphosphine $\mathbf{1 0 5} \mathrm{b}$ and tetraphenylphosphonium bromide salt 114 was obtained (Scheme 32).

The first conversion of an aryltriflate to an arylphosphine using diphenylphosphine was reported by Cai et al. (Scheme 33) $[208,209]$. The method was developed for the synthesis of chiral $(R)$-BINAP 116; a successful chiral ligand. Nickel was chosen as catalyst instead of palladium to minimize catalyst poisoning by binding of the metal with the phosphines present. 


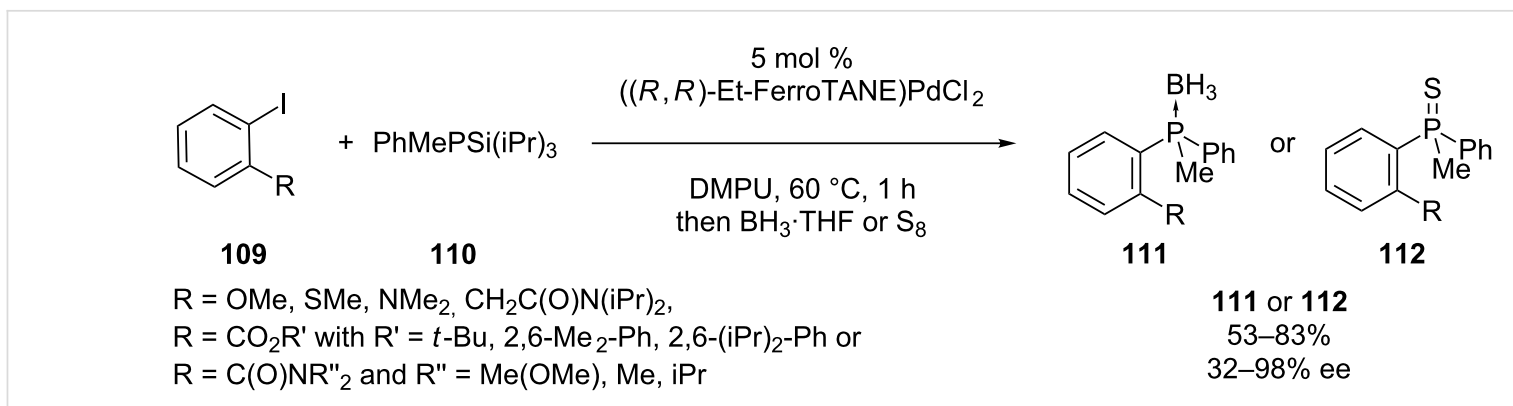

Scheme 31: Enantioselective arylation of silylphosphine $110((R, R)$-Et-FerroTANE = 1,1'-bis((2R,4R)-2,4-diethylphosphotano)ferrocene).

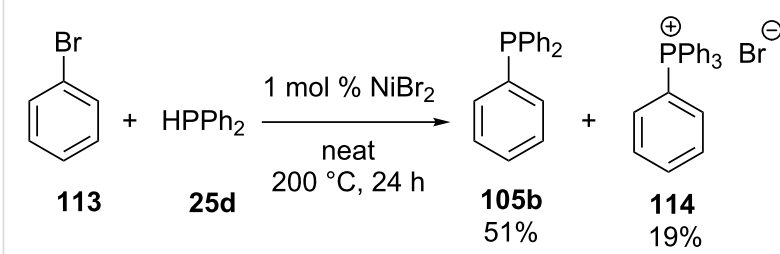

Scheme 32: Nickel-catalyzed arylation of diphenylphosphine $\mathbf{2 5 d}$.

After optimization, the desired chiral BINAP 116 was obtained in $77 \%$ yield. This protocol has been adopted by other research groups for the synthesis of a range of phosphines [138,210216]. Analogous palladium-catalyzed reactions coupling aryl triflates with diphenylphosphine have been reported [217,218].

Laneman et al. later developed a modified version of Cai's method and synthesized several tertiary phosphines $\mathbf{1 1 8}$ via the cross-coupling of aryl triflates and halides 117 with chlorodiphenylphosphine (22a) instead of diphenylphosphine (Table 12) [53]. The reaction was catalyzed by $\mathrm{NiCl}_{2}$ (dppe) in the presence of zinc. A hydrodehalogenation side reaction resulted in lower yields of aryl halide substrates compared to aryl triflates.

Zhao and co-workers disclosed a method for the cross coupling of various aryl bromides 119 with diphenylphosphine (25d) in the absence of external reductants and supporting ligands [219]. The reaction gave mixtures of phosphines $\mathbf{1 2 0}$ and phos-
Table 12: Preparation of tertiary phosphines 118 via nickel-catalyzed cross-coupling (dppe = 1,2-bis(diphenylphosphino)ethane).

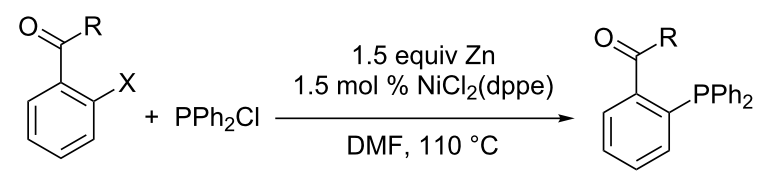

$11722 a \quad 118$

\begin{tabular}{cccc}
\hline Entry & $\mathrm{R}$ & $\mathrm{X}$ & Yield of 118 (\%) \\
\hline 1 & OMe & OTf & 84 \\
2 & OMe & $\mathrm{Br}$ & 46 \\
3 & NHBn & OTf & 67 \\
4 & (S)-NHCHMePh & $\mathrm{Br}$ & 46
\end{tabular}

phine oxides 121 (Scheme 34). Several functional groups (ester, ether, ketone and cyano groups) remained intact under the conditions. The reaction was also performed with diphenylphosphine-borane complex but this resulted in only small amounts of products due to decomposition of the phosphinating reagent at $100{ }^{\circ} \mathrm{C}$.

Copper: Copper was first used as a co-catalyst in palladiumcatalyzed phosphorylation reactions, Livinghouse et al. demonstrated that the aromatic phosphorylation proceeded even at low temperatures of $\leq 0{ }^{\circ} \mathrm{C}$ when copper was added [220]. The method also allows for the stereocontrolled $\mathrm{Pd}(0)-\mathrm{Cu}(\mathrm{I})$

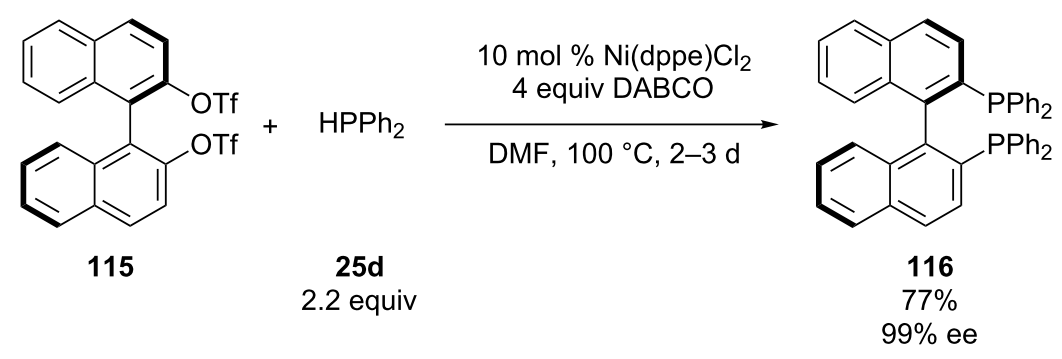

Scheme 33: Nickel-catalyzed synthesis of (R)-BINAP 116 (dppe = 1,2-bis(diphenylphosphino)ethane, DABCO = 1,4-diazabicyclo[2.2.2]octane). 


$$
\begin{aligned}
& 5 \mathrm{~mol} \% \mathrm{NiCl}_{2} \text { (dppp) } \\
& \mathrm{Ar}-\mathrm{Br}+\mathrm{HPPh}_{2} \frac{2 \text { equiv } \mathrm{K}_{3} \mathrm{PO}_{4}}{\text { dioxane }} \mathrm{Ar}-\mathrm{PPh}_{2}+\mathrm{Ar}-\mathrm{P}(\mathrm{O}) \mathrm{Ph}_{2} \\
& 100{ }^{\circ} \mathrm{C}, 10-18 \mathrm{~h} \\
& 11925 d \\
& 1.2 \text { equiv } \\
& 120 \quad 121 \\
& 120+12164-99 \%
\end{aligned}
$$

Scheme 34: Nickel-catalyzed cross-coupling between aryl bromides 119 and diphenylphosphine (25d) (dppp = 1,3-

bis(diphenylphosphino)propane).

co-catalyzed coupling of enantiopure secondary phosphine borane 13b with aryl iodides 122 (Scheme 35) [221].

In 2003, copper-catalyzed palladium free phosphorylation methods were developed by Venkataraman and Van Allen [222] and Buchwald et al. [168]. Both methodologies use catalytic amounts of copper(I) salts in the presence of $\mathrm{K}_{2} \mathrm{CO}_{3}$ or $\mathrm{Cs}_{2} \mathrm{CO}_{3}$ as a base. Buchwald et al. also added $N, N^{\prime}$-dimethylethylenediamine 96 as a ligand to enhance the efficiency of the coupling. A secondary phosphine $\mathbf{2 5 e}$ was coupled with a variety of aryl halides 124 with electron-withdrawing or -donating substituents. The method tolerated the presence of functional groups such as esters or amines (Table 13). This approach was also used for the synthesis of phosphinoxazolines [223].

\section{Hydrophosphination of alkynes}

The addition of $\mathrm{P}-\mathrm{H}$ to a triple bond is a highly desirable method when taking atom economy principles into account. Activated [224,225] or unactivated alkynes were investigated as substrates. Phosphines as well as silylphosphines $[65,66,226,227]$ or phosphine-borane complexes can be used as phosphinating agents. The addition reaction has been initiated in several ways including base [228-233], radical (thermal radical [234] or AIBN radical $[77,78,83,235,236])$ or transition metal activation.

Depending on the regioselectivity of the procedure, the addition of $\mathrm{P}-\mathrm{H}$ to the triple bond results in the formation of two

\begin{tabular}{|c|c|c|c|c|}
\hline Entry & $\mathrm{R}^{1}$ & $x$ & $\mathrm{R}^{2}$ & Yield of $106 \mathrm{~b}(\%)$ \\
\hline 1 & $2-\mathrm{MeO}$ & I & $\mathrm{Ph}$ & 91 \\
\hline 2 & $2-\mathrm{NH}_{2}$ & 1 & $\mathrm{Ph}$ & 86 \\
\hline 3 & $4-\mathrm{CO}_{2} \mathrm{Me}$ & $\mathrm{Br}$ & $\mathrm{Ph}$ & 70 \\
\hline 4 & 2-Ph & I & tol & 79 \\
\hline 5 & $4-\mathrm{NH}_{2}$ & 1 & Cy & 72 \\
\hline 6 & $4-\mathrm{CO}_{2} \mathrm{Et}$ & I & Cy & 85 \\
\hline 7 & 4-CN & I & $\mathrm{iBu}$ & 65 \\
\hline
\end{tabular}
regioisomers (Scheme 36). The product that results from the Markovnikov addition of $\mathrm{P}-\mathrm{H}$ corresponds to the $\alpha$-adduct 126

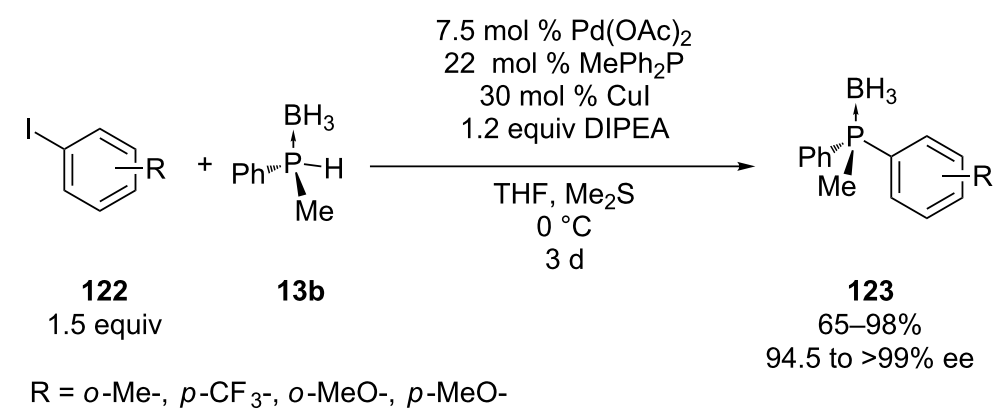

Scheme 35: Stereocontrolled $\mathrm{Pd}(0)-\mathrm{Cu}(\mathrm{I})$ cocatalyzed aromatic phosphorylation.

Table 13: Copper-catalyzed synthesis of triarylphosphines 106b

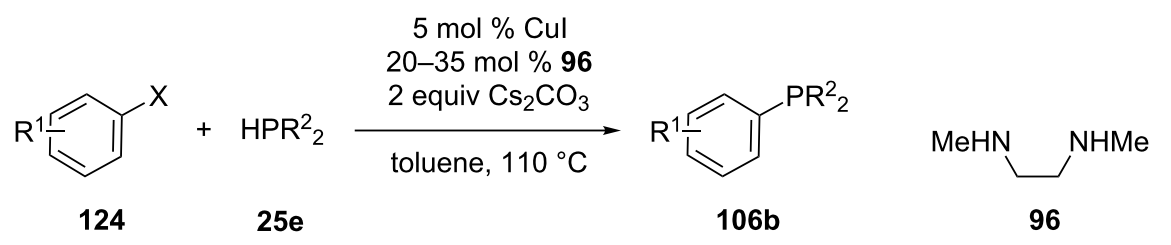




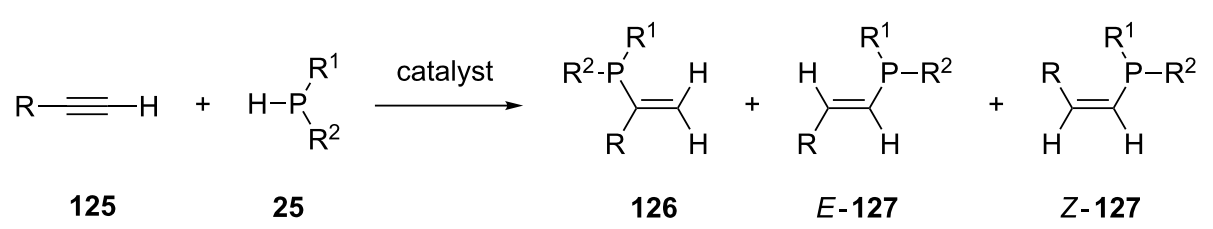

Scheme 36: Preparation of alkenylphosphines by hydrophosphination of alkynes.

and the anti-Markovnikov addition results in the $\beta$-adduct $\mathbf{1 2 7}$. The stereoselectivity of the reaction determines the formation of E- or Z-127.

Despite the great appeal of this method for the preparation of vinylphosphines it does not allow the syntheses of the widely used arylphosphines or alkenes bearing no hydrogen on the double bond. Additionally, due to the absence of small rings containing a triple bond, no cyclic alkenylphosphines are accessible. Until now, the protocols lack sufficient control over selectivity and mostly give mixtures. Most addition products (radical, base, metal) are anti-Markovnikov 127, only a few palladium catalyzed reactions give the Markovnikov products 126.

Several reviews on hydrophosphination of alkynes have been published $[90,91,237]$. Some recent developments will be discussed. In recent years research has mainly focused on metal-catalyzed hydrophosphinations.

\section{Metal complex-catalyzed hydrophosphinations}

Hydrophosphination catalysts are mainly based on transition metals. However, it has been shown that lanthanides and alkaline earth metals can offer a valid alternative.

Palladium and nickel complexes were used to catalyze the addition of the $\mathrm{P}-\mathrm{H}$ bond to alkynes 125a (Scheme 37). The regioselectivity was strongly dependent on the catalytic precursor. In the presence of palladium $(0)$ and nickel $(0)$ complexes the $\beta$-adduct 127a was formed as the major product. By contrast palladium(II) and nickel(II) complexes mainly gave rise to the $\alpha$-adduct 126a $[98,238]$. The nickel based catalyst was more effective than the palladium so the reaction proceeded at lower temperature.

Join et al. had the objective to enantioselectively create $P$-stereogenic vinylphosphine boranes [239]. To achieve this goal some asymmetric hydrophosphination reactions were performed using a palladium catalyst in combination with a chiral ligand. After optimizing the conditions, the addition of methylphenylphosphine borane (13b) to 1-ethynylcyclohexene (128) with the Pd-catalyst afforded tertiary phosphine borane 129 with a conversion of $70 \%$ and only $42 \%$ ee (Scheme 38 ).

Nagata et al. performed the palladium-catalyzed hydrophosphination of alkynes by using tetraphenyldiphospine (130) (Table 14) [240]. Since there is no P-H bond in this phosphinating agent, a bisphosphination was expected but a hydrophosphination took place. However, an excess (3-5 equiv) of alkyne was used. The reaction proceeded regioselectively and the $\alpha$-adducts $\mathbf{1 2 6} \mathrm{b}$ of several terminal alkynes $\mathbf{1 2 5 b}$ were formed. Air-oxidation during work-up resulted in the formation of the corresponding phosphine oxides 131. The products 131 were isolated in moderate yields with respect to the diphosphine $\mathbf{1 3 0}$ as limiting reagent. It was suggested that the alkynyl hydrogen acts as the hydrogen source for the hydrophosphination. This can also explain why the method was not applicable to internal alkynes. Silanes have also been added as the source for hydrogen [241].

Ruthenium complexes are the first catalysts reported for the direct hydrophosphination of propargyl alcohols [242]. Several catalytic systems were tested and the reaction with $5 \mathrm{~mol} \%$ $\mathrm{RuCl}(\operatorname{cod})\left(\mathrm{C}_{5} \mathrm{Me}_{5}\right)$ in the presence of $\mathrm{Na}_{2} \mathrm{CO}_{3}$ provided the best

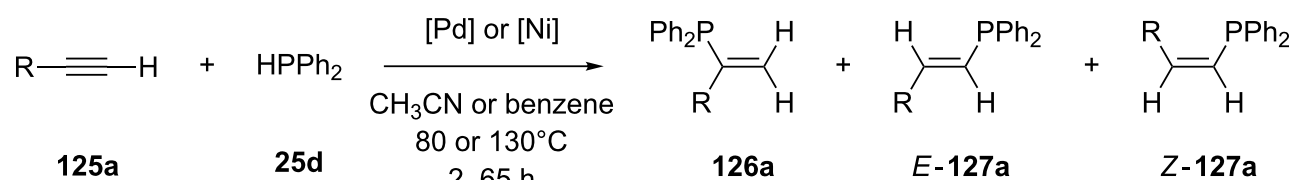

$$
\begin{aligned}
& \mathrm{R}=\mathrm{Ph}, n-\mathrm{Pr}, n \text {-Pent, } t-\mathrm{Bu}, \mathrm{MeOCH}{ }_{2}, \mathrm{Me}_{2} \mathrm{NCH}_{2}
\end{aligned}
$$




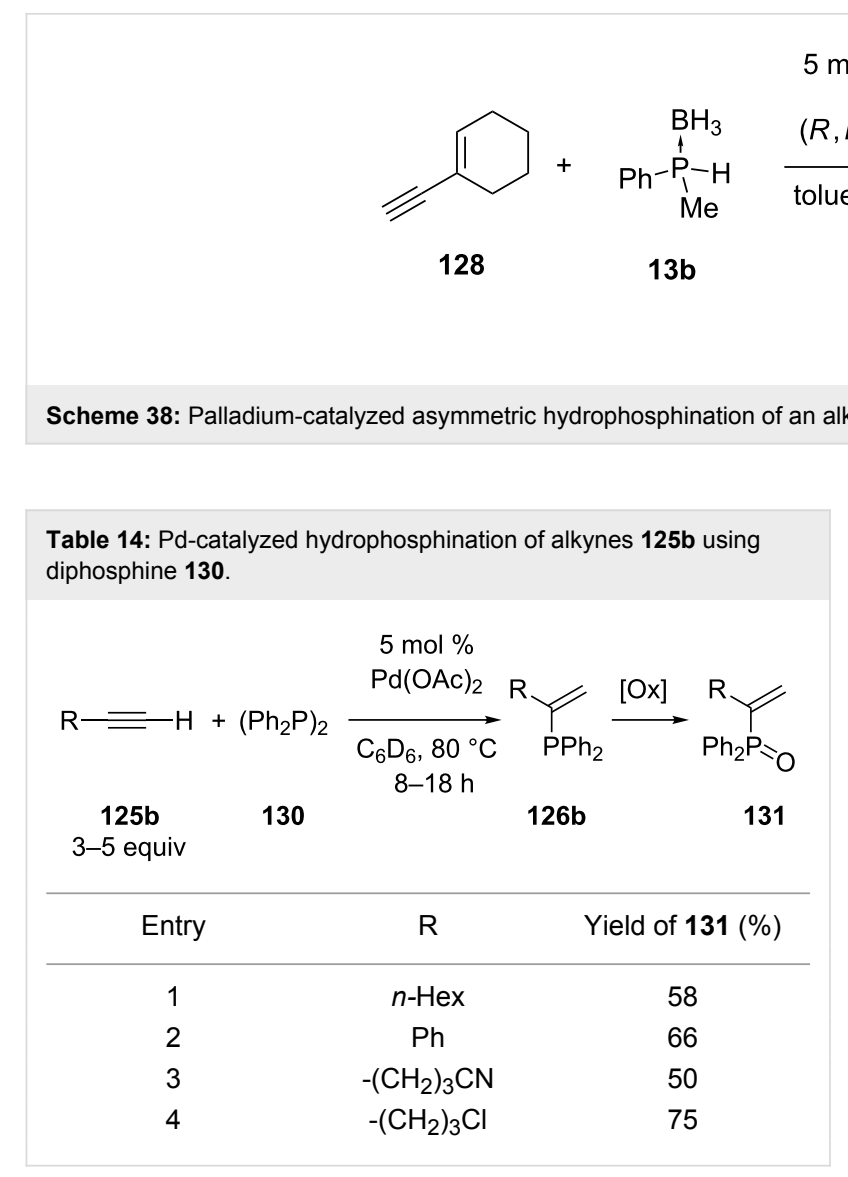

$\mathrm{mol} \% \mathrm{Pd}(\mathrm{OAc})_{2}$

$7.5 \mathrm{~mol} \%$

$(R, R)$-Me-DuPhos

toluene, $50^{\circ} \mathrm{C}, 17 \mathrm{~h}$<smiles>C=C(C1=CCCCC1)[P+](C)(P)P</smiles>

129

conversion $70 \%$

$42 \%$ ee

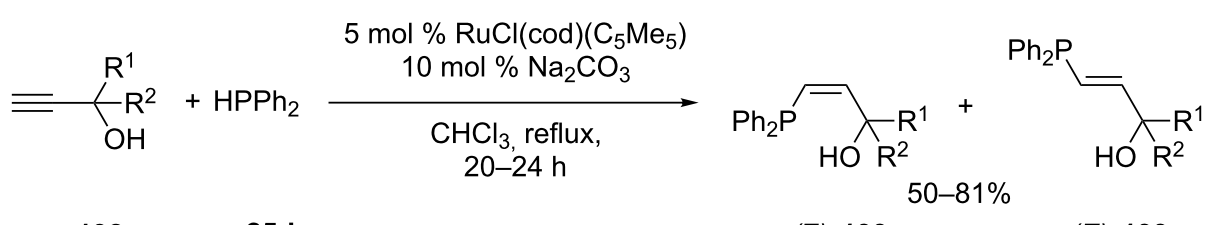

132

25d

(Z)-133

(E)-133

ZIE ratio $75 / 25-95 / 5$

Scheme 39: Ruthenium catalyzed hydrophosphination of propargyl alcohols 132 (cod = 1,5-cyclooctadiene).

$$
\begin{aligned}
& \text { 1) } 20 \mathrm{~mol} \% n \text {-BuLi }
\end{aligned}
$$

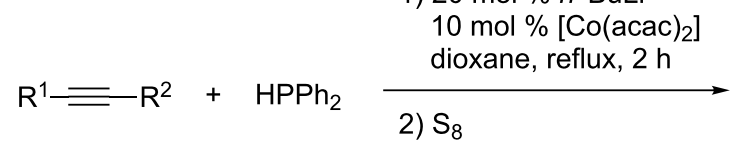

$$
\begin{aligned}
& >_{\mathrm{H}}^{\mathrm{R}_{\mathrm{S}^{\prime}} \mathrm{PPh}_{2}} \mathrm{R}_{\mathrm{Ph}_{2} \mathrm{P}_{\mathrm{S}}}^{\mathrm{R}_{\mathrm{S}}^{1}}+\mathrm{H}_{\mathrm{H}}^{\mathrm{R}^{2}} \\
& 42-89 \%
\end{aligned}
$$


Hayashi and co-workers have reported a rhodium-catalyzed phosphination of alkynes 134b using silylphosphines 137 as phosphinating agents (Table 15) [108]. The cationic rhodium catalyst was generated in situ by adding silver triflate to a chlororhodium complex. The silylgroup was not incorporated in the vinylphosphine product 138a and methanol was added as a proton source for completing the reaction. The adducts 138a were formed with good to high $s y n$-selectivity.

Kondoh et al. demonstrated the $\mathrm{P}-\mathrm{H}$ addition to 1-alkynylphosphines under copper catalysis (Table 16) [244]. Besides
copper(I) iodide several other copper salts effectuated the reaction albeit in lower yields as did silver(I) iodide, palladium(II) chloride and platinum(II) chloride. Other transition metal catalysts such as gold(I) chloride, nickel(II) chloride and cobalt(II) chloride gave no reaction. In the presence of copper(I) iodide and cesium carbonate diphenylphospine (25d) added to the triple bond in an anti-fashion. A diverse set of alkynylphosphines 139 was subjected to the protocol proving the compatibility of the method with certain functional groups. The $Z$-adducts were formed exclusively and isolated as the phosphine sulfides $\mathbf{1 4 0}$ to prevent lower yields by oxidation to the

Table 15: Rhodium-catalyzed hydrophosphination of alkynes $134 \mathrm{~b}$ with a silylphosphine 137 (cod = 1,5-cyclooctadiene).

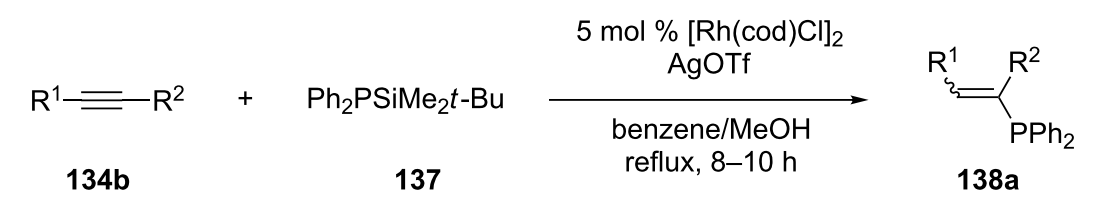

\begin{tabular}{|c|c|c|c|c|}
\hline Entry & $\mathrm{R}^{1}$ & $\mathrm{R}^{2}$ & Yield of 138a (\%) & $E / Z$ \\
\hline 1 & $\mathrm{Ph}$ & $\mathrm{H}$ & 89 & $96 / 4$ \\
\hline 2 & $\mathrm{MeO}-\mathrm{C}_{6} \mathrm{H}_{4}$ & $\mathrm{H}$ & 53 & $92 / 8$ \\
\hline 3 & $n-\mathrm{C}_{5} \mathrm{H}_{11}$ & $\mathrm{H}$ & 78 & $95 / 5$ \\
\hline 4 & $\mathrm{HOCH}_{2}$ & $\mathrm{H}$ & 66 & $80 / 20$ \\
\hline 5 & $\mathrm{Ph}$ & $\mathrm{Me}$ & 68 & $92 / 8$ \\
\hline 6 & $\mathrm{Ph}$ & $n-\mathrm{Bu}$ & 72 & $95 / 5$ \\
\hline 7 & $n-\mathrm{C}_{5} \mathrm{H}_{11}$ & $n-\mathrm{C}_{5} \mathrm{H}_{11}$ & 67 & $>99 / 1$ \\
\hline 8 & $\mathrm{EtO}_{2} \mathrm{C}$ & $n-\mathrm{Bu}$ & 81 & $>99 / 1$ \\
\hline 9 & $\mathrm{EtO}_{2} \mathrm{C}$ & $\mathrm{Ph}$ & 76 & $80 / 20$ \\
\hline
\end{tabular}

Table 16: Copper-catalyzed hydrophosphination of 1-alkynylphosphines 139.

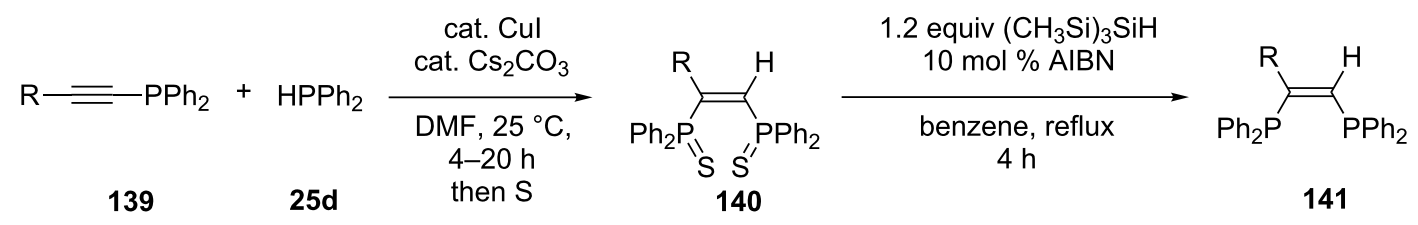

\begin{tabular}{|c|c|c|c|}
\hline Entry & $\mathrm{R}$ & Yield of $140(\%)$ & Yield of $141(\%)$ \\
\hline 1 & $n$-Hex & 88 & 87 \\
\hline 2 & $\mathrm{iPr}$ & 84 & \\
\hline 3 & $t-\mathrm{Bu}$ & 84 & 89 \\
\hline 4 & $\mathrm{Ph}$ & 72 & 78 \\
\hline 5 & $4-\mathrm{Ac}^{-} \mathrm{C}_{6} \mathrm{H}_{4}$ & 87 & 63 \\
\hline 6 & 3-pyridyl & 62 & 44 \\
\hline 7 & $\mathrm{EtOC}(\mathrm{O})\left(\mathrm{CH}_{2}\right)_{3}$ & 79 & \\
\hline 8 & $\operatorname{AcS}\left(\mathrm{CH}_{2}\right)_{9}$ & 75 & \\
\hline 9 & $\mathrm{PhCH}(\mathrm{OH})$ & 84 & \\
\hline
\end{tabular}


corresponding oxides. The phosphines 141 were obtained by radical reduction of $\mathbf{1 4 0}$ with tris(trimethylsilyl)silane (TTMSS).

However, when Kumaraswamy et al. explored the coppercatalyzed hydrophosphination on substituted phenylacetylenes $125 \mathrm{c}$ further oxidation of the double bond led to the corresponding phenacyl tertiary phosphine boranes $\mathbf{1 4 2}$ in moderate to good yields (Scheme 41). The products $\mathbf{1 4 2}$ were obtained when the reactions were performed under inert atmosphere and in open air. Since the latter gave slightly better yields, it was argued that the dissolved air contributed to the product formation. A Cu(II)-TMEDA catalyzed tandem phosphorus-carbon bond formation-oxyfunctionalization was developed [245] When methyl propiolate was subjected to the same reaction conditions only the $\beta$-adducts were isolated.

The intramolecular hydrophosphination and cyclization of primary alkynyl phosphines $\mathbf{1 4 3}$ has been accomplished using organolanthanide precatalysts of the type $\mathrm{Cp}_{2}{ }_{2} \mathrm{LnCH}\left(\mathrm{SiMe}_{3}\right)_{2}$ $\left(\mathrm{Cp}^{\prime}=\eta^{5}-\mathrm{C}_{5} \mathrm{Me}_{5}\right)$ and $\mathrm{Me}_{2} \mathrm{Si}\left(\mathrm{Me}_{4} \mathrm{C}_{5}\right)(t-\mathrm{BuN}) \mathrm{SmN}\left(\mathrm{SiMe}_{3}\right)_{2}$ $[111,112]$. The reaction succeeded also using homoleptic lanthanocenes of the form $\mathrm{Ln}\left[\mathrm{CH}\left(\mathrm{SiMe}_{3}\right)_{2}\right]_{3}(\mathrm{Ln}=\mathrm{La}, \mathrm{Nd}, \mathrm{Sm}$, $\mathrm{Y}, \mathrm{Lu})$ or $\mathrm{Ln}\left[\mathrm{N}\left(\mathrm{SiMe}_{3}\right)_{2}\right]_{3}(\mathrm{Ln}=\mathrm{La}, \mathrm{Nd}, \mathrm{Sm}, \mathrm{Y})$ [246]. The reaction was performed in NMR tubes until full conversion to the phospholane $144(n=1)$ or phosphorinane $144(n=2)$ was obtained (Scheme 42). The reaction is regioselective as only one adduct was obtained. Several butadiene derivatives were synthesized by hydrophosphination of the triple bond in enynes in the presence of yttriumcomplexes [247].
An ytterbium-imine complex $145\left[\mathrm{Yb}\left(\eta^{2}-\mathrm{Ph}_{2} \mathrm{CNPh}\right)(\mathrm{hmpa})_{3}\right]$ has also been applied for the synthesis of alkenylphosphines [245,248-251]. The products were isolated as their corresponding phosphine oxides (146 and 147) after oxidative workup (Scheme 43). The reaction proceeded under mild conditions (rt, $5 \mathrm{~min}$ to $4 \mathrm{~h}$ ), except for the less reactive aliphatic internal alkynes $\left(80^{\circ} \mathrm{C}, 6 \mathrm{~h}\right)$. The regio- and stereoselectivity was mainly affected by the nature of the substrate and not so much by the reaction conditions. An active ytterbium phosphide species is generated in situ and therefore the imine complex could be categorized as a basic catalyst.

The only catalysts based on heavy alkaline earth metals for the hydrophosphination of alkynes are derived from calcium $[123,252,253]$. A similar behavior of calcium(II) and ytterbium(II) compounds seems possible as the oxidation state of $\mathrm{Yb}(\mathrm{II})$ does not change during the ytterbium(II)-catalyzed hydrophosphination of alkynes. The reaction of alkyne 134d in the presence of the calcium catalyst resulted in diphenylvinylphosphine $\mathbf{1 3 8 b}$ in good yield (Scheme 44). A set of butadiynes was reacted in a similar way [254]. Mixtures of butadienyldiphosphine isomers were obtained depending on the bulkiness of the end groups at the butadiyne moieties.

\section{Other hydrophosphinations}

A relatively recent example for the thermal activated hydrophosphination was from Mimeau and Gaumont and described the use of a microwave reactor [254]. This reaction is performed with secondary phosphine-borane complexes $\mathbf{1 3} \mathbf{j}$ and terminal alkynes $\mathbf{1 2 5 d}$. Mimeau and Gaumont demon-

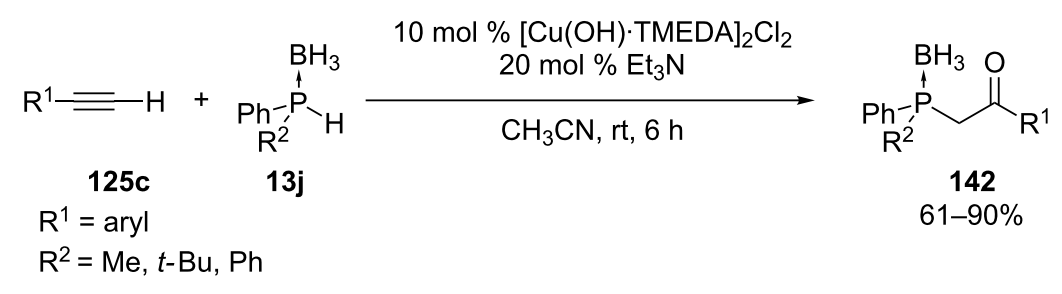

Scheme 41: Tandem phosphorus-carbon bond formation-oxyfunctionalization of substituted phenylacetylenes 125c (TMEDA = tetramethylethylenediamine)

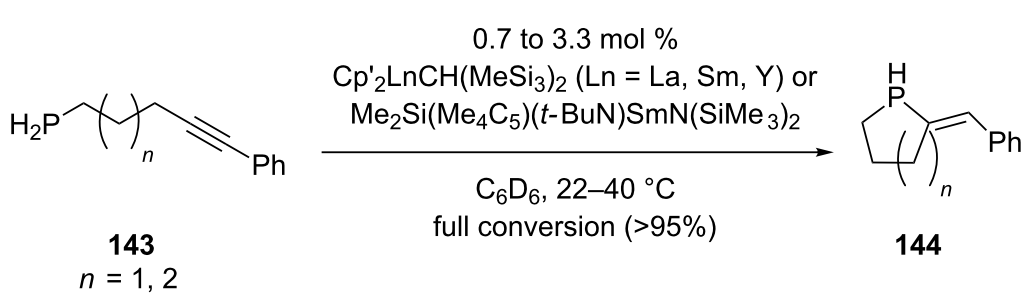

Scheme 42: Organolanthanide-catalyzed intramolecular hydrophosphination/cyclization of phosphinoalkynes 143. 


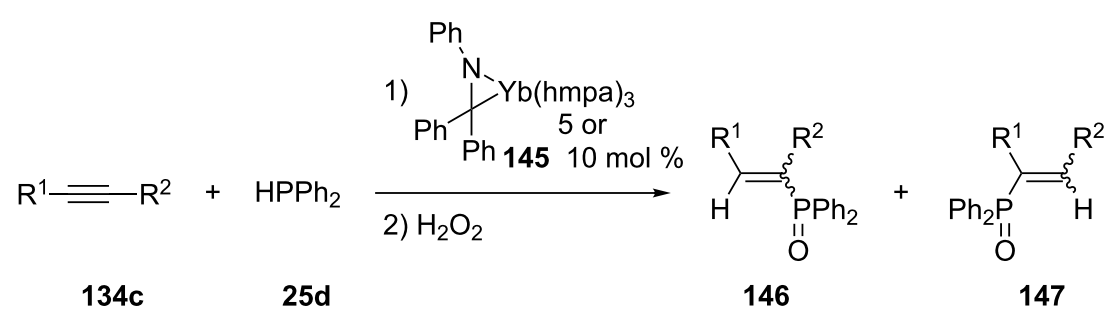

$\mathrm{R}^{1}=\mathrm{Ph}, n-\mathrm{Pr}, n$-Pent, $t$-Bu, $n$-Hex

$\mathrm{R}^{2}=\mathrm{Ph}, \mathrm{H}, \mathrm{Me}, \mathrm{SiMe}_{3}, n-\mathrm{Pr}$

Scheme 43: Hydrophosphination of alkynes 134c catalyzed by ytterbium-imine complexes 145 ( $h m p a=$ hexamethylphosphoramide).

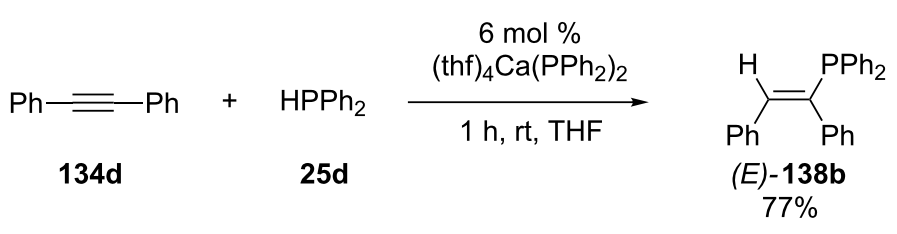

Scheme 44: Calcium-mediated hydrophosphanylation of alkyne 134d.

strated that the regioselectivity of the hydrophosphination reaction can be controlled by adjusting the activation method. Thermal activation with the microwave reactor gave the $\beta$-adducts 148 (anti-Markovnikov addition) (Table 17). In the same article the $\alpha$-adducts 149 (Markovnikov addition) were formed by using a palladium catalyst (Table 18). In both cases the regioselectivity was excellent, the stereochemistry in the case of the $\beta$-adduct 148 favoured the $Z$-product. The conditions are compatible with aliphatic and oxygen-functionalized alkynes.

Busacca et al. have described the hydrophosphination of internal alkynes with phosphine-borane complexes under basic conditions $[255,256]$. Several diaryl- and alkylarylalkynes $\mathbf{1 3 4 e}$ were reacted with a variety of phosphine boranes $\mathbf{2 5 f}$, some examples are shown in Table 19. Mixtures of $E$ and $Z$-isomers of $\mathbf{1 5 0}$ were formed, with the $E$-isomer as the major product.

\section{Preparation of alkynylphosphines via forma- tion of a $\mathrm{C}(\mathrm{sp})-\mathrm{P}$ bond}

An extensive review concerning the stoichiometric and catalytic synthesis of alkynylphosphines and their borane complexes has been published in 2012 by Gaumont et al. [257].

\section{Reaction of organometallic reagents with halophos-} phines

Alkynylphosphines are commonly synthesized by the nucleophilic displacement of the halogen at the phosphorus atom of a

Table 17: Hydrophosphination reactions of terminal alkynes $125 \mathrm{~d}$ with phosphine boranes $13 \mathrm{j}$ under microwave conditions.

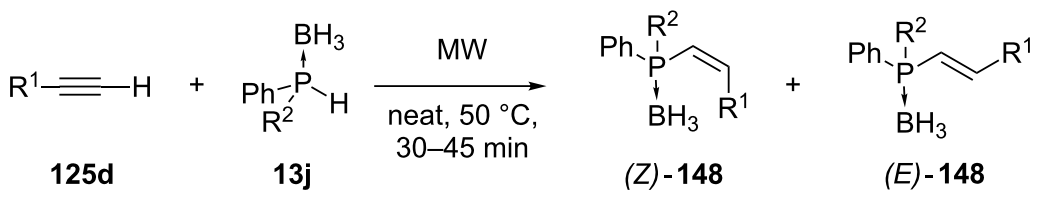

\begin{tabular}{ccccc}
\hline Entry & $\mathrm{R}^{1}$ & $\mathrm{R}^{2}$ & Yield of $\mathbf{1 4 8}(\%)$ & Z/E ratio \\
\hline 1 & $n-\mathrm{Hex}$ & $\mathrm{Ph}$ & 76 & $>95 / 5$ \\
2 & $\mathrm{Ph}$ & $\mathrm{Ph}$ & 0 & $>95 / 5$ \\
3 & $\left(\mathrm{CH}_{2}\right)_{2} \mathrm{OH}$ & $\mathrm{Ph}$ & 49 & $>95 / 5$ \\
4 & $\mathrm{CH}_{2} \mathrm{OCH}$ & $\mathrm{Ph}$ & 33 & $80 / 20$ \\
5 & $n-\mathrm{Hex}$ & $\mathrm{Me}$ & 82 & $70 / 30$ \\
6 & $n-\mathrm{Hex}$ & $t-\mathrm{Bu}$ & 49 &
\end{tabular}


Table 18: Hydrophosphination reactions of terminal alkynes 125e with phosphine boranes $13 f$ using a Pd catalyst (dba = dibenzylideneacetone, dppp = 1,3-bis(diphenylphosphino)propane).

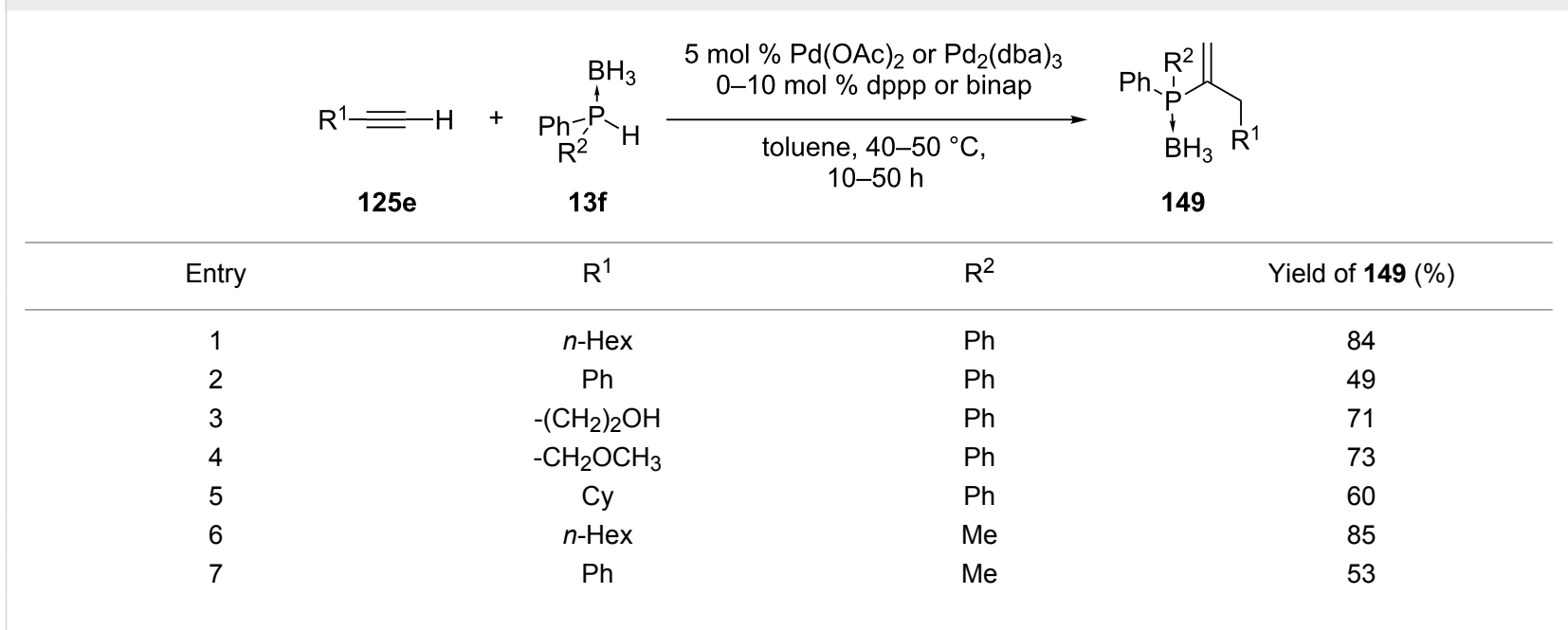

Table 19: Hydrophosphination of alkynes $134 \mathrm{e}$ with phosphine-borane complexes $25 \mathrm{f}$ (DMAc = dimethylacetamide).

\begin{tabular}{|c|c|c|c|c|c|}
\hline \multirow[b]{2}{*}{ Entry } & $\begin{array}{r}\mathrm{R}^{1}= \\
134 \mathrm{e}\end{array}$ & $\begin{array}{c}+\mathrm{HPR}_{2}^{3} \\
\mathbf{2 5 f}\end{array}$ & \multicolumn{2}{|c|}{$\underbrace{\mathrm{BH}_{3}^{2}}_{150}$} & \multirow[b]{2}{*}{$E / Z$ ratio } \\
\hline & $\mathrm{R}^{1}$ & $\mathrm{R}^{2}$ & $\mathrm{R}^{3}$ & Yield of $150(\%)$ & \\
\hline 1 & $\mathrm{Ph}$ & $\mathrm{Me}$ & Cy & 85 & $>20 / 1$ \\
\hline 2 & $\mathrm{Ph}$ & $\mathrm{Ph}$ & $t-\mathrm{Bu}$ & 88 & $>20 / 1$ \\
\hline 3 & $\mathrm{Ph}$ & $\mathrm{Me}$ & $p-(\mathrm{iPrO})-\mathrm{C}_{6} \mathrm{H}_{4}$ & 78 & $>20 / 1$ \\
\hline 4 & $\mathrm{Ph}$ & $\mathrm{Ph}$ & $\mathrm{iBu}$ & 79 & $4 / 1$ \\
\hline 5 & $p-\mathrm{CF}_{3}-\mathrm{C}_{6} \mathrm{H}_{4}$ & $p-\mathrm{CF}_{3}-\mathrm{C}_{6} \mathrm{H}_{4}$ & $\mathrm{Ph}$ & 98 & $>20 / 1$ \\
\hline 6 & o-Tol & o-Tol & Cy & 99 & $>20 / 1$ \\
\hline
\end{tabular}

halophosphine with a metal acetylide. Grignard [258,259] and organolithium [244,260-262] reagents have frequently been used since many years. The main disadvantage is the incompatability of lithium and magnesium reagents with alkynylphosphines having labile functional groups susceptible to nucleophilic attack.

This approach is mainly used for the synthesis of tertiary phosphines. It is difficult to synthesize secondary alkynylphosphines since they easily convert into their phosphaallene tautomer. They can only be obtained when they have sterically hindering substituents [263,264].

The asymmetric synthesis of alkynylphosphines also suffers from limited availability of unsymmetrical halophosphines and their weak configurational stability. Stereospecific substitution at chiral phosphorus atoms by alkynyl nucleophiles has been reported by Imamoto et al. (Scheme 45) [265]. Firstly, a bromo(tert-butyl)methylphosphanyl borane $\mathbf{1 5 1}$ was formed in situ by treating the enantiomerically pure $(S)$-(tertbutyl)methylphosphine borane 13d with $n$-BuLi and 1,2-dibromoethane. An alkynyl lithium reagent was directly added to intermediate 151. The expected substitution products 152 were obtained in high yield and almost exclusively with inversion of configuration, resulting in excellent stereospecificities.

\section{Catalytic C(sp)-P bond formation}

This type of carbon-phosphorus bond formation relies on the cross-coupling reaction in the presence of a catalyst. The crosscoupling reaction is in general performed between a terminal alkyne 125 and an electrophilic phosphorus reagent in the form of a halophoshine 153, mostly chlorophosphine, in the presence of a catalyst such as nickel $\left(\mathrm{Ni}(\mathrm{acac})_{2}\right)[244,266,267]$ or copper (CuI) [268-270] (Scheme 46). The nickel based catalyst was not 


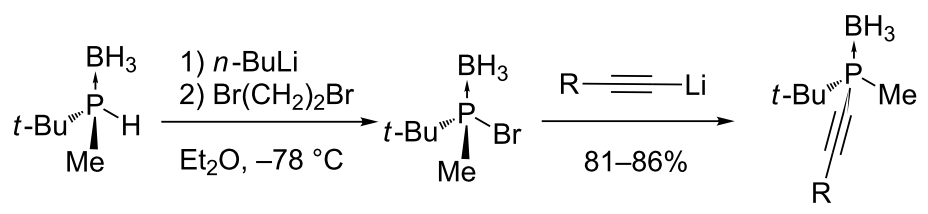

$$
\begin{aligned}
& \text { 13d } 151 \\
& >99 \% \text { ee } \\
& 152 \\
& 97-99 \% \text { ee }
\end{aligned}
$$

Scheme 45: Formation and substitution of bromophosphine borane 151.

suitable for the cross-coupling of alkynes containing a sensitive alkoxy or amino functional group. Therefore, another catalytic method was developed using copper(I) salts.

$$
3-n \mathrm{R}^{\prime} \underset{125}{=} \mathrm{H}+\mathrm{R}_{n} \mathrm{PCl}_{3-n} \stackrel{[\mathrm{Ni}] \text { or }[\mathrm{Cu}]}{\longrightarrow} \mathrm{R}_{n} \mathrm{P}\left(\stackrel{-}{=} \mathrm{R}^{\prime}\right)_{3-n}
$$

Scheme 46: General scheme for a nickel or copper catalyzed crosscoupling reaction.

Alkynylphosphines were synthesized through the use of a copper-catalyzed reaction between a secondary phosphine borane 13k and various 1-bromoalkynes 155 in the presence of 1,10-phenanthroline as a ligand and $\mathrm{K}_{2} \mathrm{CO}_{3}$ or $\mathrm{K}_{3} \mathrm{PO}_{4}$ as a base (Scheme 47). This was the first method involving a nucleophilic phosphorus reagent in the synthesis of alkynylphosphines and was presented by the group of Gaumont [271,272]. The method was applicable for dialkyl, diaryl or alkylaryl phosphine boranes $13 \mathbf{k}$ and required only mild conditions.

\section{Conclusion}

The developments over the past years in the field were reviewed. The use of phosphines as ligands in metal complex catalysis has been a major driving force for the synthesis of functionalized phosphines. In recent years many catalytic procedures have emerged. In general these catalytic protocols proceed under milder conditions that tolerate the presence of functional groups. Gradually a broader variety of phosphines is accessible. Due to the growing importance of asymmetric catalysis, a lot of attention has been paid to the asymmetric synthesis of chiral phosphines. The challenge to find a general protocol that permits simple access to chiral phosphines, is still ongoing and further developments are required.

\section{Acknowledgements}

Financial support from the Research Foundation Flanders (FWO Vlaanderen; I.W. and W.D.) is gratefully acknowledged.

\section{References}

1. Methot, J. L.; Roush, W. R. Adv. Synth. Catal. 2004, 346, 1035-1050. doi:10.1002/adsc.200404087

2. Gilheany, D. G.; Mitchell, C. M. Preparation of Phosphines. In Organophosphorus Compounds; Hartley, F. R., Ed.; John Wiley and Sons: Chichester, U.K., 1990; Vol. 1, pp 151-190. doi:10.1002/9780470034439.ch7

3. Beletskaya, I. P.; Kazankova, M. A. Russ. J. Org. Chem. 2002, 38, 1391-1430. doi:10.1023/A:1022685801622

4. Tappe, F. M. J.; Trepohl, V. T.; Oestreich, M. Synthesis 2010, 3037-3062. doi:10.1055/s-0030-1257960

5. Zhou, Q.-L. Privileged Chiral Ligands and Catalysts; Wiley-VCH: Weinheim, Germany, 2011.

6. Busacca, C. A.; Senanayake, C. H. The use of New Phosphines as Powerful Tools in Asymmetric Synthesis of Biologically Active Compounds. In Comprehensive Chirality; Carreira, E. M.; Yamamoto, H., Eds.; Elsevier: Amsterdam, 2012; pp 167-216. doi:10.1016/B978-0-08-095167-6.00110-5

$$
\begin{aligned}
& \mathrm{R}^{1}=-\mathrm{Br}+\left.\mathrm{R}^{2}\right|_{\mathrm{R}^{3}} \begin{array}{c}
10 \mathrm{~mol} \% \text { Cul } \\
155
\end{array} \\
& \mathrm{R}^{1}=n-\mathrm{Bu}, \mathrm{C}_{10} \mathrm{H}_{21}, \mathrm{Si}(\mathrm{iPr})_{3}, \mathrm{Ph}, \mathrm{O}-\mathrm{MeO}-\mathrm{C}_{6} \mathrm{H}_{4} \\
& \mathrm{R}^{2}=\mathrm{R}^{3}=\mathrm{Ph}, \mathrm{Et} \text { or } \mathrm{R}^{2}=\mathrm{Ph}, \mathrm{R}^{3}=\mathrm{Me}
\end{aligned}
$$


7. Grabulosa, A.; Granell, J.; Muller, G. Coord. Chem. Rev. 2007, 251, 25-90. doi:10.1016/j.ccr.2006.05.009

8. Harvey, J. S.; Gouverneur, V. Chem. Commun. 2010, 46, 7477-7485. doi:10.1039/c0cc01939a

9. Kolodiazhnyi, O. Tetrahedron: Asymmetry 2012, 23, 1-46. doi:10.1016/j.tetasy.2012.01.007

10. Horner, L.; Balzer, W. D. Tetrahedron Lett. 1965, 6, 1157-1162. doi:10.1016/S0040-4039(01)83990-3

11. Naumann, K.; Zon, G.; Mislow, K. J. Am. Chem. Soc. 1969, 91, 7012-7023. doi:10.1021/ja01053a021

12. Imamoto, T.; Kikuchi, S.-i.; Miura, T.; Wada, Y. Org. Lett. 2001, 3, 87-90. doi:10.1021/ol0068041

13. Kondoh, A.; Yorimitsu, H.; Oshima, K. J. Am. Chem. Soc. 2007, 129, 6996-6997. doi:10.1021/ja071622o

14. Petit, C.; Favre-Réguillon, A.; Albela, B.; Bonneviot, L.; Mignani, G.; Lemaire, M. Organometallics 2009, 28, 6379-6382. doi:10.1021/om900747b

15. Li, Y.; Das, S.; Zhou, S.; Junge, K.; Beller, M. J. Am. Chem. Soc. 2012, 134, 9727-9732. doi:10.1021/ja301764m

16. Carboni, B.; Monnier, L. Tetrahedron 1999, 55, 1197-1248. doi:10.1016/S0040-4020(98)01103-X

17. Staubitz, A.; Robertson, A. P. M.; Sloan, M. E.; Manners, I. Chem. Rev. 2010, 110, 4023-4078. doi:10.1021/cr100105a

18. Brunel, J. M.; Faure, B.; Maffei, M. Coord. Chem. Rev. 1998, 178-180, 665-698. doi:10.1016/S0010-8545(98)00072-1

19. Hiney, R. M.; Ficks, A.; Müller-Bunz, H.; Gilheany, D. G.; Higham, L. J. Air-stable chiral primary phosphines part (i) synthesis, stability and applications. Organometallic Chemistry; The Royal Society of Chemistry, 2011; Vol. 37, pp 27-45. doi:10.1039/9781849732802-00027

20. Kanbara, T.; Takase, S.; Hayashi, R.; Kagaya, S.; Hasegawa, K.; Yamamoto, T. J. Polym. Sci., Part A: Polym. Chem. 2002, 40, 2637-2647. doi:10.1002/pola.10343

21. Casey, C. P.; Paulsen, E. L.; Beuttenmueller, E. W.; Proft, B. R.; Petrovich, L. M.; Matter, B. A.; Powell, D. R. J. Am. Chem. Soc. 1997, 119, 11817-11825. doi:10.1021/ja9719440

22. Jiménez, M. V.; Pérez-Torrente, J. J.; Bartolomé, M. I.; Oro, L. A. Synthesis 2009, 1916-1922. doi:10.1055/s-0028-1088060

23. Langer, F.; Knochel, P. Tetrahedron Lett. 1995, 36, 4591-4594. doi:10.1016/0040-4039(95)00813-R

24. Langer, F.; Püntener, K.; Stürmer, R.; Knochel, P. Tetrahedron: Asymmetry 1997, 8, 715-738. doi:10.1016/S0957-4166(97)00027-X

25. Kharasch, M. S.; Jensen, E. V.; Weinhouse, S. J. Org. Chem. 1949, 14, 429-432. doi:10.1021/jo01155a014

26. Larock, R. C. Tetrahedron 1982, 38, 1713-1754. doi:10.1016/0040-4020(82)80245-7

27. Soroka, M. Synthesis 1977, 450. doi:10.1055/s-1977-24435

28. Dopp, E.; Hartmann, L. M.; Florea, A.-M.; Rettenmeier, A. W.; Hirner, A. V. Crit. Rev. Toxicol. 2004, 34, 301-333. doi:10.1080/10408440490270160

29. Gerber, G. B.; Léonard, A.; Jacquet, P. Mutat. Res., Rev. Genet. Toxicol. 1980, 76, 115-141. doi:10.1016/0165-1110(80)90006-8

30. Humbel, S.; Bertrand, C.; Darcel, C.; Bauduin, C.; Jugé, S. Inorg. Chem. 2003, 42, 420-427. doi:10.1021/ic026128u

31. Miura, T.; Yamada, H.; Kikuchi, S.-i.; Imamoto, T. J. Org. Chem. 2000, 65, 1877-1880. doi:10.1021/jo991460h
32. Watanabe, T.; Gridnev, I. D.; Imamoto, T. Chirality 2000, 12, 346-351. doi:10.1002/(SICI)1520-636X(2000)12:5/6<346::AID-CHIR8>3.0.CO;2 $-\mathrm{R}$

33. Hoge, G. J. Am. Chem. Soc. 2003, 125, 10219-10227. doi:10.1021/ja034715o

34. Takahashi, Y.; Yamamoto, Y.; Katagiri, K.; Danjo, H.; Yamaguchi, K.; Imamoto, T. J. Org. Chem. 2005, 70, 9009-9012. doi:10.1021/jo051034y

35. Tsuruta, H.; Imamoto, T. Synlett 2001, 999-1002. doi:10.1055/s-2001-14645

36. Jugé, S.; Stephan, M.; Laffitte, J. A.; Genet, J. P. Tetrahedron Lett. 1990, 31, 6357-6360. doi:10.1016/S0040-4039(00)97063-1

37. Jugé, S. Phosphorus, Sulfur Silicon Relat. Elem. 2008, 183, 233-248. doi:10.1080/10426500701734125

38. Rippert, A. J.; Linden, A.; Hansen, H.-J. Helv. Chim. Acta 2000, 83, 311-321. doi:10.1002/(SICI)1522-2675(20000216)83:2<311::AID-HLCA311>3.3 .CO;2-9

39. Bauduin, C.; Moulin, D.; Kaloun, E. B.; Darcel, C.; Jugé, S. J. Org. Chem. 2003, 68, 4293-4301. doi:10.1021/jo026355d

40. Schuman, M.; Trevitt, M.; Redd, A.; Gouverneur, V. Angew. Chem., Int. Ed. 2000, 39, 2491-2493. doi:10.1002/1521-3773(20000717)39:14<2491::AID-ANIE2491>3.3.C 0;2-8

41. Imamoto, T.; Oshiki, T.; Onozawa, T.; Kusumoto, T.; Sato, K. J. Am. Chem. Soc. 1990, 112, 5244-5252. doi:10.1021/ja00169a036

42. King, R. B. Acc. Chem. Res. 1972, 5, 177-185. doi:10.1021/ar50053a003

43. Gaumont, A. C.; Morise, X.; Denis, J. M. J. Org. Chem. 1992, 57, 4292-4295. doi:10.1021/jo00041a043

44. Ohashi, A.; Imamoto, T. Tetrahedron Lett. 2001, 42, 1099-1101. doi:10.1016/S0040-4039(00)02192-4

45. Honaker, M. T.; Salvatore, R. N. Phosphorus, Sulfur Silicon Relat. Elem. 2004, 179, 277-283. doi:10.1080/10426500490262261

46. de Quadras, L.; Stahl, J.; Zhuravlev, F.; Gladysz, J. A. J. Organomet. Chem. 2007, 692, 1859-1870. doi:10.1016/j.jorganchem.2006.12.023

47. Schrems, M. G.; Pfaltz, A. Chem. Commun. 2009, 6210-6212. doi:10.1039/b912680e

48. Nandi, P.; Dye, J. L.; Bentley, P.; Jackson, J. E. Org. Lett. 2009, 11, 1689-1692. doi:10.1021/ol900222v

49. Wolfe, B.; Livinghouse, T. J. Am. Chem. Soc. 1998, 120, 5116-5117. doi:10.1021/ja973685k

50. Lebel, H.; Morin, S.; Paquet, V. Org. Lett. 2003, 5, 2347-2349. doi:10.1021/ol0347139

51. Imamoto, T.; Yashio, K.; Crépy, K. V. L.; Katagiri, K.; Takahashi, H.; Kouchi, M.; Gridnev, I. D. Organometallics 2006, 25, 908-914. doi:10.1021/om050759p

52. Chaux, F.; Frynas, S.; Laureano, H.; Salomon, C.; Morata, G.; Auclair, M.-L.; Stephan, M.; Merdès, R.; Richard, P.; Ondel-Eymin, M.-J.; Henry, J.-C.; Bayardon, J.; Darcel, C.; Jugé, S. C. R. Chim. 2010, 13, 1213-1226. doi:10.1016/j.crci.2010.06.001

53. Ager, D. J.; Laneman, S. A. Chem. Commun. 1997, 2359-2360. doi:10.1039/a705106i

54. Butti, P.; Rochat, R.; Sadow, A.; Togni, A. Angew. Chem., Int. Ed. 2008, 47, 4878-4881. doi:10.1002/anie.200801287

55. Lanteri, M. N.; Rossi, R. A.; Martín, S. E. J. Organomet. Chem. 2009, 694, 3425-3430. doi:10.1016/j.jorganchem.2009.06.035 
56. Kumaraswamy, G.; Venkata Rao, G.; RamaKrishna, G. Synlett 2006, 1122-1124. doi:10.1055/s-2006-939696

57. Glueck, D. S. Synlett 2007, 2627-2634. doi:10.1055/s-2007-991077

58. Glueck, D. S. Coord. Chem. Rev. 2008, 252, 2171-2179. doi:10.1016/j.ccr.2007.12.023

59. Chan, V. S.; Stewart, I. C.; Bergman, R. G.; Toste, F. D. J. Am. Chem. Soc. 2006, 128, 2786-2787. doi:10.1021/ja058100y

60. Chan, V. S.; Chiu, M.; Bergman, R. G.; Toste, F. D. J. Am. Chem. Soc. 2009, 131, 6021-6032. doi:10.1021/ja9014887

61. Scriban, C.; Glueck, D. S. J. Am. Chem. Soc. 2006, 128, 2788-2789. doi:10.1021/ja058096q

62. Anderson, B. J.; Glueck, D. S.; DiPasquale, A. G.; Rheingold, A. L. Organometallics 2008, 27, 4992-5001. doi:10.1021/om800534k

63. Scriban, C.; Glueck, D. S.; Golen, J. A.; Rheingold, A. L. Organometallics 2007, 26, 1788-1800. doi:10.1021/om061116s

64. Anderson, B. J.; Guino-o, M. A.; Glueck, D. S.; Golen, J. A.; DiPasquale, A. G.; Liable-Sands, L. M.; Rheingold, A. L. Org. Lett. 2008, 10, 4425-4428. doi:10.1021/ol801616s

65. Hayashi, M.; Matsuura, Y.; Watanabe, Y. Tetrahedron Lett. 2004, 45, 9167-9169. doi:10.1016/j.tetlet.2004.10.098

66. Hayashi, M.; Matsuura, Y.; Watanabe, Y. Tetrahedron Lett. 2005, 46, 5135-5138. doi:10.1016/j.tetlet.2005.05.128

67. Yorimitsu, H. Beilstein J. Org. Chem. 2013, 9, 1269-1277. doi:10.3762/bjoc.9.143

68. Mann, F. G.; Millar, I. T. J. Chem. Soc. 1952, 4453-4457. doi:10.1039/jr9520004453

69. Hinton, R. C.; Mann, F. G.; Todd, D. J. Chem. Soc. 1961, 5454-5470. doi:10.1039/jr9610005454

70. Hoff, M. C.; Hill, P. J. Org. Chem. 1959, 24, 356-359. doi:10.1021/jo01085a019

71. Dombek, B. D. J. Org. Chem. 1978, 43, 3408-3409. doi:10.1021/jo00411a038

72. Wolfsberger, W. Chem.-Ztg. 1988, 112, 53-68.

73. Rauhut, M. M.; Hechenbleikner, I.; Currier, H. A.; Schaefer, F. C.; Wystrach, V. P. J. Am. Chem. Soc. 1959, 81, 1103-1107. doi:10.1021/ja01514a022

74. Bunlaksananusorn, T.; Knochel, P. Tetrahedron Lett. 2002, 43, 5817-5819. doi:10.1016/S0040-4039(02)01177-2

75. Mimeau, D.; Delacroix, O.; Gaumont, A.-C. Chem. Commun. 2003, 2928-2929. doi:10.1039/b311892d

76. Mimeau, D.; Delacroix, O.; Join, B.; Gaumont, A.-C. C. R. Chim. 2004, 7, 845-854. doi:10.1016/j.crci.2004.02.016

77. Rauhut, M. M.; Currier, H. A.; Semsel, A. M.; Wystrach, V. P. J. Org. Chem. 1961, 26, 5138-5145. doi:10.1021/j001070a087

78. Heesche-Wagner, K.; Mitchell, T. N. J. Organomet. Chem. 1994, 468, 99-106. doi:10.1016/0022-328X(94)80036-7

79. Robertson, A.; Bradaric, C.; Frampton, C. S.; McNulty, J.; Capretta, A. Tetrahedron Lett. 2001, 42, 2609-2612. doi:10.1016/S0040-4039(01)00264-7

80. Trofimov, B. A.; Sukhov, B. G.; Malysheva, S. F.; Belogorlova, N. A.; Tantsirev, A. P.; Parshina, L. N.; Oparina, L. A.; Tunik, S. P.; Gusarova, N. K. Tetrahedron Lett. 2004, 45, 9143-9145. doi:10.1016/j.tetlet.2004.09.172

81. Trofimov, B. A.; Malysheva, S. F.; Belogorlova, N. A.; Kuimov, V. A.; Albanov, A. I.; Gusarova, N. K. Eur. J. Org. Chem. 2009, 3427-3431. doi:10.1002/ejoc.200900382

82. Gusarova, N. K.; Malysheva, S. F.; Oparina, L. A.; Belogorlova, N. A.; Tantsyrev, A. P.; Parshina, L. N.; Sukhov, B. G.; Tlegenov, R. T.; Trofimov, B. A. ARKIVOC 2009, No. vii, 260-267. doi:10.3998/ark.5550190.0010.725
83. Guillemin, J.-C.; Breneman, C. M.; Joseph, J. C.; Ferris, J. P. Chem.-Eur. J. 1998, 4, 1074-1082. doi:10.1002/(SICI)1521-3765(19980615)4:6<1074::AID-CHEM1074>3 .0.CO;2-B

84. Trofimov, B. A.; Malysheva, S. F.; Sukhov, B. G.; Belogorlova, N. A.; Schmidt, E. Y.; Sobenina, L. N.; Kuimov, V. A.; Gusarova, N. K. Tetrahedron Lett. 2003, 44, 2629-2632. doi:10.1016/S0040-4039(03)00382-4

85. Oparina, L. A.; Malysheva, S. F.; Gusarova, N. K.; Belogorlova, N. A.; Vysotskaya, O. V.; Stepanov, A. V.; Albanov, A. I.; Trofimov, B. A. Synthesis 2009, 3427-3432. doi:10.1055/s-0029-1216964

86. Bourumeau, K.; Gaumont, A.-C.; Denis, J.-M. Tetrahedron Lett. 1997, 38, 1923-1926. doi:10.1016/S0040-4039(97)00247-5

87. Join, B.; Lohier, J.-F.; Delacroix, O.; Gaumont, A.-C. Synthesis 2008, 3121-3125. doi:10.1055/s-2008-1067275

88. Alonso, F.; Moglie, Y.; Radivoy, G.; Yus, M. Green Chem. 2012, 14, 2699-2702. doi:10.1039/c2gc35898k

89. Baillie, C.; Xiao, J. Curr. Org. Chem. 2003, 7, 477-514. doi:10.2174/1385272033372761

90. Delacroix, O.; Gaumont, A.-C. Curr. Org. Chem. 2005, 9, 1851-1882. doi:10.2174/138527205774913079

91. Arbuzova, S. N.; Gusarova, N. K.; Trofimov, B. A. ARKIVOC 2006, No. v, 12-36. doi:10.3998/ark.5550190.0007.503

92. Pringle, P. G.; Smith, M. B. J. Chem. Soc., Chem. Commun. 1990, 1701-1702. doi:10.1039/c39900001701

93. Wicht, D. K.; Kourkine, I. V.; Lew, B. M.; Nthenge, J. M.; Glueck, D. S. J. Am. Chem. Soc. 1997, 119, 5039-5040. doi:10.1021/ja970355r

94. Wicht, D. K.; Kourkine, I. V.; Kovacik, I.; Glueck, D. S.; Concolino, T. E.; Yap, G. P. A.; Incarvito, C. D.; Rheingold, A. L. Organometallics 1999, 18, 5381-5394. doi:10.1021/om990745h

95. Scriban, C.; Kovacik, I.; Glueck, D. S. Organometallics 2005, 24, 4871-4874. doi:10.1021/om050433g

96. Scriban, C.; Glueck, D. S.; Zakharov, L. N.; Kassel, W. S.; DiPasquale, A. G.; Golen, J. A.; Rheingold, A. L. Organometallics 2006, 25, 5757-5767. doi:10.1021/om060631n

97. Nagel, U.; Rieger, B.; Bublewitz, A. J. Organomet. Chem. 1989, 370, 223-239. doi:10.1016/0022-328X(89)87286-9

98. Kazankova, M. A.; Efimova, I. V.; Kochetkov, A. N.; Afanas'ev, V. V.; Beletskaya, I. P. Russ. J. Org. Chem. 2002, 38, 1465-1474. doi:10.1023/A:1022548303903

99. Trepohl, V. T.; Mori, S.; Itami, K.; Oestreich, M. Org. Lett. 2009, 11, 1091-1094. doi:10.1021/ol8028466

100.Shulyupin, M. O.; Kazankova, M. A.; Beletskaya, I. P. Org. Lett. 2002, 4, 761-763. doi:10.1021/ol017238s

101. Kazankova, M. A.; Shulyupin, M. O.; Borisenko, A. A.; Beletskaya, I. P. Russ. J. Org. Chem. 2002, 38, 1479-1484. doi:10.1023/A:1022552404812

102. Kazankova, M. A.; Shulyupin, M. O.; Beletskaya, I. P. Synlett 2003, 2155-2158. doi:10.1055/s-2003-42092

103.Shulyupin, M. O.; Trostyanskaya, I. G.; Kazankova, M. A.; Beletskaya, I. P. Russ. J. Org. Chem. 2006, 42, 17-22. doi:10.1134/S1070428006010039

104. Ganushevich, Y. S.; Miluykov, V. A.; Polyancev, F. M.; Latypov, S. K.; Lönnecke, P.; Hey-Hawkins, E.; Yakhvarov, D. G.; Sinyashin, O. G. Organometallics 2013, 32, 3914-3919. doi:10.1021/om400408e

105. Malisch, W.; Klüpfel, B.; Schumacher, D.; Nieger, M. J. Organomet. Chem. 2002, 661, 95-110. doi:10.1016/S0022-328X(02)01808-9

106. Gaumont, A.-C.; Routaboul, L.; Taillefer, M. Method for Synthesizing Phosphine. WO Patent WO2012049424, July 12, 2012. 
107.Routaboul, L.; Toulgoat, F.; Gatignol, J.; Lohier, J.-F.; Norah, B.; Delacroix, O.; Alayrac, C.; Taillefer, M.; Gaumont, A.-C. Chem.-Eur. J. 2013, 19, 8760-8764. doi:10.1002/chem.201301417

108. Hayashi, M.; Matsuura, Y.; Watanabe, Y. J. Org. Chem. 2006, 71, 9248-9251. doi:10.1021/jo061739f

109. Trepohl, V. T.; Oestreich, M. Chem. Commun. 2007, 3300-3302. doi:10.1039/b706137d

110.Trepohl, V. T.; Fröhlich, R.; Oestreich, M. Tetrahedron 2009, 65, 6510-6518. doi:10.1016/j.tet.2009.04.038

111.Douglass, M. R.; Marks, T. J. J. Am. Chem. Soc. 2000, 122, 1824-1825. doi:10.1021/ja993633q

112.Douglass, M. R.; Stern, C. L.; Marks, T. J. J. Am. Chem. Soc. 2001, 123, 10221-10238. doi:10.1021/ja010811i

113. Motta, A.; Fragalà, I. L.; Marks, T. J. Organometallics 2005, 24 , 4995-5003. doi:10.1021/om050570d

114. Hu, H.; Cui, C. Organometallics 2012, 31, 1208-1211. doi:10.1021/om201223

115.Leyva-Pérez, A.; Vidal-Moya, J. A.; Cabrero-Antonino, J. R.; Al-Deyab, S. S.; Al-Resayes, S. I.; Corma, A. J. Organomet. Chem. 2011, 696, 362-367. doi:10.1016/j.jorganchem.2010.09.069

116.Liu, B.; Roisnel, T.; Carpentier, J.-F.; Sarazin, Y. Angew. Chem., Int. Ed. 2012, 51, 4943-4946. doi:10.1002/anie.201200364

117. Börner, A. Phosphorus Ligands in Asymmetric Catalysis; Wiley-VCH: Weinheim, Germany, 2008

118. Glueck, D. S. Chem.-Eur. J. 2008, 14, 7108-7117. doi:10.1002/chem.200800267

119. Glueck, D. S. In Recent Advances in Metal-Catalyzed C-P Bond Formation; Vigalok, A., Ed.; Topics in Organometallic Chemistry; Springer: Berlin, 2010; pp 65-100.

120.Pullarkat, S. A.; Leung, P.-H. In Chiral Metal Complex-Promoted Asymmetric Hydrophosphinations; Ananikov, V. P.; Tanaka, M., Eds.; Topics in Organometallic Chemistry, Vol. 43; Springer: Berlin, 2013; pp 145-166.

121. Kovacik, I.; Wicht, D. K.; Grewal, N. S.; Glueck, D. S.; Incarvito, C. D.; Guzei, I. A.; Rheingold, A. L. Organometallics 2000, 19, 950-953. doi:10.1021/om990882e

122.Douglass, M. R.; Ogasawara, M.; Hong, S.; Metz, M. V.; Marks, T. J. Organometallics 2002, 21, 283-292. doi:10.1021/om0104013

123.Crimmin, M. R.; Barrett, A. G. M.; Hill, M. S.; Hitchcock, P. B.; Procopiou, P. A. Organometallics 2007, 26, 2953-2956. doi:10.1021/om070200k

124.Sadow, A. D.; Haller, I.; Fadini, L.; Togni, A. J. Am. Chem. Soc. 2004, 126, 14704-14705. doi:10.1021/ja0449574

125.Sadow, A. D.; Togni, A. J. Am. Chem. Soc. 2005, 127, 17012-17024. doi:10.1021/ja0555163

126.Feng, J.-J.; Chen, X.-F.; Shi, M.; Duan, W.-L. J. Am. Chem. Soc. 2010, 132, 5562-5563. doi:10.1021/ja100606v

127.Liu, F.; Pullarkat, S. A.; Li, Y.; Chen, S.; Yuan, M.; Lee, Z. Y.; Leung, P.-H. Organometallics 2009, 28, 3941-3946. doi:10.1021/om900305u

128. Yuan, M.; Zhang, N.; Pullarkat, S. A.; Li, Y.; Liu, F.; Pham, P.-T.; Leung, P.-H. Inorg. Chem. 2010, 49, 989-996. doi:10.1021/ic9018053

129.Xu, C.; Kennard, G. J. H.; Hennersdorf, F.; Li, Y.; Pullarkat, S. A.; Leung, P.-H. Organometallics 2012, 31, 3022-3026. doi:10.1021/om201115n

130.Lu, J.; Ye, J.; Duan, W.-L. Org. Lett. 2013, 15, 5016-5019. doi:10.1021/ol402351c

131. Huang, Y.; Chew, R. J.; Li, Y.; Pullarkat, S. A.; Leung, P.-H. Org. Lett. 2011, 13, 5862-5865. doi:10.1021/ol202480r
132.Bartoli, G.; Bosco, M.; Carlone, A.; Locatelli, M.; Mazzanti, A.; Sambri, L.; Melchiorre, P. Chem. Commun. 2007, 722-724. doi:10.1039/b613477g

133. Carlone, A.; Bartoli, G.; Bosco, M.; Sambri, L.; Melchiorre, P. Angew. Chem., Int. Ed. 2007, 46, 4504-4506. doi:10.1002/anie.200700754

134. Ibrahem, I.; Rios, R.; Vesely, J.; Hammar, P.; Eriksson, L.; Himo, F.; Córdova, A. Angew. Chem., Int. Ed. 2007, 46, 4507-4510. doi:10.1002/anie.200700916

135. Julienne, D.; Delacroix, O.; Gaumont, A.-C. Curr. Org. Chem. 2010, 14, 457-482. doi:10.2174/138527210790601152

136. Rabinowitz, R.; Pellon, J. J. Org. Chem. 1961, 26, 4623-4626. doi:10.1021/jo01069a101

137.Peer, M.; de Jong, J. C.; Kiefer, M.; Langer, T.; Rieck, H.; Schell, H.; Sennhenn, P.; Sprinz, J.; Steinhagen, H.; Wiese, B.; Helmchen, G. Tetrahedron 1996, 52, 7547-7583. doi:10.1016/0040-4020(96)00267-0

138. Bélanger, E.; Pouliot, M.-F.; Paquin, J.-F. Org. Lett. 2009, 11, 2201-2204. doi:10.1021/ol9005618

139. Veits, Yu. A.; Neganova, E. G.; Vinogradova, O. S. Russ. J. Gen. Chem. 2005, 75, 1060-1068. doi:10.1007/s11176-005-0368-x

140.Grelaud, G.; Argouarch, G.; Paul, F. Tetrahedron Lett. 2010, 51 , 3786-3788. doi:10.1016/j.tetlet.2010.05.055

141.Stefani, H. A.; Silva, N. C. S.; Vasconcelos, S. N. S.; Manarin, F.; Souza, F. B. Tetrahedron Lett. 2013, 54, 2809-2812. doi:10.1016/j.tetlet.2013.03.061

142.Saha, D.; Ghosh, R.; Sarkar, A. Tetrahedron 2013, 69, 3951-3960. doi:10.1016/j.tet.2013.03.030

143.Buchner, B.; Lockhart, L. B., Jr.. J. Am. Chem. Soc. 1951, 73, 755-756. doi:10.1021/ja01146a076

144. Kaesz, H. D.; Stone, F. G. A. J. Org. Chem. 1959, 24, 635-637. doi:10.1021/jo01087a015

145. Miyaji, T.; Xi, Z.; Ogasawara, M.; Nakajima, K.; Takahashi, T. J. Org. Chem. 2007, 72, 8737-8740. doi:10.1021/jo071089v

146. Nelson, D. J.; Nagarajan, A. J. Organomet. Chem. 1993, 463, 1-5. doi:10.1016/0022-328X(93)83391-8

147. Gaumont, A.-C.; Guillemin, J.-C.; Denis, J.-M. J. Chem. Soc., Chem. Commun. 1994, 945-946. doi:10.1039/c39940000945

148. Seipel, K. R.; Platt, Z. H.; Nguyen, M.; Holland, A. W. J. Org. Chem. 2008, 73, 4291-4294. doi:10.1021/j08001497

149. Hayashi, M.; Yamasaki, T.; Kobayashi, Y.; Imai, Y.; Watanabe, Y. Eur. J. Org. Chem. 2009, 4956-4962. doi:10.1002/ejoc.200900429

150. Katagiri, K.; Danjo, H.; Yamaguchi, K.; Imamoto, T. Tetrahedron 2005, 61, 4701-4707. doi:10.1016/j.tet.2005.01.129

151. Imamoto, T.; Sugita, K.; Yoshida, K. J. Am. Chem. Soc. 2005, 127, 11934-11935. doi:10.1021/ja053458f

152.Liancheng, Y.; Xiangyang, Q.; Longhe, X. Prog. Chem. 2011, 23 , 893-902.

153.Li, Y.-M.; Yang, S.-D. Synlett 2013, 1739-1744. doi:10.1055/s-0033-1339341

154. Veits, Y. A.; Karlstedt, N. B.; Beletskaya, I. P. Zh. Org. Khim. 1994, 30, 66-69.

155. Veits, Y. A.; Karlstedt, N. B.; Beletskaya, I. P. Tetrahedron Lett. 1995, 36, 4121-4124. doi:10.1016/0040-4039(95)00674-2

156. Trostyanskaya, I. G.; Maslova, E. N.; Kazankova, M. A.; Beletskaya, I. P. Russ. J. Org. Chem. 2008, 44, 24-30. doi:10.1134/S1070428008010028 
157.Kazankova, M. A.; Chirkov, E. A.; Kochetkov, A. N.; Efimova, I. V.; Beletskaya, I. P. Tetrahedron Lett. 1999, 40, 573-576. doi:10.1016/S0040-4039(98)02359-4

158.Lipshutz, B. H.; Buzard, D. J.; Yun, C. S. Tetrahedron Lett. 1999, 40, 201-204. doi:10.1016/S0040-4039(98)02334-X

159. Julienne, D.; Lohier, J.-F.; Delacroix, O.; Gaumont, A.-C. J. Org. Chem. 2007, 72, 2247-2250. doi:10.1021/jo062482o

160.Gilbertson, S. R.; Fu, Z.; Starkey, G. W. Tetrahedron Lett. 1999, 40, 8509-8512. doi:10.1016/S0040-4039(99)01819-5

161. Gilbertson, S. R.; Fu, Z. Org. Lett. 2001, 3, 161-164. doi:10.1021/ol006747b

162.Vandyck, K.; Matthys, B.; Willen, M.; Robeyns, K.; Van Meervelt, L.; Van der Eycken, J. Org. Lett. 2006, 8, 363-366. doi:10.1021/ol0522788

163. Han, Z.; Wang, Z.; Zhang, X.; Ding, K. Angew. Chem., Int. Ed. 2009, 48, 5345-5349. doi:10.1002/anie.200901630

164.Julienne, D.; Delacroix, O.; Gaumont, A.-C. Phosphorus, Sulfur Silicon Relat. Elem. 2009, 184, 846-856. doi:10.1080/10426500802715551

165.Julienne, D.; Delacroix, O.; Gaumont, A.-C. C. R. Chim. 2010, 13, 1099-1103. doi:10.1016/j.crci.2010.06.003

166. Cieslikiewicz, M.; Bouet, A.; Jugé, S.; Toffano, M.; Bayardon, J.; West, C.; Lewinski, K.; Gillaizeau, I. Eur. J. Org. Chem. 2012, 1101-1106. doi:10.1002/ejoc.201101293

167.Shulyupin, M. O.; Chirkov, E. A.; Kazankova, M. A.; Beletskaya, I. P. Synlett 2005, 658-660. doi:10.1055/s-2005-863714

168. Gelman, D.; Jiang, L.; Buchwald, S. L. Org. Lett. 2003, 5, 2315-2318. doi: $10.1021 /$ ol0346640

169. Tunney, S. E.; Stille, J. K. J. Org. Chem. 1987, 52, 748-753. doi:10.1021/jo00381a008

170.Martín, S. E.; Bonaterra, M.; Rossi, R. A. J. Organomet. Chem. 2002, 664, 223-227. doi:10.1016/S0022-328X(02)02014-4

171.Bonaterra, M.; Rossi, R. A.; Martín, S. E. Organometallics 2009, 28, 933-936. doi:10.1021/om8009816

172. Oshiki, T.; Imamoto, T. J. Am. Chem. Soc. 1992, 114, 3975-3977. doi:10.1021/ja00036a054

173. Imamoto, T.; Oshiki, T.; Onozawa, T.; Matsuo, M.; Hikosaka, T.; Yanagawa, M. Heteroat. Chem. 1992, 3, 563-575. doi:10.1002/hc.520030519

174.Gaumont, A.-C.; Brown, J. M.; Hursthouse, M. B.; Coles, S. J. Chem. Commun. 1999, 63-64. doi:10.1039/a807830k

175.Pican, S.; Gaumont, A.-C. Chem. Commun. 2005, 2393-2395. doi:10.1039/b501078k

176.Vallette, H.; Pican, S.; Boudou, C.; Levillain, J.; Plaquevent, J.-C.; Gaumont, A.-C. Tetrahedron Lett. 2006, 47, 5191-5193. doi:10.1016/j.tetlet.2006.05.100

177.Herd, O.; Heßler, A.; Hingst, M.; Tepper, M.; Stelzer, O. J. Organomet. Chem. 1996, 522, 69-76. doi:10.1016/0022-328X(96)06136-0

178. Herd, O.; Heßler, A.; Hingst, M.; Machnitzki, P.; Tepper, M.; Stelzer, O. Catal. Today 1998, 42, 413-420. doi:10.1016/S0920-5861(98)00123-0

179.Brauer, D. J.; Hingst, M.; Kottsieper, K. W.; Liek, C.; Nickel, T.; Tepper, M.; Stelzer, O.; Sheldrick, W. S. J. Organomet. Chem. 2002, 645, 14-26. doi:10.1016/S0022-328X(01)01371-7

180.Bergbreiter, D. E.; Liu, Y.-S.; Furyk, S.; Case, B. L. Tetrahedron Lett. 1998, 39, 8799-8802. doi:10.1016/S0040-4039(98)01976-5

181.Kraatz, H.-B.; Pletsch, A. Tetrahedron: Asymmetry 2000, 11, 1617-1621. doi:10.1016/S0957-4166(00)00103-8
182. Murata, M.; Buchwald, S. L. Tetrahedron 2004, 60, 7397-7403. doi:10.1016/j.tet.2004.05.044

183. Jin, Z.; Lucht, B. L. J. Am. Chem. Soc. 2005, 127, 5586-5595. doi:10.1021/ja043358u

184.Kazul'kin, D. N.; Ryabov, A. N.; Izmer, V. V.; Churakov, A. V.; Beletskaya, I. P.; Burns, C. J.; Voskoboynikov, A. Z. Organometallics 2005, 24, 3024-3035. doi:10.1021/om050236h

185. Ropartz, L.; Meeuwenoord, N. J.; van der Marel, G. A.; van Leeuwen, P. W. N. M.; Slawin, A. M. Z.; Kamer, P. C. J. Chem. Commun. 2007, 1556-1558. doi:10.1039/b617871e

186. Matano, Y.; Matsumoto, K.; Nakao, Y.; Uno, H.; Sakaki, S.; Imahori, H. J. Am. Chem. Soc. 2008, 130, 4588-4589. doi:10.1021/ja710542e

187. Mamat, C.; Flemming, A.; Köckerling, M.; Steinbach, J.; Wuest, F. R. Synthesis 2009, 3311-3321. doi:10.1055/s-0029-1216947

188. Bonnafoux, L.; Gramage Doria, R.; Colobert, F.; Leroux, F. R. Chem.-Eur. J. 2011, 17, 11008-11016. doi:10.1002/chem.201101529

189.Stadler, A.; Kappe, C. O. Org. Lett. 2002, 4, 3541-3543. doi:10.1021/ol026716b

190.Damian, K.; Clarke, M. L.; Cobley, C. J. Appl. Organomet. Chem. 2009, 23, 272-276. doi:10.1002/aoc.1510

191.Buchgraber, P.; Mercier, A.; Yeo, W. C.; Besnard, C.; Kündig, E. P. Organometallics 2011, 30, 6303-6315. doi:10.1021/om200897k

192. Kwong, F. Y.; Chan, K. S. Chem. Commun. 2000, 1069-1070. doi:10.1039/b002656p

193. Kwong, F. Y.; Lai, C. W.; Tian, Y.; Chan, K. S. Tetrahedron Lett. 2000, 41, 10285-10289. doi:10.1016/S0040-4039(00)01850-5

194.Kwong, F. Y.; Lai, C. W.; Yu, M.; Tian, Y.; Chan, K. S. Tetrahedron 2003, 59, 10295-10305. doi:10.1016/j.tet.2003.10.061

195.Kwong, F. Y.; Lai, C. W.; Yu, M.; Chan, K. S. Tetrahedron 2004, 60, 5635-5645. doi:10.1016/j.tet.2004.04.085

196. Kwong, F. Y.; Chan, K. S. Organometallics 2000, 19, 2058-2060. doi:10.1021/om9909338

197. Kwong, F. Y.; Chan, K. S. Organometallics 2001, 20, 2570-2578. doi:10.1021/om0100277

198. Kwong, F. Y.; Lai, C. W.; Chan, K. S. Tetrahedron Lett. 2002, 43, 3537-3539. doi:10.1016/S0040-4039(02)00582-8

199. Lai, C. W.; Kwong, F. Y.; Wang, Y.; Chan, K. S. Tetrahedron Lett. 2001, 42, 4883-4885. doi:10.1016/S0040-4039(01)00890-5

200.Wang, Y.; Lai, C. W.; Kwong, F. Y.; Jia, W.; Chan, K. S. Tetrahedron 2004, 60, 9433-9439. doi:10.1016/j.tet.2004.08.020

201. Moncarz, J. R.; Laritcheva, N. F.; Glueck, D. S. J. Am. Chem. Soc. 2002, 124, 13356-13357. doi:10.1021/ja0267324

202. Blank, N. F.; McBroom, K. C.; Glueck, D. S.; Kassel, W. S.; Rheingold, A. L. Organometallics 2006, 25, 1742-1748. doi:10.1021/om050993f

203. Brunker, T. J.; Anderson, B. J.; Blank, N. F.; Glueck, D. S.; Rheingold, A. L. Org. Lett. 2007, 9, 1109-1112. doi:10.1021/ol0700512

204.Blank, N. F.; Moncarz, J. R.; Brunker, T. J.; Scriban, C.; Anderson, B. J.; Amir, O.; Glueck, D. S.; Zakharov, L. N.; Golen, J. A.; Incarvito, C. D.; Rheingold, A. L. J. Am. Chem. Soc. 2007, 129, 6847-6858. doi:10.1021/ja070225a

205.Korff, C.; Helmchen, G. Chem. Commun. 2004, 530-531. doi:10.1039/b315009g

206. Chan, V. S.; Bergman, R. G.; Toste, F. D. J. Am. Chem. Soc. 2007, 129, 15122-15123. doi:10.1021/ja076457r

207.Cristau, H.-J.; Chêne, A.; Christol, H. J. Organomet. Chem. 1980, 185, 283-295. doi:10.1016/S0022-328X(00)85905-7 
208.Cai, D.; Payack, J. F.; Bender, D. R.; Hughes, D. L.; Verhoeven, T. R.; Reider, P. J. J. Org. Chem. 1994, 59, 7180-7181. doi:10.1021/jo00102a059

209. Cai, D. W.; Payack, J. F.; Bender, D. R.; Hughes, D. L.; Verhoeven, T. R.; Reider, P. J. Org. Synth. 1999, 76, 6-11.

210.Shimizu, H.; Nagasaki, I.; Saito, T. Tetrahedron 2005, 61, 5405-5432. doi:10.1016/j.tet.2005.03.022

211.Fleming, W. J.; Müller-Bunz, H.; Lillo, V.; Fernández, E.; Guiry, P. J. Org. Biomol. Chem. 2009, 7, 2520-2524. doi:10.1039/b900741e

212.Fleming, W. J.; Müller-Bunz, H.; Guiry, P. J. Eur. J. Org. Chem. 2010, 5996-6004. doi:10.1002/ejoc.201000794

213.Liu, L.; Wu, H.-C.; Yu, J.-Q. Chem.-Eur. J. 2011, 17, 10828-10831. doi:10.1002/chem.201101467

214.Rafter, E.; Muldoon, J.; Müller Bunz, H.; Gilheany, D. G. Tetrahedron: Asymmetry 2011, 22, 1680-1686. doi:10.1016/j.tetasy.2011.09.007

215. Clarke, E. F.; Rafter, E.; Müller-Bunz, H.; Higham, L. J.; Gilheany, D. G. J. Organomet. Chem. 2011, 696, 3608-3615. doi:10.1016/j.jorganchem.2011.08.010

216.Pereira, M. M.; Calvete, M. J. F.; Carrilho, R. M. B.; Abreu, A. R. Chem. Soc. Rev. 2013, 42, 6990-7027. doi:10.1039/c3cs60116a

217. Gilbertson, S. R.; Starkey, G. W. J. Org. Chem. 1996, 61, 2922-2923. doi:10.1021/jo960077z

218. Martorell, G.; Garcías, X.; Janura, M.; Saá, J. M. J. Org. Chem. 1998, 63, 3463-3467. doi:10.1021/j0971428s

219.Zhao, Y.-L.; Wu, G.-J.; Li, Y.; Gao, L.-X.; Han, F.-S. Chem.-Eur. J. 2012, 18, 9622-9627. doi:10.1002/chem.201103723

220.Al-Masum, M.; Livinghouse, T. Tetrahedron Lett. 1999, 40, 7731-7734. doi:10.1016/S0040-4039(99)01636-6

221.Al-Masum, M.; Kumaraswamy, G.; Livinghouse, T. J. Org. Chem. 2000, 65, 4776-4778. doi:10.1021/j00003605

222.Van Allen, D.; Venkataraman, D. J. Org. Chem. 2003, 68, 4590-4593. doi:10.1021/jo0343376

223. Tani, K.; Behenna, D. C.; McFadden, R. M.; Stoltz, B. M. Org. Lett. 2007, 9, 2529-2531. doi:10.1021/ol070884s

224.Trofimov, B. A.; Arbuzova, S. N.; Mal'kina, A. G.; Gusarova, N. K.; Malysheva, S. F.; Nikitin, M. V.; Vakul'skaya, T. I.

Mendeleev Commun. 1999, 9, 163-164. doi:10.1070/MC1999v009n04ABEH001054

225. Gusarova, N. K.; Shaikhudinova, S. I.; Arbuzova, S. N.; Vakul'skaya, T. I.; Sukhov, B. G.; Sinegovskaya, L. M.; Nikitin, M. V.; Mal\#kina, A. G.; Chernysheva, N. A.; Trofimov, B. A. Tetrahedron 2003, 59, 4789-4794. doi:10.1016/S0040-4020(03)00694-X

226. Enders, D.; Saint-Dizier, A.; Lannou, M.-I.; Lenzen, A. Eur. J. Org. Chem. 2006, 29-49. doi:10.1002/ejoc.200500593

227. Hayashi, M. Chem. Rec. 2009, 9, 236-245. doi:10.1002/tcr.200900011

228.Aguiar, A. M.; Archibald, T. G. Tetrahedron Lett. 1966, 7, 5471-5475. doi:10.1016/S0040-4039(00)70125-0

229. Khachatryan, R. A.; Sayadyan, S. V.; Grigoryan, N. Y.; Indzhikyan, M. G. Zh. Obshch. Khim. 1988, 58, 2472-2478.

230.Schmidbaur, H.; Frazão, C. M.; Reber, G.; Müller, G. Chem. Ber. 1989, 122, 259-263. doi:10.1002/cber.19891220208

231.Bookham, J. L.; McFarlane, W.; Thornton-Pett, M.; Jones, S. J. Chem. Soc., Dalton Trans. 1990, 3621-3627. doi:10.1039/dt9900003621

232.Pullarkat, S. A.; Yi, D.; Li, Y.; Tan, G.-K.; Leung, P.-H. Inorg. Chem. 2006, 45, 7455-7463. doi:10.1021/ic060937m

233.Greenberg, S.; Gibson, G. L.; Stephan, D. W. Chem. Commun. 2009, 304-306. doi:10.1039/b817960c
234. Hoffmann, H.; Diehr, H. J. Chem. Ber. 1965, 98, 363-368. doi:10.1002/cber.19650980206

235. Mitchell, T. N.; Heesche, K. J. Organomet. Chem. 1991, 409, 163-170. doi:10.1016/0022-328X(91)86141-C

236. Guillemin, J.-C.; Janati, T.; Lassalle, L. Adv. Space Res. 1995, 16, 85-92. doi:10.1016/0273-1177(95)00196-L

237. Alonso, F.; Beletskaya, I. P.; Yus, M. Chem. Rev. 2004, 104, 3079-3160. doi:10.1021/cr0201068

238. Kazankova, M. A.; Efimova, I. V.; Kochetkov, A. N.; Afanas'ev, V. V.; Beletskaya, I. P.; Dixneuf, P. H. Synlett 2001, 497-500. doi:10.1055/s-2001-12317

239. Join, B.; Mimeau, D.; Delacroix, O.; Gaumont, A.-C. Chem. Commun. 2006, 3249-3251. doi:10.1039/b607434k

240.Nagata, S.; Kawaguchi, S.-i.; Matsumoto, M.; Kamiya, I.; Nomoto, A.; Sonoda, M.; Ogawa, A. Tetrahedron Lett. 2007, 48, 6637-6640. doi:10.1016/j.tetlet.2007.07.121

241.Kawaguchi, S.-i.; Nagata, S.; Nomoto, A.; Sonoda, M.; Ogawa, A. J. Org. Chem. 2008, 73, 7928-7933. doi:10.1021/jo801267y

242. Jérôme, F.; Monnier, F.; Lawicka, H.; Dérien, S.; Dixneuf, P. H. Chem. Commun. 2003, 696-697. doi:10.1039/b212408d

243. Ohmiya, H.; Yorimitsu, H.; Oshima, K. Angew. Chem., Int. Ed. 2005, 44, 2368-2370. doi:10.1002/anie.200500255

244.Kondoh, A.; Yorimitsu, H.; Oshima, K. J. Am. Chem. Soc. 2007, 129, 4099-4104. doi:10.1021/ja070048d

245. Kumaraswamy, G.; Rao, G. V.; Murthy, A. N.; Sridhar, B. Synlett 2009, 1180-1184. doi:10.1055/s-0028-1088120

246. Kawaoka, A. M.; Douglass, M. R.; Marks, T. J. Organometallics 2003, 22, 4630-4632. doi:10.1021/om030439a

247.Komeyama, K.; Kawabata, T.; Takehira, K.; Takaki, K. J. Org. Chem. 2005, 70, 7260-7266. doi:10.1021/jo0509206

248. Takaki, K.; Takeda, M.; Koshoji, G.; Shishido, T.; Takehira, K. Tetrahedron Lett. 2001, 42, 6357-6360. doi:10.1016/S0040-4039(01)01280-1

249. Takaki, K.; Koshoji, G.; Komeyama, K.; Takeda, M.; Shishido, T.; Kitani, A.; Takehira, K. J. Org. Chem. 2003, 68, 6554-6565. doi:10.1021/jo030163g

250. Takaki, K.; Komeyama, K.; Kobayashi, D.; Kawabata, T.; Takehira, K. J. Alloys Compd. 2006, 408-412, 432-436. doi:10.1016/j.jallcom.2004.11.088

251. Komeyama, K.; Kobayashi, D.; Yamamoto, Y.; Takehira, K.; Takaki, K. Tetrahedron 2006, 62, 2511-2519. doi:10.1016/j.tet.2005.12.049

252.Al-Shboul, T. M. A.; Görls, H.; Westerhausen, M. Inorg. Chem. Commun. 2008, 11, 1419-1421. doi:10.1016/j.inoche.2008.09.019

253.Al-Shboul, T. M. A.; Pálfi, V. K.; Yu, L.; Kretschmer, R.; Wimmer, K.; Fischer, R.; Görls, H.; Reiher, M.; Westerhausen, M. J. Organomet. Chem. 2011, 696, 216-227. doi:10.1016/j.jorganchem.2010.08.058

254. Mimeau, D.; Gaumont, A.-C. J. Org. Chem. 2003, 68, 7016-7022. doi:10.1021/jo030096q

255.Busacca, C. A.; Farber, E.; DeYoung, J.; Campbell, S.; Gonnella, N. C.; Grinberg, N.; Haddad, N.; Lee, H.; Ma, S.; Reeves, D.; Shen, S.; Senanayake, C. H. Org. Lett. 2009, 11, 5594-5597. doi:10.1021/ol9022547

256.Busacca, C. A.; Qu, B.; Farber, E.; Haddad, N.; Grět, N.; Saha, A. K.; Eriksson, M. C.; Wu, J.-P.; Fandrick, K. R.; Han, S.; Grinberg, N.; Ma, S.; Lee, H.; Li, Z.; Spinelli, M.; Gold, A.; Wang, G.; Wipf, P.; Senanayake, C. H. Org. Lett. 2013, 15, 1132-1135. doi:10.1021/ol400309y 
257.Bernoud, E.; Veillard, R.; Alayrac, C.; Gaumont, A.-C. Molecules 2012, 17, 14573-14587. doi:10.3390/molecules 171214573

258. Voskuil, W.; Arens, J. F. Recl. Trav. Chim. Pays-Bas 1962, 81 , 993-1008. doi:10.1002/recl.19620811109

259. Charrier, C.; Chodkiewicz, W.; Cadiot, P. Bull. Soc. Chim. Fr. 1966, 1002-1011.

260.Davidsohn, W. E.; Henry, M. C. Chem. Rev. 1967, 67, 73-106. doi:10.1021/cr60245a003

261. Ionin, B. I.; Bogolyubov, G. M.; Petrov, A. A. Russ. Chem. Rev. 1967, 36, 249-260. doi:10.1070/RC1967v036n04ABEH001609

262. Himbert, G.; Regitz, M. Chem. Ber. 1974, 107, 2513-2536. doi:10.1002/cber.19741070811

263.Märkl, G.; Reitinger, S. Tetrahedron Lett. 1988, 29, 463-466. doi:10.1016/S0040-4039(00)80122-7

264.Märkl, G.; Kreitmeier, P. Angew. Chem., Int. Ed. Engl. 1988, 27, 1360-1361. doi:10.1002/anie.198813601

265.Imamoto, T.; Saitoh, Y.; Koide, A.; Ogura, T.; Yoshida, K. Angew. Chem., Int. Ed. 2007, 46, 8636-8639. doi:10.1002/anie.200702513

266. Beletskaya, I. P.; Afanasiev, V. V.; Kazankova, M. A.; Efimova, I. V. Org. Lett. 2003, 5, 4309-4311. doi:10.1021/ol035562c

267.Di Credico, B.; Fabrizi de Biani, F.; Gonsalvi, L.; Guerri, A.; lenco, A.; Laschi, F.; Peruzzini, M.; Reginato, G.; Rossin, A.; Zanello, P. Chem.-Eur. J. 2009, 15, 11985-11998. doi:10.1002/chem.200901642 268. Afanasiev, V. V.; Beletskaya, I. P.; Kazankova, M. A.; Efimova, I. V.; Antipin, M. U. Synthesis 2003, 2835-2838. doi:10.1055/s-2003-42493

269. Ochida, A.; Ito, H.; Sawamura, M. J. Am. Chem. Soc. 2006, 128, 16486-16487. doi:10.1021/ja066800c

270. Ochida, A.; Sawamura, M. Chem.-Asian J. 2007, 2, 609-618. doi:10.1002/asia.200700006

271.Bernoud, E.; Alayrac, C.; Delacroix, O.; Gaumont, A.-C. Chem. Commun. 2011, 47, 3239-3241. doi:10.1039/c0cc04645k

272.Abdellah, I.; Bernoud, E.; Lohier, J.-F.; Alayrac, C.; Toupet, L.; Lepetit, C.; Gaumont, A.-C. Chem. Commun. 2012, 48, 4088-4090. doi:10.1039/c2cc30723e

\section{License and Terms}

This is an Open Access article under the terms of the Creative Commons Attribution License (http://creativecommons.org/licenses/by/2.0), which permits unrestricted use, distribution, and reproduction in any medium, provided the original work is properly cited.

The license is subject to the Beilstein Journal of Organic Chemistry terms and conditions:

(http://www.beilstein-journals.org/bjoc)

The definitive version of this article is the electronic one which can be found at: $\underline{\text { doi: } 10.3762 / \text { bjoc. } 10.106}$ 